WSRC-TR-2003-00180

Page 1 of 66

Sorption Modeling of Strontium, Plutonium, Uranium and Neptunium Adsorption on Monosodium Titanate

F. F. Fondeur

D. T. Hobbs

S. D. Fink

M. J. Barnes

May 7, 2003

Westinghouse

Savannah River Company

Aiken, SC 29808

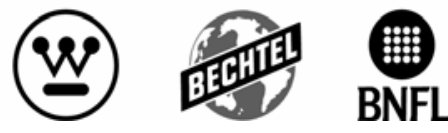


This document was prepared in conjunction with work accomplished under Contract No. DE-AC09-96SR18500 with the U. S. Department of Energy.

\section{DISCLAIMER}

This report was prepared as an account of work sponsored by an agency of the United States Government. Neither the United States Government nor any agency thereof, nor any of their employees, makes any warranty, express or implied, or assumes any legal liability or responsibility for the accuracy, completeness, or usefulness of any information, apparatus, product or process disclosed, or represents that its use would not infringe privately owned rights. Reference herein to any specific commercial product, process or service by trade name, trademark, manufacturer, or otherwise does not necessarily constitute or imply its endorsement, recommendation, or favoring by the United States Government or any agency thereof. The views and opinions of authors expressed herein do not necessarily state or reflect those of the United States Government or any agency thereof.

This report has been reproduced directly from the best available copy.

Available for sale to the public, in paper, from: U.S. Department of Commerce, National Technical Information Service, 5285 Port Royal Road, Springfield, VA 22161, phone: (800) 553-6847, fax: (703) 605-6900

email: orders@ntis.fedworld.gov

online ordering: http://www.ntis.gov/help/index.asp

Available electronically at http://www.osti.gov/bridge

Available for a processing fee to U.S. Department of Energy and its contractors, in paper, from: U.S. Department of Energy, Office of Scientific and Technical Information, P.O. Box 62, Oak Ridge, TN 37831-0062,

phone: (865)576-8401,

fax: (865)576-5728

email: $\underline{\text { reports@ adonis.osti.gov }}$ 
This page intentionally left blank 
WSRC-TR-2003-00180

Page 4 of 66

\title{
Sorption Modeling of Strontium, Plutonium, Uranium and Neptunium on Monosodium Titanate
}

\author{
F. F. Fondeur, D. T. Hobbs, S. D. Fink, and M. J. Barnes \\ Waste Processing Technology Section \\ Savannah River Technology Center
}

\begin{abstract}
$\underline{\text { Abstract }}$
We examined the ability of various equilibrium isotherms to replicate the available data for the adsorption of strontium ( $\mathrm{Sr}$ ), plutonium $(\mathrm{Pu})$, uranium $(\mathrm{U})$ and neptunium $(\mathrm{Np})$ on monosodium titanate (MST) during the treatment of simulated and actual Savannah River Site high-level waste. The data comes from numerous experimental studies conducted between 1999 and 2002. The analysis considered 29 isotherm models from the literature. As part of this study, we developed a general method for selecting the best isotherm models. The selection criteria for rating the isotherms considered the relative error in predicting the experimental data, the complexity of the mathematical expressions, the thermodynamic validity of the expressions, and statistical significance for the expressions.

The Fowler Guggenheim-Jovanovic Freundlich (FG-JF), the Fowler GuggenheimLangmuir Freundlich (FG-LF) and the Dubinin-Astashov (DA) models each reliably predicted the actinide and strontium adsorption on MST. The first two models describe the adsorption process by single layer formation and lateral interactions between adsorbed sorbates while the Dubinin-Astashov model assumes volume filling of micropores (by osmotic pressure difference). These two mechanisms include mutually exclusive assumptions. However, we can not determine which model best represents the various adsorption mechanisms on MST. Based on our analysis, the DA model predicted the data well. The DA model assumes that an initial sorption layer forms after which networking begins in the pore spaces, filling the volume by a second mechanism. If this mechanism occurs in MST, as the experimental data suggests, then we expect all the empty and closed spaces of MST to contain actinides and strontium when saturated. Prior microstructure analyses determined that the MST surface is best described as heterogeneous (i.e., a semi-crystalline outer layer on an amorphous core) or composite material for adsorption. Therefore, we expect the empty spaces (of nanometer size) between the crystalline units in the fibrous material to provide sorption area for the actinides and strontium. Additional conclusions from this study follow.

Since each of the three models work reliably, we recommend use of the computationally simplest model as the primary tool until future work can differentiate between the two mechanisms. The Dubinin-Astashov model possesses a simpler mathematical form with fewer parameters and operations.
\end{abstract}


The experimental data for actual and simulated wastes generally showed consistent agreement. However, the data sets do include considerable variance from a number of causes including the following.

- The plutonium sorption data appears most consistent (e.g., between actual and simulated waste) and most easily predicted. Since plutonium removal efficiency proves most important for the process design efforts, this consistency of the data proves especially beneficial.

- Extremely high mass loadings of uranium on MST result in multilayer sorption behavior and divergence from classical single monolayer isotherm forms. Prior xray studies demonstrate that uranium begins to network, or form dimers, which agrees with this interpretation. This uranium behavior also shows a complex interaction, and a direct correlation, with sorption data for the other radionuclides. We believe this data suggests nucleation (e.g., precipitation) of the actinides in the micropore space for both neptunium and plutonium. For strontium, the high uranium loadings appear to inhibit the sorption of strontium.

- Nearly all the solutions contained uranium as the radionuclide with the highest mass concentration. This data shows the widest variance.

- The composite data set indicates a notable variance in sorption for different batches of MST. The sorption of strontium with different batches of MST shows the largest variance among the four radionuclides for different batches of MST. This variance remains a relatively unexplored aspect of the process design.

- Similarly, the experimental data included a wide variety of solution compositions. As such, the mathematical expressions implicitly account for variances in solution chemistry typical of that anticipated within the Salt Waste Processing Facility and Actinide Removal Process. The reader must consider the ranges of these concentrations when applying the expressions.

- Increasing temperature decreases strontium, plutonium and to a lesser extent uranium sorption on MST. The opposite effect occurs with neptunium. This temperature variance further suggests a nucleation behavior for neptunium.

- Nearly all the data used in developing the sorption models came from experiments using solutions with all the principle radionuclides of interest present simultaneously. We modeled the data without invoking competition between the actinides and strontium despite the large concentrations of both uranium and neptunium. Since the model does not explicitly invoke competition, the optimized parameters implicitly carry the impact of interaction within the concentration ranges of the original data. Hence, extrapolation of the models to concentrations markedly outside those ranges may result in poorer predictive ability.

This analysis suggests several key efforts needed to improve the reliability of the sorption models including the following.

- We recommend that the Salt Processing Program expand the investigation of variability for MST coming from different production batches. Testing should 
WSRC-TR-2003-00180

Page 6 of 66

also include the effect of storage (temperature and shelf-life) and pretreatment on MST adsorption capabilities.

- Additional tests should investigate $\mathrm{Pu}$ and $\mathrm{Sr}$ adsorption at $\mathrm{Pu}$ and $\mathrm{Sr}$ solution concentrations larger than $0.1 \mathrm{M}$. The recommended $\mathrm{Pu}$ model relies on two data points in this region that originated from one researcher.

- The program needs to assess fully the implications of increased uranium sorption of uranium on MST beyond that previously considered for nuclear criticality safety.

- The program should expand the modeling effort to consider behavior at shorter process times, such as 4 hours after addition of MST to the waste.

- We recommend studies that investigate adsorptions of single actinide and two actinides in solution at a time. This testing will validate the values of the parameters obtained in the multi-component tests and will also explore the nature of the complex interaction (e.g., between uranium and neptunium) observed at high mass loadings.

- We recommend collecting additional data for americium and curium adsorption from testing.

\section{$\underline{\text { Introduction }}$}

The Salt Waste Processing Facility at Savannah River Site (SRS) includes adsorption as a unit operation for removing traces of alpha and beta-emitting elements from the waste solution. The facility uses monosodium titanate for $\mathrm{Sr}$ and actinide removal. In particular, the objective of the process is the removal of strontium (90), plutonium (238 and 239), and neptunium (237) with MST. To this end, personnel conducted a number of batch contacting experiments to obtain information related to the kinetics and capacity of the media. The tests demonstrated the ability of MST to remove both Sr and the actinides from alkaline solutions containing up to 90,000 times as much sodium as sorbate (on a molar basis).

These successful performance tests identified the need for additional scientific work to understand the interaction between the actinides and MST. Recently, SRTC personnel conducted X-ray scattering experiments such as EXAFS (Extended X-rays Adsorption Fine Structure) and TEM (Transmission Electron Microscopy) on MST. ${ }^{1,2,3}$ The analysis indicated MST is an amorphous, spherical particle (with average diameter of about 4-5 microns) coated with about 150-500 nanometers of a crystalline and fibrous material. The fibrous material contains distorted titanium oxide octahedra. An EDS (Energy Dispersive Spectrometry in a TEM) scan of the fibrous layer of strontium-loaded MST indicated that $\mathrm{Sr}$ tends to adsorb on the fibrous layer of MST. The studies could not definitively identify the physical location of the actinides within the microstructure due to the low detection limits for these elements and their lower relative concentrations. The structural studies identified the differing nature of the surface chemistry for the various radionuclides. These findings include the following.

- Presence of Ti in the second coordination shell of the $\mathrm{Sr}^{2+}$ on the MST suggests that specific adsorption is the predominant mechanism and that electrostatic bonding (also 
known as ion exchange of hydrated surface-associated species such as dissolved $\mathrm{Na}^{+}$) in the electric double-layer of the HLW salt simulant solution does not occur.

- Uranium(VI) sorbs via an inner sphere/specific adsorption mechanism as predominantly dimeric nitrato or carbonato complexes of U(VI) species via bidentate linkages (i.e., assuming the presence of Ti octahedra in the MST structure, the U(VI) is bound to Ti groups at two different U-Ti radial distances) at high loadings. Monomeric species predominate at low loadings.

- Plutonium, added as $\mathrm{Pu}(\mathrm{IV})$, exhibits inner sphere/specific adsorption as polymeric (colloidal) $\mathrm{Pu}$ species - with a local environment that is consistent with $\mathrm{Pu}(\mathrm{IV})$.

- Neptunium, from salt solutions spiked with a $\mathrm{Np}(\mathrm{V})$ stock solution, exhibits inner sphere specific adsorption as polymeric $\mathrm{Np}$ species. The $\mathrm{Np}$ may be present as $\mathrm{Np}(\mathrm{V})$ or $\mathrm{Np}(\mathrm{IV})$.

From the above spectroscopy and scattering work conclusions, the actinides of interest and strontium bind specifically to MST. Therefore, we can neglect non-specific or electrostatic adsorption as described by the Diffuse Double Layer, Triple Layer, Capacitance Layer, Debye-Huckel, and Donnan Theories. This work focused only on specific adsorption as described by isotherms.

For successful implementation of MST, the adsorption process needs to use an optimal amount of MST and must remain predictable under plant-upset conditions. These recent studies provide, for the first time, sufficient data to derive a model for predicting such performance.

Adsorption is a general term that refers to the disappearance of solutes from solutions with the presumption of adsorption to a solid surface. The accumulation of solutes at the solid-liquid interface results from physical or chemical interactions with the surface. Physical bonding is relatively weak while chemical bonding is a stronger interaction which may involve ionic or covalent bonding (in addition to van der Waals and London forces). The nature of both the solid surface and the solute determines the interaction.

Inorganic surfaces consist of mostly oxygen and hydroxides. In high $\mathrm{pH}$ (very caustic solutions), the inorganic surfaces are mainly oxygen anions. Exchangeable cations (e.g., alkali metals such as $\mathrm{Li}$ and $\mathrm{Na}$ ) are assumed to be fully hydrated and may completely shed their waters when sorbing on the surface (due to weak interaction with the surface). Cations such as $\mathrm{K}^{+}$and $\mathrm{Cs}^{+}$completely dehydrate during sorption and form strong ionic bonds with the surface. In caustic solutions, alkaline earth metals such as strontium do not fully hydrate $\left(\mathrm{Sr}-\mathrm{OH}^{+}\right)$. Therefore, a strong (ionic) interaction with inorganic surfaces is expected. In contrast, anions are expected to strongly sorb on solid surfaces. The adsorption of anions is believed to occur via displacement of surface hydroxyls and the formation of mono and bidentate surface complexes with covalent bonding character. In SRS supernate, uranium and plutonium exist as anion complexes of hydroxyls, carbonates and nitrates. The hydroxyls in the complex can be displaced and covalent bond formation with the surface oxygen is expected. 
To predict and scale-up adsorption operations, personnel require a detailed knowledge (including mathematical relationships) of the adsorption process of the nuclides on MST. They require a mathematical relationship describing distribution of the nuclides between the waste and the sorbent (e.g., isotherms). Numerous such models exist based on both thermodynamics and empirical regression.

If the adsorption increases proportionally to the solute concentration, the adsorption process follows Hooke's law. If the adsorption reaches a steady state value regardless of the solute concentration, then one can mathematically describe the adsorption process with a Langmuir equation. ${ }^{4,5}$ For systems that exhibit nonlinear increases in adsorption with solute concentration, several mathematical formulas can describe the adsorption process. Examples of nonlinear isotherms include Freundlich, ${ }^{6}$ Dubinin-Ashtakov, ${ }^{7,8,9}$ Tempkin, ${ }^{10}$ Volmer, ${ }^{11}$ Sips, ${ }^{12}$ Fowler-Guggenheim, ${ }^{13,14}$ Frumkin-Damskin, ${ }^{15}$ RedlichPeterson, ${ }^{16}$ Toth, ${ }^{17}$ Levan-Vermeulen, ${ }^{18}$ Vacancy Solute Theory, ${ }^{19}$ Radke-Prausnitz, ${ }^{20}$ Sigmoidal, ${ }^{21}$ General Adsorption Theory, ${ }^{22}$ Langmuir-Freundlich, ${ }^{23}$ Margules, FowlerGuggenheim/Langmuir-Freundlich, ${ }^{24}$ Fowler-Guggenheim/Jovanovic-Freundlich, ${ }^{25}$ Jaroniec, ${ }^{26,24}$ Ideal Adsorbed Solute Theory, ${ }^{27,28,29}$ and Sheindorf-Rebuhn-Sheintuch ${ }^{30}$ (see Appendix A). It is important to note that successfully fitting isotherms to adsorption data does not, in general, provide information about the mechanism of sorption. These expressions are best looked at as mathematical descriptors of the sorption data. However, the mathematical relations are useful for predicting and scaling adsorption operations. Personnel must derive mechanistic details of sorption processes from other techniques such as surface spectroscopy (infrared, Raman, EXAFS, etc.).

We numerically optimized the parameters for the various published isotherms to available actinide and strontium adsorption data for sorption onto MST. We attempted to identify the best isotherm model that fit available data and reliably predicted MST performance as a function of MST and sorbate concentrations.

\section{Experimental Data: Simulated and Actual Waste}

We obtained the actinide and strontium data for simulated waste from previous research efforts and compiled the information into one data set. ${ }^{31,32,33,34}$ These experiments used the same basic protocols for studying the removal efficiency of MST. Personnel kept a slurry of MST and simulated waste at constant temperature. Most data comes from work at ambient temperature (e.g., $25^{\circ} \mathrm{C}$ ) although a few experiments examined performance at elevated temperatures (i.e., 45 and $65^{\circ} \mathrm{C}$ ). Tests most typically used solutions containing uranium, strontium, plutonium, and neptunium in combination. Table 1 shows the range of concentrations studies. The experiments also examined removal performance as a function of solution composition and, to a more limited extent, for different manufacturing lots of MST. Table 2 shows the range of solution compositions included in the studies. 
Table 1. Initial sorbate concentrations.

\begin{tabular}{|c|c|c|c|c|}
\hline \multirow[b]{2}{*}{$\underline{\text { Dataset }}$} & \multicolumn{3}{|c|}{ Concentration $(\mu \mathrm{g} / \mathrm{L})$} & \multirow[b]{2}{*}{$\underline{\mathrm{U}}$} \\
\hline & $\underline{\mathrm{Sr}}$ & $\underline{\mathrm{Pu}}$ & $\underline{N p}$ & \\
\hline Phase III ${ }^{31}$ & $5-100$ & $1.1-280$ & $340-36000$ & $1500-26000$ \\
\hline Phase IV $^{32}$ & 90 & 62 & 420 & 9000 \\
\hline Phase $\mathrm{V}^{33}$ & 87 & 190 & 420 & 9000 \\
\hline Alternate Matls ${ }^{34}$ & $65-100$ & $98-220$ & $460-650$ & $10000-12000$ \\
\hline Soln Comp ${ }^{34}$ & $300-830$ & $36-240$ & $190-310$ & $4300-10000$ \\
\hline
\end{tabular}

Table 2. Experimental compositions.

$\underline{\text { Dataset }}$

Phase III $^{31}$

Phase $\mathrm{IV}^{32}$

Phase $\mathrm{V}^{33}$

Alternate Matls ${ }^{34}$

Soln Comp ${ }^{34}$

$\frac{\mathrm{MST}}{(\mathrm{g} / \mathrm{L})}$
$0.2,1.1,2.0$
$0.2,0.4$
$0.2,0.4$
0.4
0.4

0.4

$\underline{\text { Sorbate Equiv }}$

$(\mu \mathrm{mole} / \mathrm{L})$

$13-380$
$51-99$
84
$92-110$
$51-110$

$13-380$

$51-110$

$\begin{array}{ll}\frac{\mathrm{OH}^{-}}{(\mathrm{M})} & \frac{\mathrm{NO}_{3}^{-}}{(\mathrm{M})} \\ 1.1-1.8 & 2.1-3.5 \\ 2.4 & 1.1 \\ 1.3 & 2.6 \\ 2.6 & 1.3 \\ 1-3 & 1-3\end{array}$

$\underline{\mathrm{Na}+}$

(M)

$4.5-7.5$

4.5

5.6

5.6

$4.8-5.9$ 
WSRC-TR-2003-00180

Page 10 of 66

The bottles were shaken in a temperature-controlled bath for finite length of times. At the end of the shaking, personnel filtered the solutions and analyzed the filtrate using Inductively Coupled Plasma Mass and Emission Spectroscopy as well as analyzing for plutonium by PuTTA separation and radiocounting. Personnel assumed the loaded amount of actinide and strontium on MST equaled the difference between the original concentration in stock solutions and the final concentration in the bottles. The amount of uncertainty reached 10 to $15 \% \mathrm{CV}$ (Coefficient of Variation, or percent uncertainty). The error associated with weighting MST equaled 5\%. Propagation of errors calculation places the uncertainty in the actinide and strontium loading between 5 and $10 \% \mathrm{CV}$.

The experimental data for actual and simulated wastes generally showed consistent agreement. However, the data sets do include considerable variance from a number of causes including the following.

- Extremely high mass or molar loadings of uranium on MST result in multilayer sorption behavior and a unique divergence from classical single monolayer isotherm forms.

- Nearly all the solutions contained uranium as the radionuclide with the highest mass concentration. The uranium data shows the widest variance.

- The composite data set indicates a notable variance in sorption for different batches of MST. The sorption of strontium with different batches of MST shows the largest variance. This variance remains a relative unexplored aspect of the process design.

Further examination of the experimental data set identified additional data points measured at the detection limits of measuring instruments. The large variance of the data measured at detection levels places great uncertainty on the data in the isotherm. We eliminated data points measured at the detection limit from additional calculations. In the case of the Pu experimental points, only 60 out of 110 data points remained above detection limits. Further, we imposed an additional screening criterion on the maximum radionuclide (i.e., sum of all four species) loading on MST allowed. The amount of sorbate should not exceed 2 umole/g of MST. This criterion is based on the maximum expected number of equivalence MST can absorb by analogy with typical sorbents. ${ }^{35}$ Appendix B lists the $\mathrm{Pu}, \mathrm{Np}, \mathrm{U}$ and $\mathrm{Sr}$ experimental data.

Similarly, the experimental data included a wide variety of solution compositions. As such, the mathematical expressions implicitly account for variances in solution chemistry typical of that anticipated within the Salt Waste Processing Facility and Actinide Removal Process. The reader must consider the ranges of these concentrations when applying the expressions.

\section{Model Selection}

The fitting of experimental data to complex multi-component models requires a number of decisions on approach, some of which are subjective. We adopted two strategies for modeling the data. For each model we decided to fit all of the data simultaneously. Our 
WSRC-TR-2003-00180

Page 11 of 66

second strategy constrained the parameter with the largest standard deviation. Large parameter deviations are typically due to limitations of the experimental design, the restricted size of the datasets, or an insufficient span of the data.

We evaluated the data for steady state (i.e., after 168 hours) and mass balance consistency. We identified 29 different isotherm models (see Appendix A) for fitting to the data using JMP ${ }^{\circledR}$ software (version 5.0.1 from SAS Institute). The modeling generated correlation coefficients, sum of the squares of error values (variance), "lack of fit" and significance probabilities for each isotherm. We used each of these criteria to rank the isotherms. In addition, we used Akaike's number to define a mathematical "simplicity factor" for the expression. The Akaike number is given by ${ }^{36}$

$n \log (S S E)+\frac{2 n(p+1)}{(n-p-2)}$

where $n$ is the number of data points, $p$ is the number of parameters in the model and SSE is the sum of the squares of the errors. An Akaike number closer to zero indicates a simpler mathematical expression. As a final criterion, we gave preference to those isotherms that provide a thermodynamically consistent representation of the data. In principle, such expressions hold a higher likelihood of extrapolating beyond the region of the original data used to obtain the parameters.

We ranked each isotherm expression separately for the performance relative to uranium, plutonium, strontium, and neptunium. We summed the individual rankings, with equal weightings, for each criterion for each radionuclide. Tables C1 to C4 (in Appendix C) provide the rankings for the various radionuclides.

An objective of this evaluation is the selection of one isotherm that can fit all four sorbates. The result of the fittings resides in laboratory notebook WSRC-NB-97-62. We included, in this modeling effort, 110 data points from the simulated waste tests and 27 data points from the actual waste tests. As mentioned earlier, we omitted data points that lacked mass balance consistency, that fell below the detection limit for a given radionuclide, or when the sum of masses for all the radionuclide exceeded our understanding of the available sorption sites on MST. The resulting number of data considered for $\mathrm{Sr}$ included 95 data points, for U 110 data points, for $\mathrm{Pu} 68$ data points, and for Np 82 data points.

\section{$\underline{\text { Results and Discussion }}$}

\section{Simulated and Actual Waste Modeling (Equilibrium Data)}

We found three isotherms that reproduced the data in reasonably good fashion: the Fowler-Guggenheim-Jovanovich-Freundlich (FG-JF), Fowler-Guggenheim-LangmuirFreundlich (FG-LF) and the Dubinin-Astashov isotherms. The Dubinin-Astashov model performed best per the selection criteria we defined. All three models replicated the nonclassical sorption behavior observed for uranium at extremely high mass loading 
WSRC-TR-2003-00180

Page 12 of 66

resulting in an "upswing" in the curve associated with multi-layer sorption behavior. Other models could not both incorporate this behavior and simultaneously replicate data at lower mass loadings with practical error, or offset, from the experimental data. The FG-JF and FG-LF isotherms assume interactions between the adsorbed sorbates, between the solution and surface sorbates and exponentially distributed surface energy sites on MST. The inclusion of many assumptions requires calculation of several parameters. On the other hand, the DA isotherm assumes an inverse Weibull distributed surface energy sites on MST. The DA isotherm requires only four parameters to represent sorbate loading. We provide results from the FG-JF (in Appendix C) and DA isotherms (below) in this paper. A brief introduction to inverse Weibull distributions follows.

The inverse Weibull distribution function is a two parameter function. The mathematical form of this function follows.

1) $F(x)=e^{-(S \times X)^{n}}$

In this expression, " $\mathrm{S}$ " and " $\mathrm{n}$ " are the scale and shape parameter. The parameter " $\mathrm{x}$ " is the random variable and in this case is the sites energy on MST. This function is unimodal with a maximum $\left(e^{-(1+1 / n)}\right)$ at a " $\mathrm{x}$ " value of $\mathrm{S}(1+1 / \mathrm{n})^{-1 / \mathrm{n}}$. Increasing the value of " $n$ " increases the width at half maximum of the distribution. Figure 1 shows the effect of the parameter " $n$ " on an inverse Weibull distribution with a maximum near the origin.

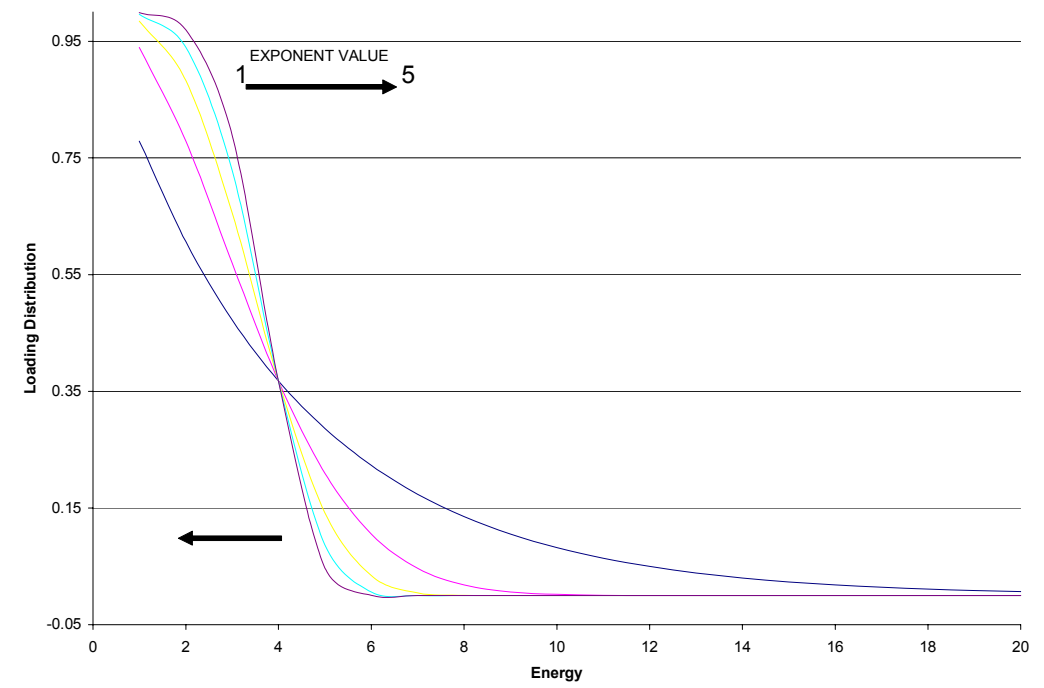

Figure 1. The effect of the exponential parameter of the distribution shape of an inverse Weibull.

The Dubinin-Astashov model incorporates this energy distribution as follows.

$$
Y=Y_{m} \exp \left[-\left(\frac{R T}{E}\right)^{n}\left(\operatorname{Ln}\left(\frac{S}{X}\right)\right)^{n}\right]
$$


WSRC-TR-2003-00180

Page 13 of 66

In this model, E represents the average adsorption energy. The parameter "S"represents the saturation limit of the radionuclide. The value $Y_{m}$ represents the maximum radionuclide loading on MST.

We used a number of isotherm models to regress the plutonium adsorption data. Table 3 lists the fitting results of the isotherm models. Not all the isotherms successfully reproduced the data and we omit from the table those isotherms that failed to converge for the data set. Table 3 also includes the overall performance of each model. The performance evaluation listed in Table 3 includes calculated results and statistical significance. We base our selection of the Dubinin-Astashov model on the overall ranking using the criteria defined earlier (e.g., correlation coefficients, sum of the squares of error values (variance), "lack of fit" and significance probabilities for each isotherm, and the mathematical "simplicity factor).

None of the ideal behavior isotherms such as Langmuir or the Ideal Adsorbed Solute theory (IAST) or Freundlich performed well. The FG-JF and FG-LF models are mathematical combinations of the Fowler-Guggenheim, Langmuir, Jovanovic and Freundlich isotherms. These models include the interactions between loaded sorbents, between the loaded and free sorbate and surface heterogeneity. The successful prediction of the $\mathrm{Pu}, \mathrm{Sr}, \mathrm{U}$ and $\mathrm{Np}$ data with the FG-JF and FG-LF models may indicate appreciable sorbate interactions and surface heterogeneity. On the other hand, the Dubinin-Astashov (DA) model successfully reproduced this data. The DA model is based on the thermodynamic potential for adsorption (Gibbs energy) on sites with energies distribution described by a Weibull function. The DA isotherm successfully models filling of micropore spaces that occurs subsequent to the initial sorption layers. The DA model does not include loaded sorbate-to-sorbate interactions terms but has successfully fitted multi-layer adsorption data. The successful fitting with the DA model reinforced the view of a heterogeneous MST surface. Since two different types of models (FG-JF or FG-LF and DA) successfully reproduced the data, we chose the model with the least number of variables and mathematical operations. Models with complex mathematical operations and numerous parameters exhibit large sensitivity to small variations. We recommend the DA model for further engineering calculations.

We fitted the $\mathrm{Pu}$ adsorption data at $25^{\circ} \mathrm{C}$. Figure 2 shows the DA isotherm for the $25^{\circ} \mathrm{C}$ results. Most of the data shown on Figure 2 derives from simulant testing. The two data points at concentrations larger than $0.55 \mu \mathrm{M}$ (i.e., $1757 \mathrm{nCi} / \mathrm{g}$ of ${ }^{238} \mathrm{Pu}$ or $6.4 \mathrm{nCi} / \mathrm{g}$ of ${ }^{239} \mathrm{Pu}$ ) derived from actual waste testing. The actual waste data came from testing under non-steady state conditions (i.e., after only 24 hours of sorption testing). Glancing at Figure 2, the DA model successfully explained $72 \%$ of the variance $\left(\mathrm{R}^{2}=0.72\right)$ in the $\mathrm{Pu}$ adsorption data. Note the relatively large data scatter at plutonium concentrations less than $0.1 \mu \mathrm{M}$. The scatter represents the collection at several different experimental conditions. To ensure accurate calculation of the parameters in the model, the data must include the initial rise and plateau (i.e., saturation) of the loading-final concentration curve. Figure 2 shows a large compilation of data at the initial rise of the curve and only two points at the plateau of the curve. The two data points at a plutonium concentration 
WSRC-TR-2003-00180

Page 14 of 66

of 0.55 (i.e., $1757 \mathrm{nCi} / \mathrm{g}$ of ${ }^{238} \mathrm{Pu}$ or $6.4 \mathrm{nCi} / \mathrm{g}$ of ${ }^{239} \mathrm{Pu}$ ) and $0.7 \mu \mathrm{M}$ (i.e., $2236 \mathrm{nCi} / \mathrm{g}$ of ${ }^{238} \mathrm{Pu}$ or $8.14 \mathrm{nCi} / \mathrm{g}$ of ${ }^{239} \mathrm{Pu}$ ) originated from one adsorption experiment terminated 24 hours after initiation of sorption testing. Therefore, the proposed calculated parameters depend heavily upon the accuracy of these two data points. The additional two dashedline curves are the $95 \%$ prediction confidence curves. The predictions curves agree well at low $\mathrm{Pu}$ concentrations and diverge widely at high $\mathrm{Pu}$ concentrations. The large variance in the 45 and $65^{\circ} \mathrm{C}$ data resulted in a poor fitting with the DA model. In general, the amount of $\mathrm{Pu}$ loaded on MST at 45 and $65^{\circ} \mathrm{C}$ proved lower than at $25^{\circ} \mathrm{C}$.

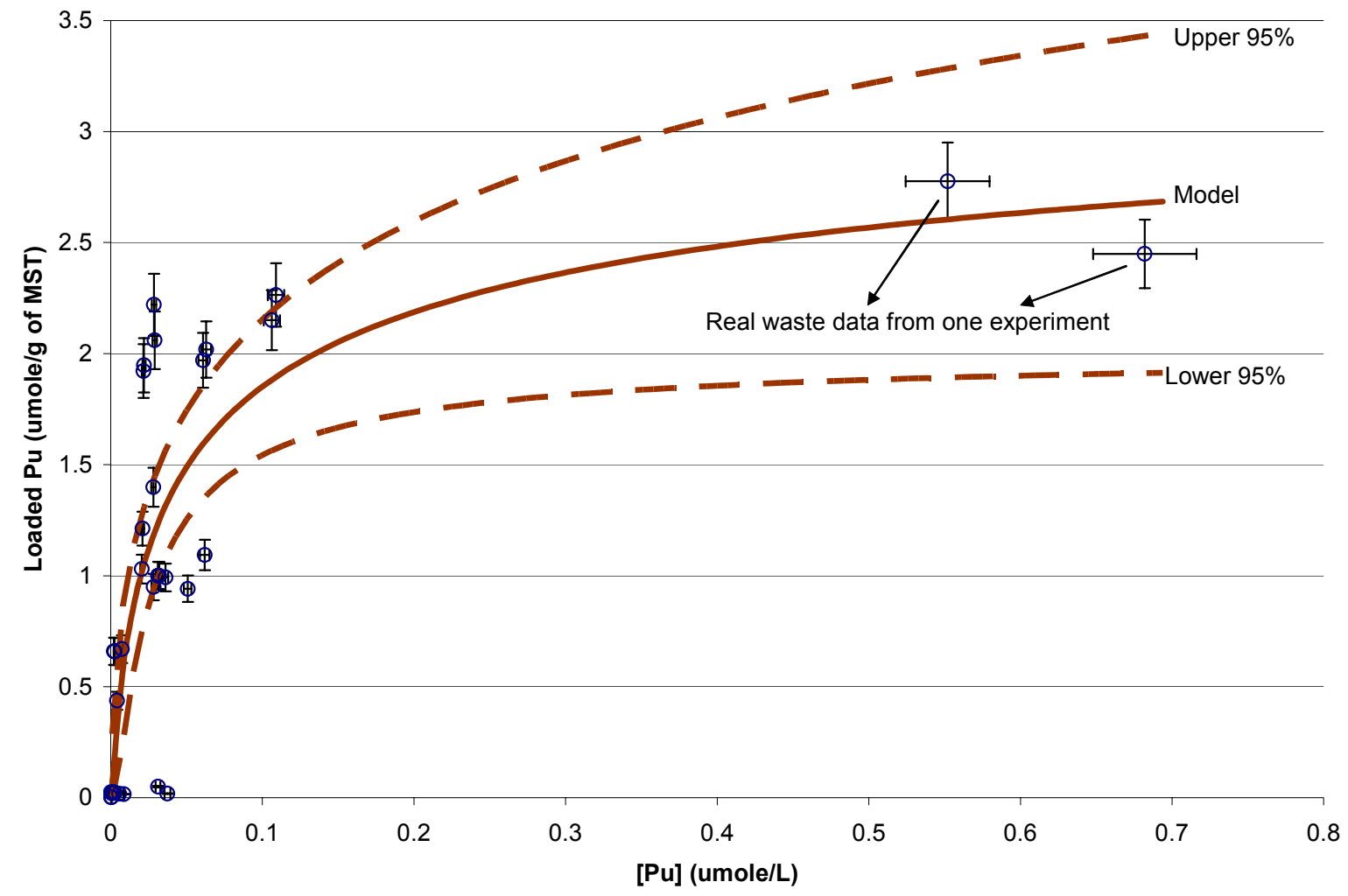

Figure 2. The prediction of the Pu data with the Dubinin-Astashov model. (NOTE: The data shown comes from experiments at $25^{\circ} \mathrm{C}$.). The two data points above $0.55 \mu \mathrm{M}$ are actual waste data. The waste data results from testing under unsteady state conditions (i.e., only 24 hours of testing). 
WSRC-TR-2003-00180

Page 15 of 66

Table 3. Relative performance of models for plutonium and overall.

\begin{tabular}{|c|c|c|c|c|}
\hline Model & Plutonium $\mathbf{r}^{2}$ & Plutonium Akiake & $\begin{array}{c}\text { Overall } \\
\text { Score }\end{array}$ & $\begin{array}{c}\text { Overall } \\
\text { Ranking }\end{array}$ \\
\hline Competitive Quadratic with U & 0.752 & 71 & 15 & 6 \\
\hline Dubinin-Astashov & 0.72 & 66 & 5 & 1 \\
\hline Langmuir & 0.69 & 69 & 12 & 5 \\
\hline Radke-Prausnitz & 0.69 & 69 & 10 & 4 \\
\hline Langmuir Uniform Distribution & 0.69 & 69 & 9 & 3 \\
\hline Khan & 0.69 & 69 & 8 & 2 \\
\hline Langmuir-Freundlich & 0.687 & 69 & 17 & 8 \\
\hline BET & 0.687 & 69 & 17 & 8 \\
\hline Toth & 0.687 & 69 & 15 & 6 \\
\hline General-Y & 0.685 & -104 & 30 & 14 \\
\hline Jaroniec-Marczweski & 0.679 & 72 & 27 & 13 \\
\hline Bubinin-Radushevik & 0.679 & 70 & 23 & 11 \\
\hline Redlich-Peterson & 0.679 & 70 & 23 & 11 \\
\hline SRS & 0.678 & 68 & 18 & 10 \\
\hline FG-LF & 0.67 & -105 & 36 & 17 \\
\hline Myers & 0.617 & -104 & 35 & 16 \\
\hline Volmer & 0.616 & -106 & 39 & 20 \\
\hline IAST & 0.616 & -106 & 39 & 20 \\
\hline Jovanovic & 0.616 & 72 & 32 & 15 \\
\hline FG-JF & 0.585 & -99 & 38 & 18 \\
\hline Temkin & 0.46 & 81 & 38 & 18 \\
\hline
\end{tabular}


WSRC-TR-2003-00180

Page 16 of 66

\section{Plutonium Form of the Dubinin-Astashov Model}

The DA equation for $\mathrm{Pu}$ loading on MST at $25^{\circ} \mathrm{C}$ follows.

2) Loaded $P u=(2.6 \pm 0.5) \times \exp \left(-8 \pm 6 \times 10^{-4} \times\right.$ Temperature $\left.^{2 \pm 1} \times\left[\operatorname{Ln}\left(\frac{0.8 \pm 1.2}{[P u]}\right)\right]^{2 \pm 1}\right)$

In this expression, the temperature is in units of Kelvin and the plutonium concentration unit is in micromoles per liter. Note the value of the exponent for both the concentration and temperature equals 2 . A value of 3 or less is typically assigned to a narrow energy distribution for sorption sites. The surface homogeneity assumed from the DA model is not consistent with previous microscopy and spectroscopy analysis of MST. The value 0.0008 (which equals the "a" parameter) equals to the gas constant divided by the average adsorption energy $(\mathrm{R} / \mathrm{E})$ raised to the " $\mathrm{n}$ "th" power and in this the $2^{\text {nd }}$ power. From this expression we can calculated the average adsorption energy "E". The calculated average adsorption energy from the previous expression equals $294 \mathrm{~J} / \mathrm{mole}$. This energy is well below the adsorption energy of strontium on clay (typically 7 $\mathrm{kJ} / \mathrm{mole}) .{ }^{37}$ The low sorption energy value explains the ease of actinide sorption on MST. The energy of ion exchange reactions typically ranges from $8-16 \mathrm{~kJ} / \mathrm{mol}$. The calculated energy value of $294 \mathrm{~J} /$ mole indicates the mode of adsorption is specific (or multilayer), in agreement with recent XAFS findings.

We fitted the three temperature data sets simultaneously with the DA function. The DA model explained $74 \%$ of the variance in the data. The Dubinin-Astashov equation for $\mathrm{Pu}$ loading on MST follows.

3) Loaded Pu $=(471 \pm 174) \times \exp \left(-.27 \pm .14 \times\right.$ Temperature $\left.^{0.4 \pm .02} \times\left[\operatorname{Ln}\left(\frac{3.6 \pm 9}{[P u]}\right)\right]^{0.4 \pm .02}\right)$

In this expression, the larger parameter uncertainty is due to additional data scatter from the wider temperature range tested. The parameter listed before the temperature variable and the parameter in the logarithm term may not be statistically significant.

Figure 3 shows the effect of temperature on Pu adsorption. There are two curves on Figure 3. The leftmost curve is the temperature dependence of the Pu loading as predicted by the DA model. The model predicts loading decreases with increasing temperature. Raising the temperature during sorption provides additional thermal energy for the loaded $\mathrm{Pu}$ to desorb. Please note testing included only three temperatures. The right curve on Figure 3 is the DA isotherm model prediction of loading and final $\mathrm{Pu}$ concentration at $45^{\circ} \mathrm{C}$. Note the linear dependency between loaded $\mathrm{Pu}$ and temperature indicates the isotherm shape does not change with temperature. The isotherm linearly shifts to lower values at high temperatures (within the range tested). 
WSRC-TR-2003-00180

Page 17 of 66

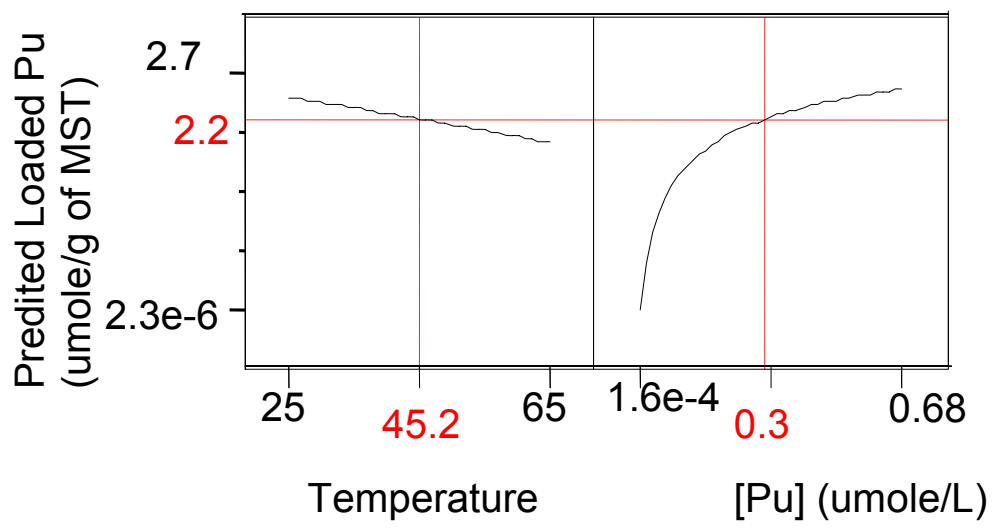

Figure 3. The effect of temperature on Pu adsorption as predicted by the Dubinin-Astashov model.

Regression of the data for the plutonium loading equation resulted in a significant uncertainty in the parameter values. For example the uncertainty of the " $\mathrm{S}$ " parameter is three times larger than the estimated value. The "S" (previously identified as the shape factor for a Weibull distribution) parameter stands for the solubility limit of the nuclide in solution. To determine how sensitive the DA equation is to parameters variations, we computed and graphed the sensitivity factors. Figure D1 in Appendix D contains the sensitivity plots.

\section{Strontium Form of the Dubinin-Astashov Model}

Figure 4 shows the loading data as well as the DA model prediction for strontium sorption at $25^{\circ} \mathrm{C}$. Again, the large variance of the 45 and $65^{\circ} \mathrm{C}$ precluded fitting with the DA model at these two temperatures alone. The DA model explained $97 \%$ of the data variability $\left(\mathrm{R}^{2}=0.97\right)$. The data scatter at $[\mathrm{Sr}]<0.1 \mathrm{M}$ is due to different experimental conditions tested in the adsorption experiments. The DA model reproduced this scatter by including the effects of temperature. In Figure 4, the points represented by the filled circles are DA model predictions. The final DA isotherm equation presents a heterogeneity value (" $n$ ") of 1 . The site energy distribution is very narrow. The surface of MST appears very homogeneous for $\mathrm{Sr}$ adsorption. The average adsorption energy, as predicted by the DA model, is $3.3 \mathrm{~kJ} /$ mole. This enthalpic energy is above the energy available at room temperature $(2477 \mathrm{~J} / \mathrm{mole})$ for Brownian motion. Therefore, the strontium sorption is irreversible. The inverse Weibull statistics indicate that, to maximize the specific loading, the energy must be as large as possible. Also from the DA equation, the maximum Sr loading on MST is predicted to be 31 micromoles per gram of MST (e.g., the pre-exponential term in the following equation) at a $95 \%$ confidence level. No experimental measurement of the maximum Sr loading on MST has been made to date for comparison. To convert from $\mu \mathrm{mol} / \mathrm{L}$ of $\mathrm{Sr}-90$ to $\mathrm{nCi} / \mathrm{g}$ of solution multiply the $\mu \mathrm{mol} / \mathrm{L}$ unit by 9960 (assuming a solution density of $1274 \mathrm{~g} / \mathrm{L}$ ). 
WSRC-TR-2003-00180

Page 18 of 66

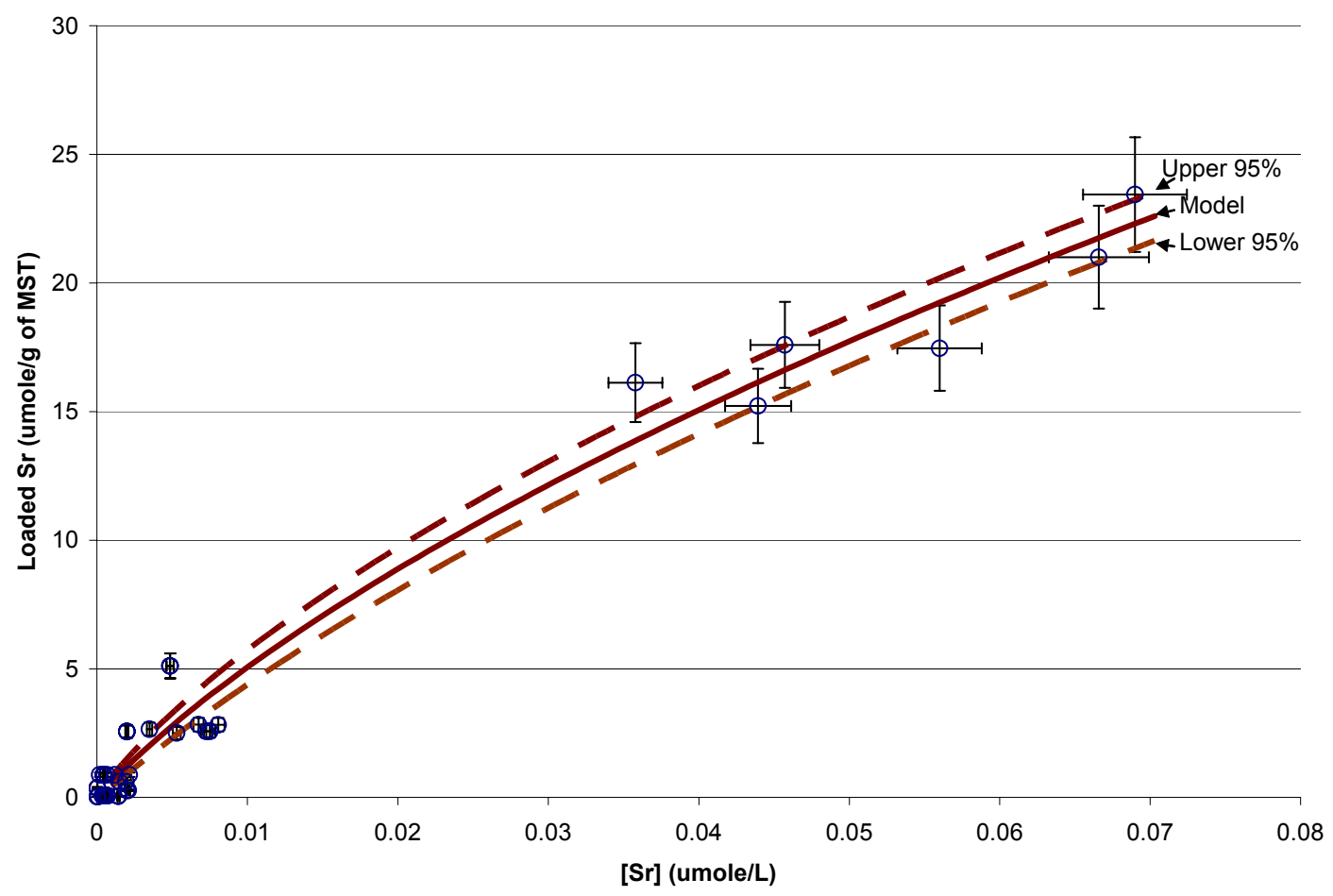

Figure 4. The Dubinin-Astashov model predictions for the Sr loading data at $25^{\circ} \mathrm{C}$. The confidence limits are for the mean response. Please note the error bars on the data.

The corresponding DA equation for strontium at $25^{\circ} \mathrm{C}$ follows. The " \pm " terms in the equations represent the standard error for the parameters.

4) Loaded $S r=22 \pm 19 \times \exp \left[-2.3 \pm 0.9 \times 10^{-3} \times 298^{1 \pm .33} \times\left(\operatorname{Ln}\left(\frac{0.07 \pm .12}{[S r]}\right)\right)^{1 \pm .33}\right]$

The pre-exponential and the logarithm parameters may not be statistically significantly since they have strong correlations with the other parameters. We also fitted the data for all three temperatures simultaneously yielding the following equation. The DubininAstashov model equation for Sr loading follows with the same units as used for plutonium.

5) Loaded $S r=410 \pm 138 \times \exp \left[-0.09 \pm 0.02 \times\right.$ Temperature $\left.^{0.55 \pm .009} \times\left(\operatorname{Ln}\left(\frac{0.42 \pm .12}{[S r]}\right)\right)^{0.55 \pm .009}\right]$

Note at $298^{\circ} \mathrm{K}$ both equation 4 and 5 predictions differ suggesting additional work is needed. We recommend equation 5 for strontium loading predictions. The effect of 
WSRC-TR-2003-00180

Page 19 of 66

temperature is shown in Figure 5. Looking at Figure 5, the DA model predicts that increasing the temperature decreases Sr loading on MST. Raising the temperature during sorption provides additional thermal energy for the loaded $\mathrm{Sr}$ to desorb. The sensitivity plots for this equation are shown in Appendix D.

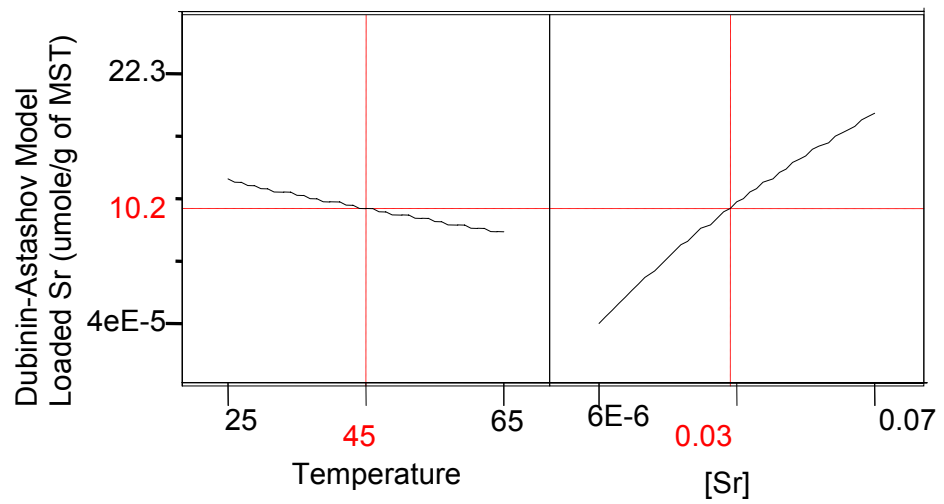

Figure 5. The effect of temperature on Sr adsorption as predicted by the Dubinin-Astashov model.

\section{Uranium form of the Dubinin-Astashov Model}

Figure 6 shows the experimental loading data as well as the DA model predictions at $25^{\circ} \mathrm{C}$. Figures 7 and 8 show similar predictions for the 45 and $65{ }^{\circ} \mathrm{C}$ data. Figure 9 shows the results for the DA model with parameters regressed simultaneously for the entire data set. The loading data display a take off or "tail" at $[\mathrm{U}]>65$ micromoles/L. This likely indicates multilayer formation as originally suggested by previous scattering spectroscopy work. The feature of the DA model in reproducing the upper "tail", or "upswing", suggests formation of chemical networks throughout the micropore space. If the DA model assumptions are correct, then the sites energy distribution on MST is very narrow and homogeneous (as indicated by the " $n$ " value of 0.16 ). 
WSRC-TR-2003-00180

Page 20 of 66

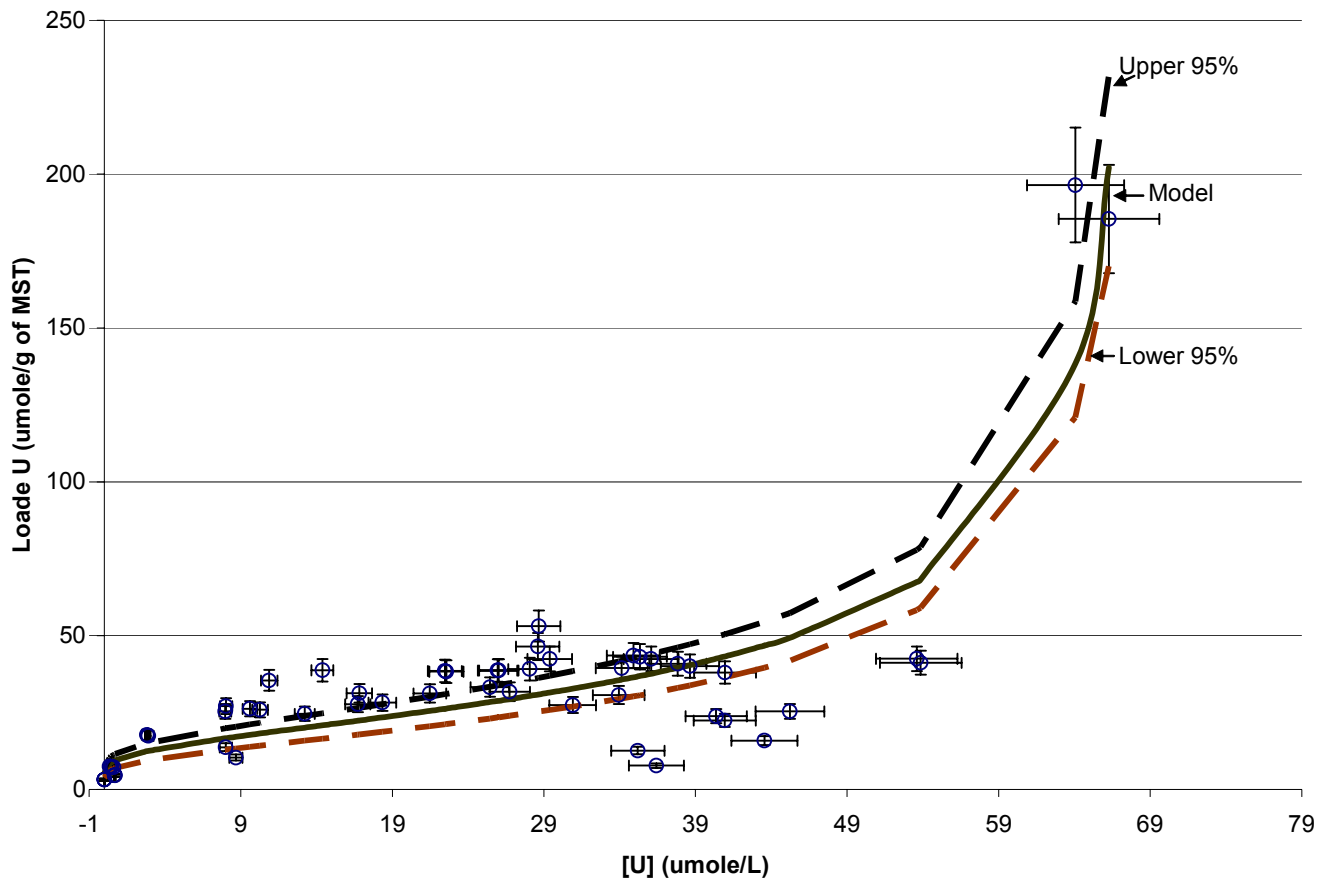

Figure 6. The Dubinin-Astashov model fit of the $\mathrm{U}$ data at $25^{\circ} \mathrm{C}$. 
WSRC-TR-2003-00180

Page 21 of 66

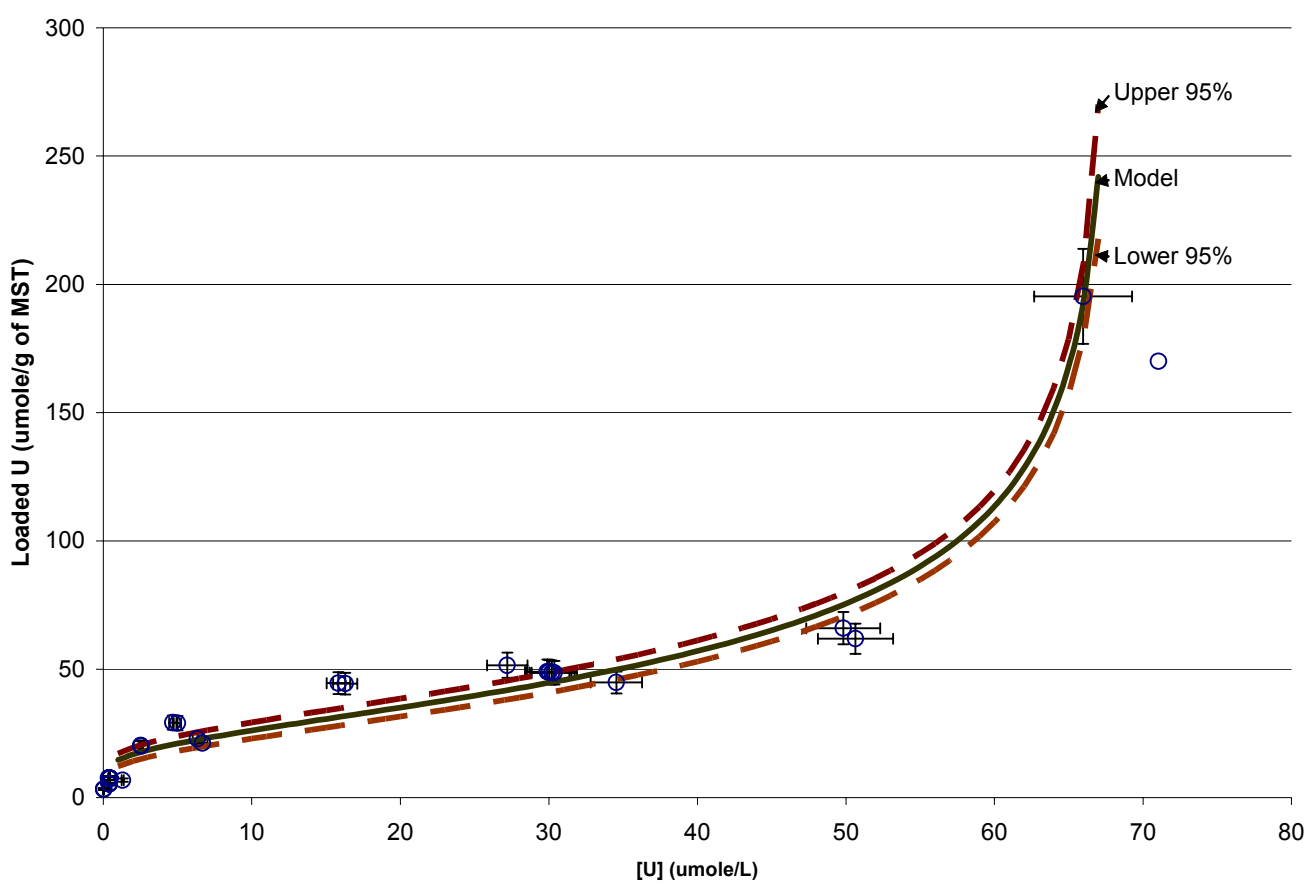

Figure 7. The Dubinin-Astashov model results and the $45^{\circ} \mathrm{C} \mathrm{U}$ adsorption data. 
WSRC-TR-2003-00180

Page 22 of 66

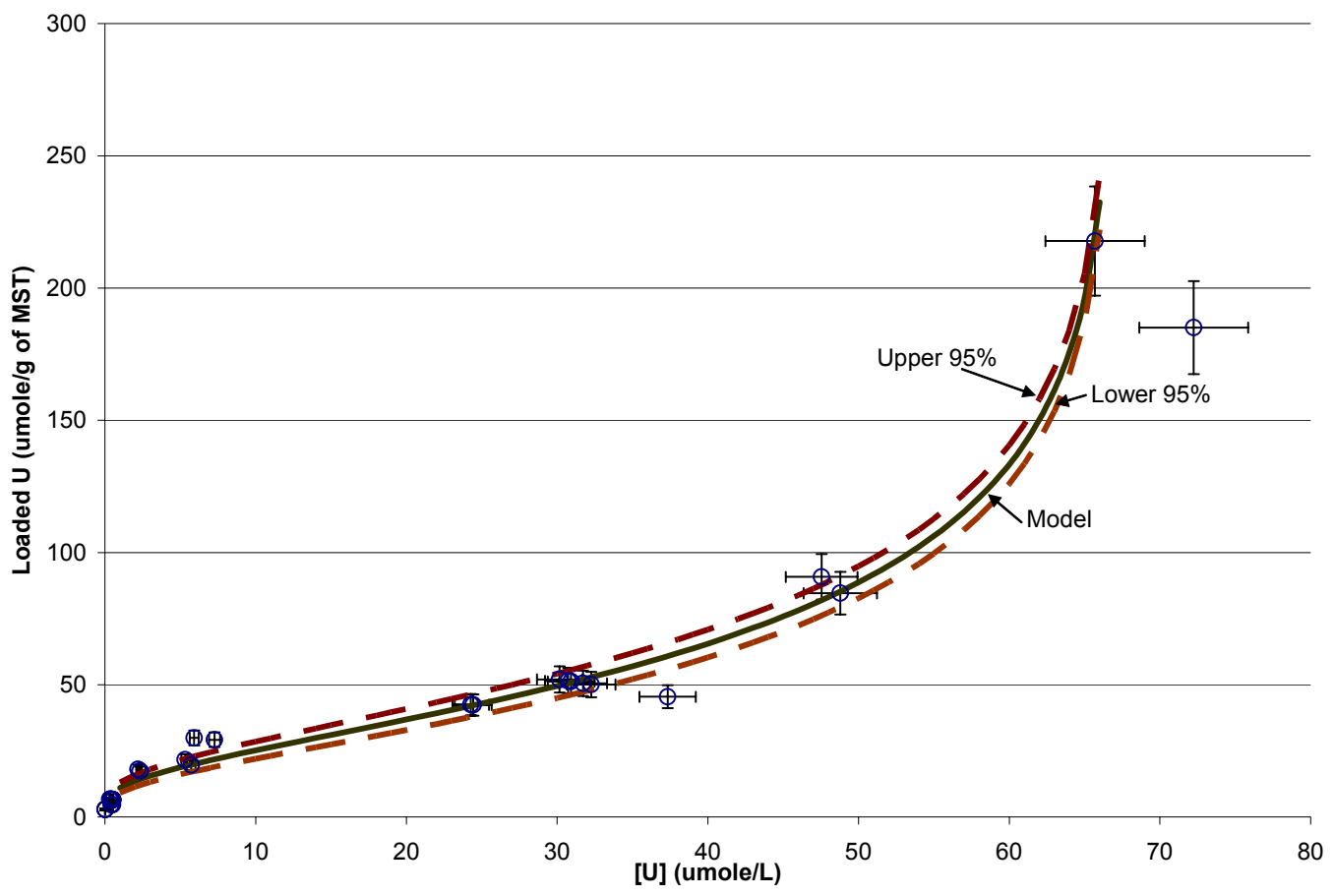

Figure 8. The Dubinin-Astashov model output for the $65^{\circ} \mathrm{C}$ uranium data. 
WSRC-TR-2003-00180

Page 23 of 66

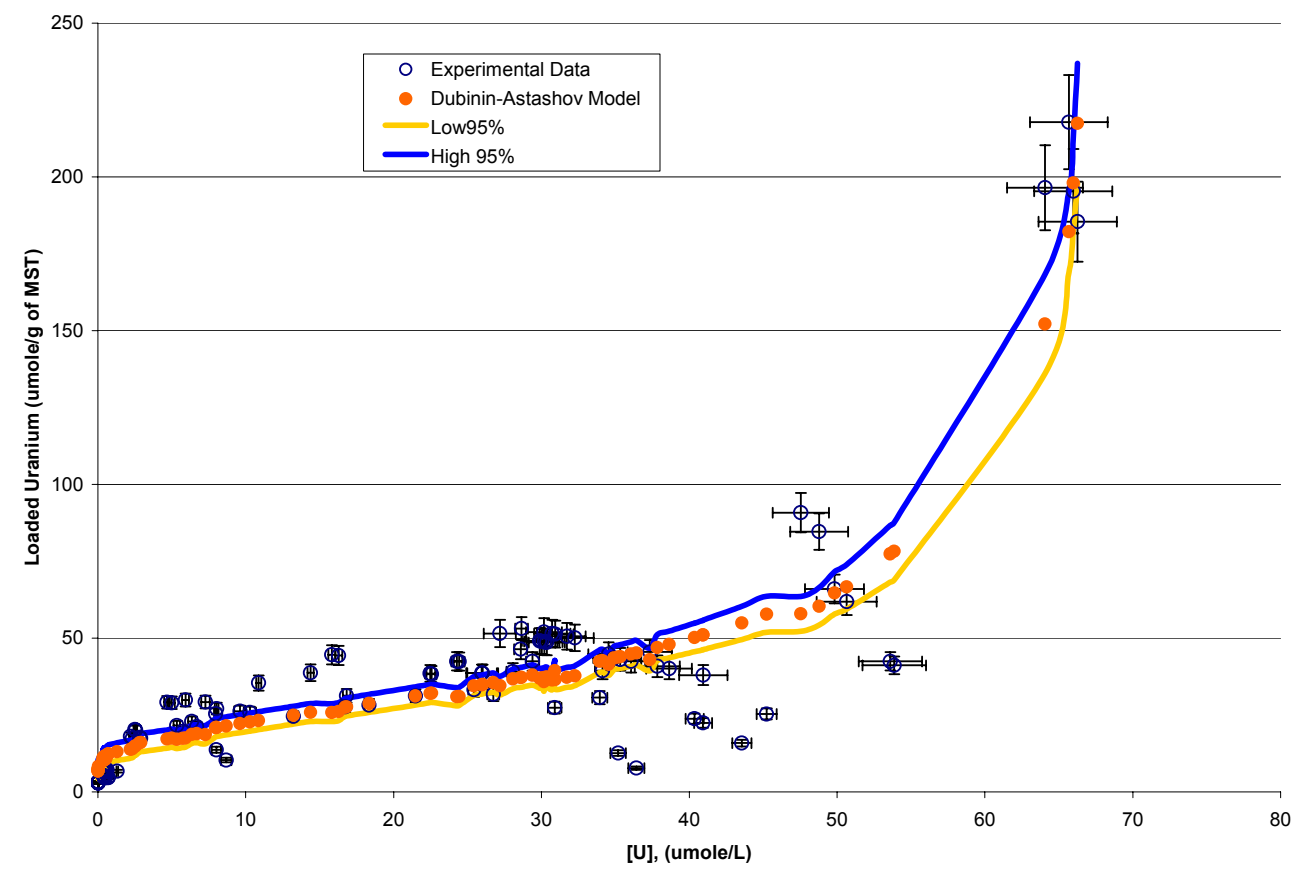

Figure 9. The Uranium loading data on MST at 25,45 and $65^{\circ} \mathrm{C}$. The figure also includes the Dubinin-Astashov model predictions.

The average adsorption energy on MST is very low, about $5 \mathrm{~J} /$ mole. The magnitude of this energy indicates multilayer formation. This low sorption energy explains the irreversibility of the adsorption process (for example low leaching under washing conditions). Note the parameter listed before the temperature variable in Eq. 6 may not be statistically significant. Figure 10 shows the effect of temperature on the predictions. From inspection of Figure 10 temperature has a minor effect on uranium loading. The DA model predicts MST can adsorb 1,865 micromoles of uranium per gram of MST (or $44 \mathrm{wt} \%$ ). The previously experimentally determined maximum loading is $1.28 \mathrm{wt} \%{ }^{32}$ The predicted maximum loading is 34 times the experimental value. We recommend additional testing at large uranium concentrations ( $>100$ umole/L) to accurately determine the maximum capacity of MST for fissile uranium. This information is essential for developing the safety bases for the operations.

The Dubinin-Astashov isotherm equation for $U$ loading follows using the same units as stated earlier.

6) Loaded Uranium $=1865 \pm 472 \times \exp \left[-20 \pm 15 \times\right.$ Temperature $\left.^{0.16 \pm .008} \times\left(\operatorname{Ln}\left(\frac{68 \pm 0.3}{[U]}\right)\right)^{0.16 \pm 0.008}\right]$ 
WSRC-TR-2003-00180

Page 24 of 66

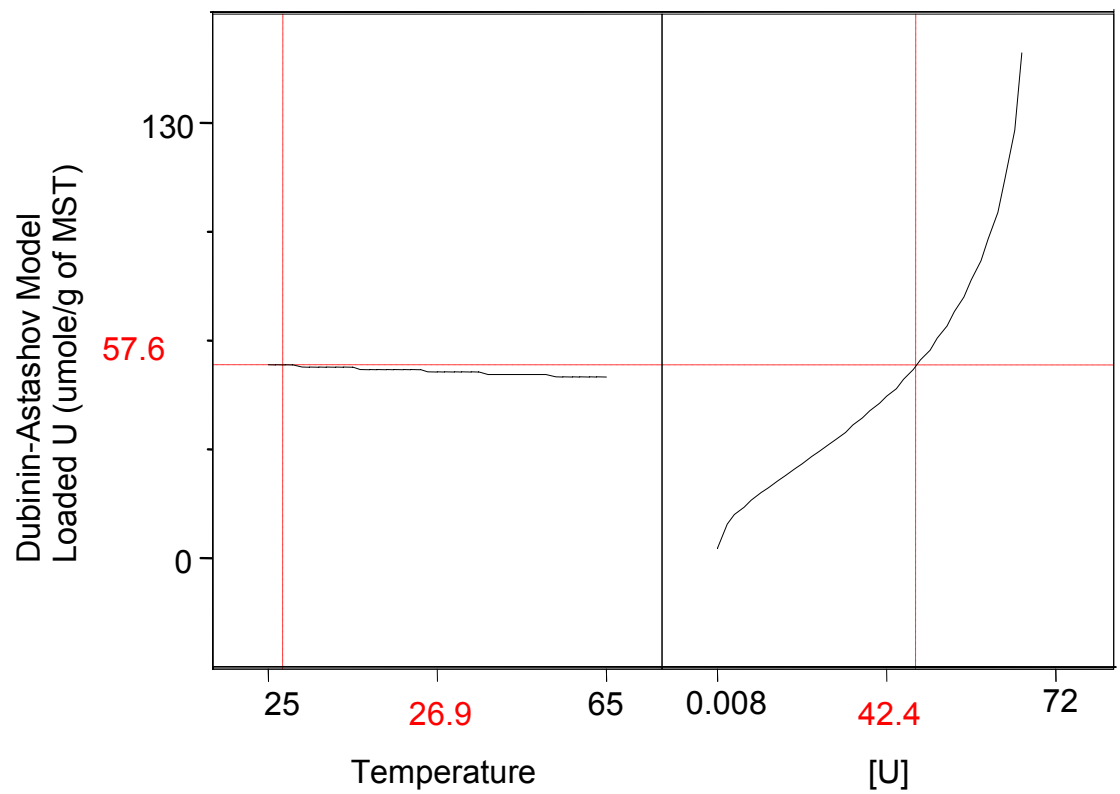

Figure 10. The effect of temperature on $\mathrm{U}$ adsorption as predicted by the Dubinin-Astashov model.

\section{Neptunium Form of the Dubinin-Astashov Model}

We organized the $\mathrm{Np}$ data according to temperature and plot it in Figure 11. Inspection of data in Figure 11 shows that higher adsorption occurred at higher temperature. This observation is contrary to the temperature dependency of $\mathrm{U}, \mathrm{Pu}$ and $\mathrm{Sr}$. At each temperature, we fitted the DA model to the data. Figures 12, 13 and 14 shows the Np adsorption data and DA predictions. The Dubinin-Astashov equation for the Np sorption data at $25^{\circ} \mathrm{C}$ follows.

Loaded $N p=64.9 \pm 9 \times \exp \left[-0.001 \pm .0006 \times 298^{1.1 \pm .5}\left(\operatorname{Ln}\left(\frac{75.3 \pm .01}{[N p]}\right)\right)^{1.1 \pm .5}\right]$ 
WSRC-TR-2003-00180

Page 25 of 66

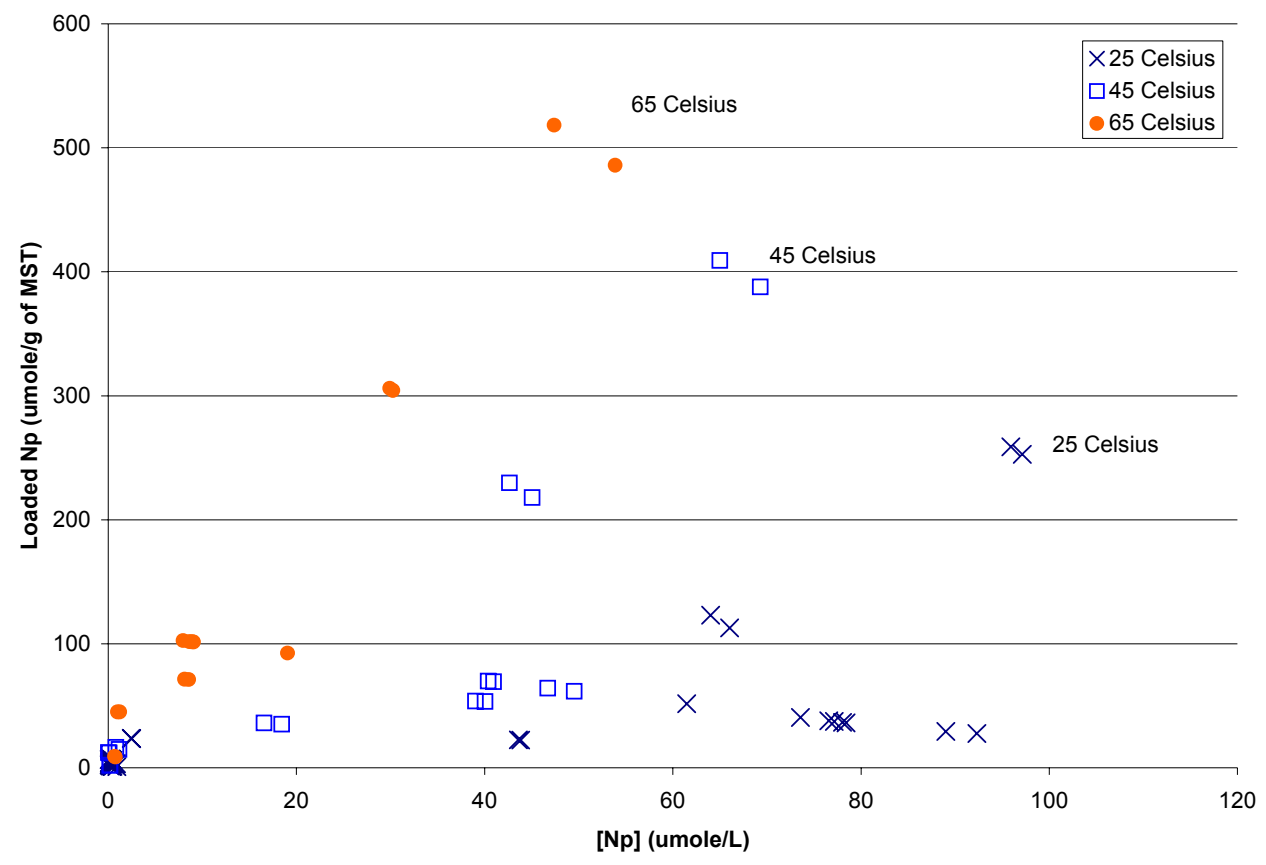

Figure 11. The $\mathrm{Np}$ adsorption data as a function of temperature. 
WSRC-TR-2003-00180

Page 26 of 66

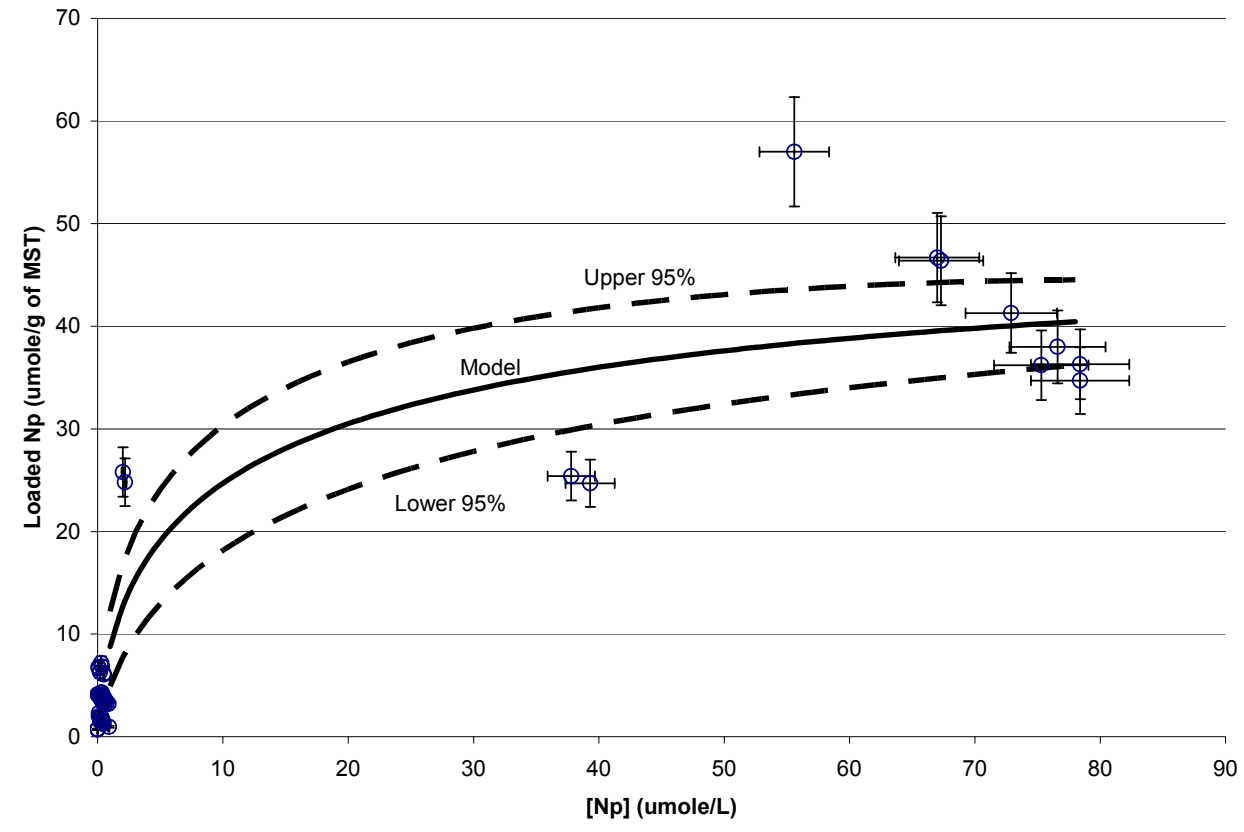

Figure 12. This figure shows the $\mathrm{Np}$ adsorption data at $25^{\circ} \mathrm{C}$ and the DubininAstashov model predictions. Please note some of the high loading data are not shown. 
WSRC-TR-2003-00180

Page 27 of 66

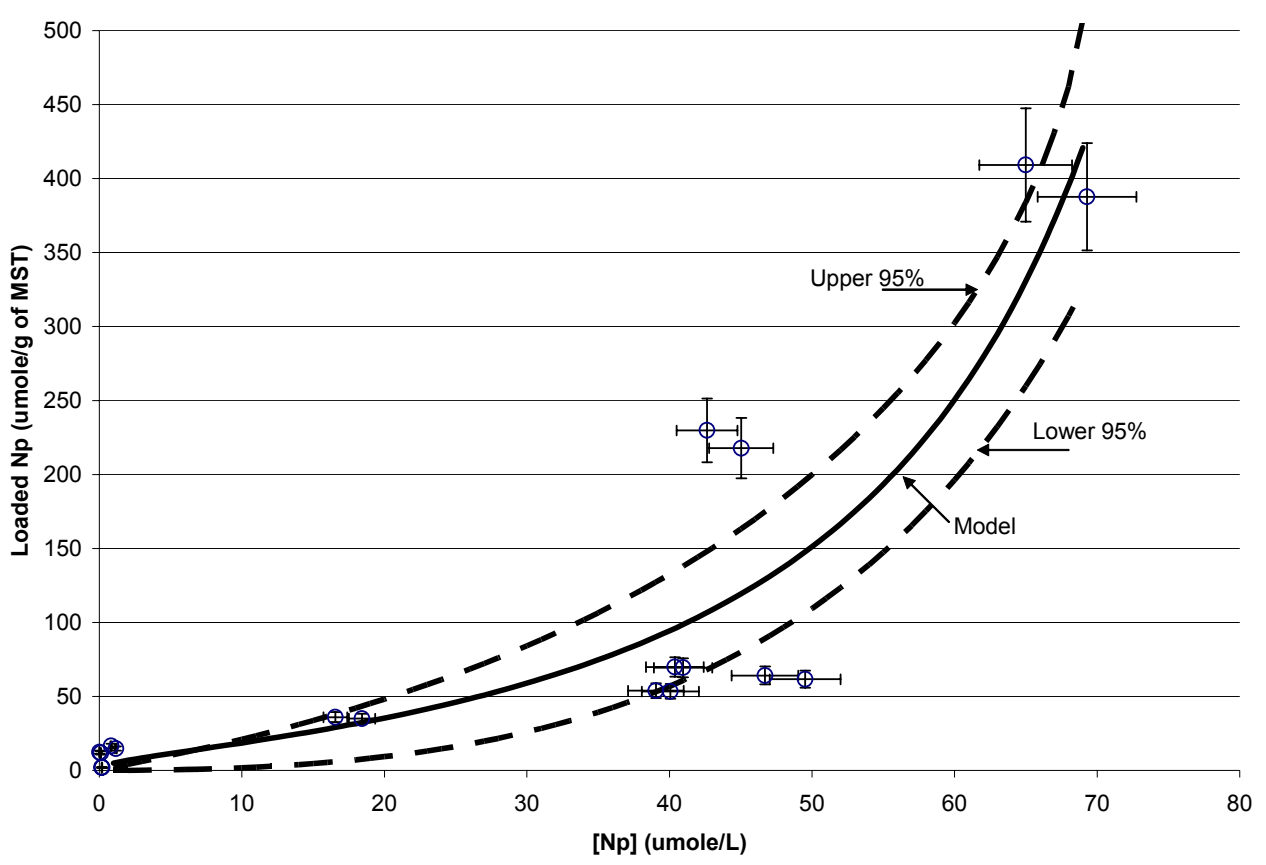

Figure 13. The Np sorption data at $45^{\circ} \mathrm{C}$ and predications by the Dubinin-Astashov model. 
WSRC-TR-2003-00180

Page 28 of 66

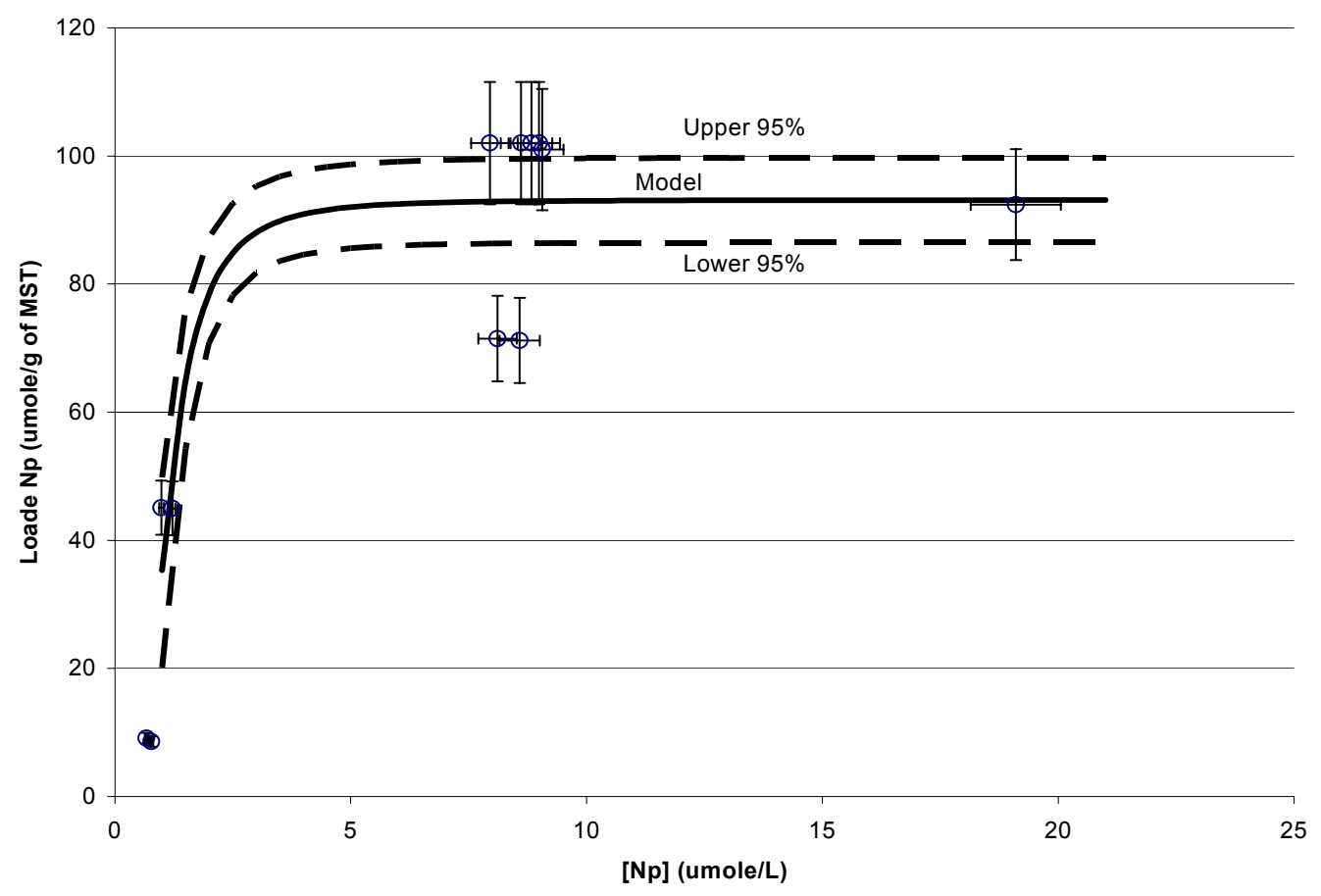

Figure 14. The $65^{\circ} \mathrm{C} \mathrm{Np}$ data fitted with the Dubinin-Astashov model.

\section{Sorption Data After 24 hours of Testing}

The U, Np, Sr and Pu sorption Figures after 24 hours are shown in Appendix E.

\section{The Effect of Excess Uranium Loading on Pu, Sr and Np Loading}

Figure 15 shows the uranium, neptunium, strontium and plutonium data side by side. Looking at the uranium plot in Figure 15, the data at large loadings (indicated by the symbol "+" in both figures) correlate with the large Pu loading (shown with the symbol "+") shown in the Pu figure. This may be evidence of co-precipitation or specific adsorption on deposited uranium. We eliminated the $\mathrm{Pu}$ data at this loading since the final $\mathrm{Pu}$ concentration fell below the detection limit. At the same time neptunium also largely loaded on MST while strontium did not load to the same extent. The large uranium sorption appears to enhance both plutonium and neptunium loading and inhibits strontium loading.

\section{Conclusions}

We identified three models, out of 29 examined, that can fit and predict uranium, strontium and plutonium loading on MST. Two of the models - the FowlerGuggenheim-Jovanovic-Freundlich and Fowler-Guggenheim-Langmuir-Freundlich (FGJF and FG-LF) - are inverse model. The Dubinin-Astashov model is a conventional isotherm. We recommend the DA model for its minimal amount of parameters and for ease of application. The DA model successfully reproduced the uranium, strontium and 
WSRC-TR-2003-00180

Page 29 of 66

plutonium data set. The binding energies derived from the model explain the observed irreversibility of the adsorption process on MST.

To enhance our predictive tools, we recommend additional testing that includes wider range of actinide and strontium concentrations, verifying in particular the limited data set for high plutonium concentrations. We also recommend adding Am and $\mathrm{Cm}$ to future experimental studies to expand our data set on these two actinides.

We recommend a more complete analysis of the implications that increased uranium trapping in the micropores has on facility operation and risk of nuclear criticality.

We recommend continuing the modeling analysis for non-equilibrium data at shorter processing times. Analyzing this data offers the greatest benefits for assessing options to accelerate production rate for the facilities.

We also recommend additional testing of single component and binary actinide solutions. These studies will either verify the parameters found from the multi-component study or indicate the need to explicitly develop the forms of the model that show binary interaction 


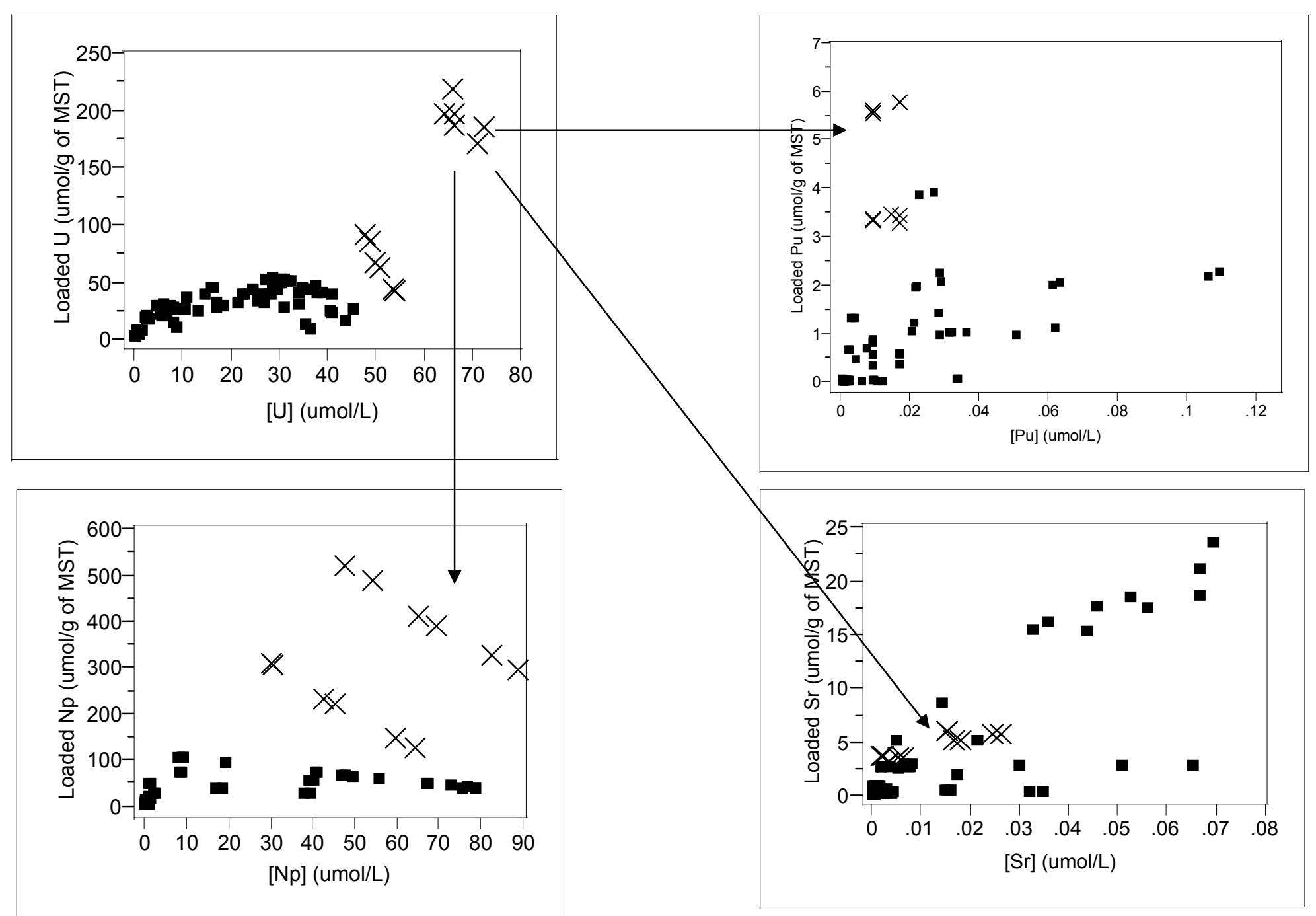

Figure 15. The effect of excess uranium loading on the $\mathrm{Np}, \mathrm{Sr}$ and Pu loading. 
WSRC-TR-2003-00180

Page 31 of 66

\section{Appendix A. Isotherm Models Evaluated during this study}

The following list shows the mathematical form of the isotherms evaluated during this study. For purposes of brevity, we omit the full definition of the mathematical terms and refer the interested reader to the references for the model.

1. Langmuir Isotherm ${ }^{39}$

$$
Y=\frac{Y_{m} K X}{1+K X}
$$

2. Competitive Quadratic ${ }^{38}$

$$
Y / Y_{m}=\frac{a_{i} X_{i}+a_{i j} X_{i} X_{j}}{1+b_{i} X_{i}+b_{j} X_{j}+b_{i j} X_{i} X_{j}}
$$

3. Freundlich Isotherm ${ }^{39}$

$$
Y=K X^{n}
$$

4. Sips (Langmuir-Freundlich) ${ }^{40}$

$$
Y=Y_{m} \frac{b X^{n}}{1+b X^{n}}
$$

5. Dubinin-Astashov (thermodynamically consistent) ${ }^{41}$

$$
Y=Y_{m} \exp \left[-a\left(\frac{R T}{E}\right)^{n}\left(\operatorname{Ln}\left(\frac{S}{X}\right)\right)^{n}\right]
$$

6. Myers ${ }^{39}$

$$
X=\frac{Y}{H} \exp \left(K Y^{n}\right)
$$

7. Redlich-Peterson ${ }^{39}$

$$
Y=\frac{K_{1} X}{1+K_{2} X^{n}}
$$

8. Radke-Prausnitz ${ }^{39}$

$$
1 / Y=\frac{1}{a X}+\frac{1}{b X^{n}}
$$


WSRC-TR-2003-00180

Page 32 of 66

9. Toth $^{17}$

$$
Y=\frac{Y_{m} X}{\left(b+X^{n}\right)^{1 / n}}
$$

10. Volmer ${ }^{39}$

$$
b X=\left(\frac{\theta}{1-\vartheta}\right) \exp \left(\frac{\theta}{1-\vartheta}\right) ; \theta=Y / Y_{m}
$$

11. Temkin (thermodynamically consistent $)^{10}$

$$
Y=\frac{R T}{b} \operatorname{Ln}(a X)
$$

12. $\mathrm{Gu}$ (Multilayer formation-Langmuir) ${ }^{42}$

$$
Y=Y_{m} \frac{a X / X_{o}\left(n^{-1}+b\left(X / X_{o}\right)^{n-1}\right)}{1+a X / X_{o}\left(1+b\left(X / X_{o}\right)^{n-1}\right)}
$$

13. Frumkin-Damaskin ${ }^{15}$

$$
b X=\frac{\theta}{n(1-\theta)^{n}} \exp (-2 a \theta) ; \theta=\frac{Y}{Y_{m}}
$$

14. Ideal Absorbed Solution Theory (Freundlich Derived) (thermodynamically consistent) ${ }^{40}$

$$
X=\frac{\theta_{i}}{\sum_{1}^{N} \theta_{j}}\left[\frac{\sum_{1}^{N} n_{j} \theta_{j}}{n_{i} K_{i}}\right]^{n_{i}} ; \theta=Y / Y_{m}
$$


WSRC-TR-2003-00180

Page 33 of 66

15. Le Van-Vermeulen Competitive (Up to second order) (thermodynamically consistent) $)^{18}$

$$
Y_{i} / Y_{m_{i}}=\left(\frac{a_{i} X_{i}+a_{j} X_{j}}{b_{i} X_{i}+b_{j} X_{j}} b_{i} X_{i} / 1+b_{i} X_{i}+b_{j} X_{j}\right)+\left(\frac{a_{i}}{b_{i}}-\frac{a_{j}}{b_{j}}\right) \frac{b_{i} b_{j} X_{i} X_{j}}{\left(b_{i} X_{i}+b_{j} X_{j}\right)^{2}} \operatorname{Ln}\left(1+b_{i} X_{i}+b_{j} X_{j}\right)
$$

16. Jovanovic ${ }^{43}$

$$
Y / Y_{m}=a\left(1-e^{-b X}\right)
$$

17. Sheindorf-Rebuhn-Sheintuch ${ }^{30}$

$$
\frac{Y_{i}}{Y_{m_{i}}}=a_{i} X_{i}\left(\sum_{1}^{N} a_{i j} X_{j}\right)^{n_{i}-1}
$$

18. Vacancy Solution Theory (thermodynamically consistent) ${ }^{19}$

$$
X=\left(\frac{\theta}{b(1-\vartheta)}\right)\left[\frac{b_{12}\left(1-\left(1-b_{21}\right) \theta\right)}{b_{12}+\left(1-b_{12}\right) \theta}\right] \exp \left[-\frac{b_{21}\left(1-b_{21}\right) \theta}{1-\left(1-b_{21}\right) \theta}-\frac{\left(1-b_{12}\right) \theta}{b_{12}+\left(1-b_{12}\right) \theta}\right] ; \theta=Y / Y_{m}
$$

19. Myers-Valenzuela ${ }^{44}$

$$
Y / Y_{m}=\frac{1}{2 b} \operatorname{Ln} \frac{a+X \exp (b)}{a+X \exp (-b)}
$$

20. $\operatorname{Khan}^{45}$

$$
Y / Y_{m}=\frac{a X}{(1+a X)^{b}}
$$

21. Khan-Riazi-AlRoomi ${ }^{46}$

$$
X=Y \exp \left[(1-Y)^{2}\left(a+b Y+c Y^{n}\right)\right]
$$


22. Jaroniec-Marczewski ${ }^{47}$

$$
Y / Y_{m}=\frac{(K X)^{a}}{\left[1+(K X)^{b}\right]^{a / b}}
$$

23. Fowler-Guggenheim ${ }^{48}$

$$
b X=\frac{\theta}{1-\theta} \exp (-2 a \theta)
$$

24. Fowler-Guggenheim-Jovanovich-Freundlich ${ }^{25}$

$$
Y / Y_{m}=\left[1-e^{\left(-\left(a X e^{b^{Y} / Y_{m}}\right)^{c}\right)}\right]
$$

25. Fowler-Guggenheim-Langmuir-Freundlich ${ }^{25}$

$$
\theta=\frac{\left(a X e^{b \theta}\right)^{c}}{1+\left(a X e^{b \theta}\right)^{c}} ; \theta=Y / Y_{m}
$$

26. Virial $^{39}$

$$
\frac{b X}{Y}=\exp \left(2 a_{1} Y+\frac{3}{2} a_{2} Y^{2}+\ldots+\frac{n+1}{n} a_{n} Y^{n}\right)
$$

27. B.E.T.-Multilayer (Brunauer-Emmett-Teller) ${ }^{39}$

$$
Y / Y_{m}=\frac{c X}{\left(1-\frac{X}{S}\right)\left(1+c X-\frac{X}{S}\right)}
$$

28. Sigmoidal ${ }^{39}$

$$
Y=\frac{(a-b)}{\left[1+e^{\frac{(X-c)}{d}}\right]}+b
$$

29. Generalized Isotherm ${ }^{39}$

$$
\frac{b X}{Y}=1+a_{1} Y+a_{2} Y^{2}+\ldots+a_{n} Y^{n}
$$




\section{Appendix B. Experimental Data used in Modeling Effort.}

The following tables contain the experimental data used in this modeling study. The values shown include many more digits than experimentally significant. The authors used the extraneous digits to avoid numerical round-off errors during calculations.

Table B1. The plutonium experimental data set.

\begin{tabular}{|c|c|c|c|c|c|c|}
\hline $\begin{array}{l}\text { Data } \\
\text { Number }\end{array}$ & Data Not Selected & Reason & {$[\mathrm{Pu}]$ (umole/L) } & Loaded Pu (umole/g of MST) & {$[\mathrm{Pu}]$ initial (umole/L) } & MST g/L \\
\hline 1 & $\mathbf{x}$ & Detection Limit & 0.008995816 & 0.842 & 0.027866 & 1.1 \\
\hline 2 & $\mathbf{x}$ & Detection Limit & 0.008995816 & 0.841 & 0.004761 & 2 \\
\hline 3 & $\mathbf{x}$ & Detection Limit & 0.008995816 & 0.807170027 & 0.007264 & 0.2 \\
\hline 4 & $\mathbf{x}$ & Detection Limit & 0.008995816 & 0.807170027 & 0.003138 & 1.1 \\
\hline 5 & $\mathbf{x}$ & Detection Limit & 0.008995816 & 0.803081019 & 0.003137 & 1.1 \\
\hline 6 & $\mathbf{x}$ & Detection Limit & 0.008995816 & 0.803081019 & 0.003138 & 1.1 \\
\hline 7 & $x$ & Detection Limit & 0.008995816 & 0.841517687 & 0.004761 & 2 \\
\hline 8 & $x$ & Detection Limit & 0.008995816 & 0.841517687 & 0.003137 & 1.1 \\
\hline 9 & $\mathbf{x}$ & Detection Limit & 0.008995816 & 0.807170027 & 0.003137 & 1.1 \\
\hline 10 & $\mathbf{x}$ & Detection Limit & 0.008995816 & 0.807170027 & 0.001961 & 2 \\
\hline 11 & $x$ & Detection Limit & 0.008995816 & 0.803081019 & 0.003137 & 1.1 \\
\hline 12 & $x$ & Detection Limit & 0.008995816 & 0.803081019 & 0.002344 & 0.2 \\
\hline 13 & $x$ & Detection Limit & 0.008995816 & 0.841517687 & 0.007264 & 2 \\
\hline 14 & $x$ & Detection Limit & 0.008995816 & 0.841517687 & 0.004688 & 0.2 \\
\hline 15 & $\mathbf{x}$ & Detection Limit & 0.008995816 & 0.807170027 & 0.002344 & 2 \\
\hline 16 & $x$ & Detection Limit & 0.008995816 & 0.807170027 & 0.004688 & 0.2 \\
\hline 17 & & & 0.008995816 & 0.803081019 & 0.003137 & 1.1 \\
\hline 18 & & & 0.008995816 & 0.803081019 & 0.002344 & 2 \\
\hline 19 & & & 0.001469418 & 0.023997308 & 0.003137 & 1.1 \\
\hline 20 & & & 0.000163735 & 0.025184292 & 0.001961 & 2 \\
\hline 21 & & & 0.00047153 & 0.002424132 & 0.007264 & 2 \\
\hline 22 & & & 0.000338078 & 0.002545452 & 0.003138 & 1.1 \\
\hline 23 & & & 0.000531154 & 0.002368612 & 0.002344 & 0.2 \\
\hline 24 & & & 0.000364424 & 0.002520185 & 0.003138 & 1.1 \\
\hline 25 & & & 0.001217517 & 0.024226308 & 0.007264 & 0.2 \\
\hline 26 & & & 0.002382556 & 0.023167182 & 0.027866 & 1.1 \\
\hline 27 & & & 0.000948991 & 0.001990076 & 0.027866 & 1.1 \\
\hline 28 & & & 0.000996441 & 0.00194694 & 0.003138 & 1.1 \\
\hline 29 & & & 0.000502572 & 0.002394596 & 0.001961 & 0.2 \\
\hline 30 & & & 0.00085985 & 0.002069798 & 0.003138 & 1.1 \\
\hline 31 & & & 0.002571481 & 0.022995432 & 0.26573 & 0.4 \\
\hline 32 & & & 0.002550489 & 0.023014515 & 0.001961 & 0.2 \\
\hline 33 & & & 0.001642942 & 0.001359213 & 0.012018 & 2 \\
\hline 34 & & & 0.001476868 & 0.001510188 & 0.027866 & 1.1 \\
\hline 35 & & & 0.000609755 & 0.002297156 & 0.26573 & 0.4 \\
\hline 36 & & & 0.000793158 & 0.002130427 & 0.027866 & 1.1 \\
\hline 37 & & & 0.000676982 & 0.020057252 & 0.027866 & 1.1 \\
\hline 38 & & & 0.000738907 & 0.019747625 & 0.26573 & 0.2 \\
\hline 39 & & & 0.000265421 & 0.034991735 & 0.26573 & 0.2 \\
\hline
\end{tabular}


WSRC-TR-2003-00180

Page 36 of 66

Table B1. The plutonium experimental data set.

\begin{tabular}{|c|c|c|c|c|c|c|}
\hline $\begin{array}{l}\text { Data } \\
\text { Number }\end{array}$ & Data Not Selected & Reason & [Pu] (umole/L) & Loaded Pu (umole/g of MST) & {$[\mathrm{Pu}]$ initial (umole/L) } & MST g/L \\
\hline 40 & & & 0.001002372 & 0.031306979 & 0.17886 & 0.4 \\
\hline 41 & & & 0.000635955 & 0.008541303 & 0.041139 & 2 \\
\hline 42 & & & 0.000981325 & 0.006814458 & 0.012018 & 2 \\
\hline 43 & $\mathbf{x}$ & Detection Limit & 0.014298434 & 3.436876029 & 0.27497 & 0.4 \\
\hline 44 & $x$ & Detection Limit & 0.014298434 & 3.436876029 & 0.041139 & 2 \\
\hline 45 & $x$ & Detection Limit & 0.008995816 & 3.328451883 & 0.93467 & 1.1 \\
\hline 46 & $\mathbf{x}$ & Detection Limit & 0.008995816 & 3.328451883 & 0.93377 & 1.1 \\
\hline 47 & $\mathbf{x}$ & Detection Limit & 0.008995816 & 3.310460251 & 0.89688 & 1.1 \\
\hline 48 & $x$ & Excessive Loading & 0.016947475 & 3.270701958 & 0.89688 & 1.1 \\
\hline 49 & & & 0.000193123 & 0.002283973 & 0.89238 & 1.1 \\
\hline 50 & & & 0.000488057 & 0.002136507 & 0.89238 & 1.1 \\
\hline 51 & & & 0.000910439 & 0.003176665 & 0.93467 & 1.1 \\
\hline 52 & & & 0.000661328 & 0.00330122 & 0.93467 & 1.1 \\
\hline 53 & & & 0.00071932 & 0.000812448 & 0.89688 & 1.1 \\
\hline 54 & & & 0.000802685 & 0.000770765 & 0.89688 & 1.1 \\
\hline 55 & $x$ & Detection Limit & 0.014298434 & 0.343687603 & 0.89238 & 1.1 \\
\hline 56 & $\mathbf{x}$ & Detection Limit & 0.014298434 & 0.343687603 & 0.89238 & 1.1 \\
\hline 57 & $\mathbf{x}$ & Detection Limit & 0.008995816 & 0.332845188 & 0.93467 & 1.1 \\
\hline 58 & $x$ & Detection Limit & 0.008995816 & 0.332845188 & 0.93467 & 1.1 \\
\hline 59 & $x$ & Detection Limit & 0.008995816 & 0.331046025 & 0.89688 & 1.1 \\
\hline 60 & $x$ & Detection Limit & 0.008995816 & 0.331046025 & 0.89688 & 1.1 \\
\hline 61 & & & 0.037365191 & 0.01887075 & 0.89238 & 1.1 \\
\hline 62 & & & 0.031172646 & 0.049833479 & 0.89238 & 1.1 \\
\hline 63 & & & 0.01055753 & 0.007303521 & 0.67469 & 0.2 \\
\hline 64 & & & 0.011921706 & 0.000482644 & 0.67469 & 0.2 \\
\hline 65 & & & 0.001562497 & 0.001993601 & 0.67109 & 0.2 \\
\hline 66 & $\mathbf{x}$ & Detection Limit & 0.002238944 & -0.001388634 & 0.67469 & 2 \\
\hline 67 & $\mathbf{x}$ & Detection Limit & 0.014298434 & 5.775788163 & 0.67469 & 2 \\
\hline 68 & $\mathbf{x}$ & Detection Limit & 0.014298434 & 5.775788163 & 0.67109 & 2 \\
\hline 69 & $x$ & Detection Limit & 0.008995816 & 5.577405858 & 0.67109 & 2 \\
\hline 70 & $\mathbf{x}$ & Detection Limit & 0.008995816 & 5.577405858 & 1.1245 & 0.2 \\
\hline 71 & $\mathbf{x}$ & Detection Limit & 0.008995816 & 5.532426778 & 1.1245 & 0.2 \\
\hline 72 & $x$ & Detection Limit & 0.008995816 & 5.532426778 & 1.1155 & 0.2 \\
\hline 73 & & & 0.00855411 & 0.016292616 & 1.1155 & 0.2 \\
\hline 74 & & & 0.005510316 & 0.017814513 & 1.1245 & 2 \\
\hline 75 & & & 0.006138789 & 0.002939723 & 1.1245 & 2 \\
\hline 76 & & & 0.002322064 & 0.004848085 & 1.1155 & 2 \\
\hline 77 & & & 0.000881287 & 0.000539965 & 0.012018 & 0.2 \\
\hline 78 & & & 0.000604991 & 0.000678113 & 0.012018 & 0.2 \\
\hline 79 & $\mathbf{x}$ & Detection Limit & 0.014298434 & 0.577578816 & 0.70167 & 0.2 \\
\hline 80 & $x$ & Detection Limit & 0.014298434 & 0.577578816 & 0.70167 & 0.2 \\
\hline 81 & $x$ & Detection Limit & 0.008995816 & 0.557740586 & 0.70167 & 2 \\
\hline 82 & $\mathbf{x}$ & Detection Limit & 0.008995816 & 0.557740586 & 0.70167 & 2 \\
\hline 83 & $x$ & Detection Limit & 0.008995816 & 0.553242678 & 1.1695 & 0.2 \\
\hline 84 & & & 0.016947475 & 0.549266848 & 1.1695 & 0.2 \\
\hline 85 & & & 0.002531547 & 0.657985597 & 1.1695 & 2 \\
\hline
\end{tabular}


WSRC-TR-2003-00180

Page 37 of 66

Table B1. The plutonium experimental data set.

Data
Number
86
87
88
89
90
91
92
93
94
95
96
97
98
99
100
101
102
103
104
105
106
107
108
109
110

\begin{tabular}{cc} 
Reason $\quad[\mathrm{Pu}$ (umole/L) & Loaded Pu (umole/g of MST) \\
0.002024928 & 0.659252144 \\
0.002772382 & 1.314767021 \\
0.003836605 & 1.309445902 \\
0.026642499 & 3.897867073 \\
0.022264373 & 3.83967003 \\
0.021516888 & 1.921703728 \\
0.021944023 & 1.947331783 \\
0.028404428 & 2.22 \\
0.028884954 & 2.06 \\
0.028297645 & 0.949 \\
0.036039453 & 0.992 \\
0.020502444 & 1.03 \\
0.031287584 & 1 \\
0.031981678 & 1 \\
0.031234193 & 1 \\
0.106249647 & 2.150354036 \\
0.050722193 & 0.941030165 \\
0.004132524 & 0.436824868 \\
0.028137469 & 1.397930342 \\
0.020929579 & 1.211726501 \\
0.061934468 & 1.093196744 \\
0.108919236 & 2.263811573 \\
0.007314674 & 0.669132513 \\
0.063002303 & 2.018209374 \\
0.060866632 & 1.97015677 \\
& \\
\hline
\end{tabular}

[Pu] initial (umole/L) MST g/L

$1.1695 \quad 2$

$0.67109 \quad 0.2$

$1.1155 \quad 2$

$0.43301 \quad 0.4$

$0.50562 \quad 0.4$

$0.7902 \quad 0.4$

$0.80088 \quad 0.4$

$0.7902 \quad 0.2$

$0.80622 \quad 0.2$

$0.58731 \quad 0.4$

$0.40805 \quad 0.4$

$0.91834 \quad 0.4$

$0.85427 \quad 0.4$

$0.041139 \quad 0.2$

$0.43301 \quad 0.4$

$0.43301 \quad 0.4$

$0.43301 \quad 0.4$

$0.43301 \quad 0.4$

$0.041139 \quad 0.2$

$0.42713 \quad 0.4$

$0.84893 \quad 0.4$

$0.49921 \quad 0.4$

$0.87029 \quad 0.4$

$0.96639 \quad 0.4$

$1.0144 \quad 0.4$ 
WSRC-TR-2003-00180

Page 38 of 66

Table B2. The strontium experimental data set.

\begin{tabular}{|c|c|c|c|c|c|c|}
\hline Data Number & $\begin{array}{l}\text { Data not } \\
\text { Selected }\end{array}$ & Reason & [Sr] (umole/L) & $\begin{array}{c}\text { Loaded Sr } \\
\text { (umole/g of } \\
\text { MST) }\end{array}$ & $\begin{array}{c}\text { Initial[Sr] } \\
\text { (umol/L) }\end{array}$ & MST g/L \\
\hline 1 & $\mathbf{x}$ & Detection Level & 0 & 0.068685024 & 0.075554 & 1.1 \\
\hline 2 & $x$ & Detection Level & 0 & 0.028418169 & 0.056836 & 2 \\
\hline 3 & & & 5.66769E-06 & 0.028415336 & 0.056836 & 2 \\
\hline 4 & & & 1.71186E-05 & 0.028295481 & 0.056608 & 2 \\
\hline 5 & $\mathbf{x}$ & Detection Level & 3.59134E-05 & 0.362912881 & 0.72586 & 2 \\
\hline 6 & $x$ & Detection Level & 3.59462E-05 & 0.362912865 & 0.72586 & 2 \\
\hline 7 & & & 3.81211E-05 & 0.832070924 & 0.91532 & 1.1 \\
\hline 8 & $\mathbf{x}$ & Detection Level & 3.82094E-05 & 0.344651062 & 0.68934 & 2 \\
\hline 9 & $\mathbf{x}$ & Detection Level & 3.82201E-05 & 0.344651057 & 0.68934 & 2 \\
\hline 10 & & & 8.25253E-05 & 0.028262778 & 0.056608 & 2 \\
\hline 11 & & & 0.000169142 & 0.028333599 & 0.056836 & 2 \\
\hline 12 & & & 0.000195815 & 0.87965432 & 0.96782 & 1.1 \\
\hline 13 & & & 0.000337576 & 0.748795642 & 0.82401 & 1.1 \\
\hline 14 & & & 0.000353292 & 0.06836385 & 0.075554 & 1.1 \\
\hline 15 & & & 0.000359763 & 0.309110235 & 0.61858 & 2 \\
\hline 16 & & & 0.000397847 & 0.748740851 & 0.82401 & 1.1 \\
\hline 17 & & & 0.000411364 & 0.028212487 & 0.05683 & 2 \\
\hline 18 & & & 0.00044985 & 0.879423379 & 0.96782 & 1.1 \\
\hline 19 & & & 0.000459491 & 0.879414615 & 0.96782 & 1.1 \\
\hline 20 & & & 0.05245 & 18.389 & 7.4082 & 0.4 \\
\hline 21 & & & 0.000463902 & 0.068263295 & 0.07555 & 1.1 \\
\hline 22 & & & 0.000472247 & 0.831676264 & 0.91532 & 1.1 \\
\hline 23 & & & 0.000473062 & 0.068254967 & 0.07555 & 1.1 \\
\hline 24 & & & 0.000526875 & 0.068206047 & 0.07555 & 1.1 \\
\hline 25 & & & 0.000533973 & 0.30902313 & 0.61858 & 2 \\
\hline 26 & & & 0.000545966 & 0.57151428 & 1.1436 & 2 \\
\hline 27 & & & 0.000581783 & 0.748573636 & 0.82401 & 1.1 \\
\hline 28 & & & 0.00066223 & 0.514391551 & 1.0294 & 2 \\
\hline 29 & & & 0.00066687 & 0.879226088 & 0.96782 & 1.1 \\
\hline 30 & & & 0.000672172 & 0.068073958 & 0.07555 & 1.1 \\
\hline 31 & & & 0.000679451 & 0.748484847 & 0.82401 & 1.1 \\
\hline 32 & & & 0.000712814 & 0.748454517 & 0.82401 & 1.1 \\
\hline 33 & & & 0.000721968 & 0.068028689 & 0.07555 & 1.1 \\
\hline 34 & & & 0.0007743 & 0.831401671 & 0.91532 & 1.1 \\
\hline 35 & & & 0.000812862 & 0.514316235 & 1.0294 & 2 \\
\hline 36 & & & 0.000861743 & 0.831322177 & 0.91532 & 1.1 \\
\hline 37 & & & 0.001088854 & 0.831115713 & 0.91532 & 1.1 \\
\hline 38 & & & 0.001107642 & 0.067678077 & 0.07555 & 1.1 \\
\hline 39 & & & 0.001123275 & 0.571225626 & 1.1436 & 2 \\
\hline 40 & & & 0.001165064 & 0.067625875 & 0.07555 & 1.1 \\
\hline 41 & & & 0.00118555 & 0.878754561 & 0.96782 & 1.1 \\
\hline 42 & & & 0.001195969 & 0.748015285 & 0.82401 & 1.1 \\
\hline 43 & & & 0.00124874 & 0.067549806 & 0.07555 & 1.1 \\
\hline 44 & & & 0.001307793 & 0.067496122 & 0.07555 & 1.1 \\
\hline 45 & & & 0.001393183 & 0.067418494 & 0.07555 & 1.1 \\
\hline
\end{tabular}


WSRC-TR-2003-00180

Page 39 of 66

Table B2. The strontium experimental data set.

\begin{tabular}{|c|c|c|c|c|c|c|}
\hline Data Number & $\begin{array}{l}\text { Data not } \\
\text { Selected }\end{array}$ & Reason & [Sr] (umole/L) & $\begin{array}{l}\text { Loaded Sr } \\
\text { (umole/g of } \\
\text { MST) }\end{array}$ & $\begin{array}{l}\text { Initial[Sr] } \\
\text { (umol/L) }\end{array}$ & MST g/L \\
\hline 46 & & & 0.001421664 & 0.046538654 & 0.09449 & 2 \\
\hline 47 & & & 0.001437425 & 0.046530774 & 0.09449 & 2 \\
\hline 48 & & & 0.001509213 & 0.604130123 & 1.2098 & 2 \\
\hline 49 & & & 0.001515032 & 0.067307722 & 0.07555 & 1.1 \\
\hline 50 & & & 0.001554775 & 0.046472099 & 0.09449 & 2 \\
\hline 51 & & & 0.001621171 & 0.067211232 & 0.07555 & 1.1 \\
\hline 52 & & & 0.001630079 & 0.83062369 & 0.91532 & 1.1 \\
\hline 53 & & & 0.00164585 & 0.067188797 & 0.07555 & 1.1 \\
\hline 54 & & & 0.001834913 & 0.067016922 & 0.07555 & 1.1 \\
\hline 55 & & & 0.001926647 & 0.603921406 & 1.2098 & 2 \\
\hline 56 & $x$ & Detection Level & 0.001996634 & 2.562915285 & 1.0272 & 0.4 \\
\hline 57 & $x$ & Detection Level & 0.001996674 & 2.562915185 & 1.0272 & 0.4 \\
\hline 58 & & & 0.002001014 & 0.273035334 & 0.0566 & 0.2 \\
\hline 59 & & & 0.002017459 & 0.046240757 & 0.09449 & 2 \\
\hline 60 & & & 0.002061161 & 0.066811242 & 0.07555 & 1.1 \\
\hline 61 & & & 0.002094289 & 0.272568956 & 0.0566 & 0.2 \\
\hline 62 & & & 0.002102266 & 3.618797046 & 0.72586 & 0.2 \\
\hline 63 & & & 0.002149888 & 0.87787789 & 0.96782 & 1.1 \\
\hline 64 & & & 0.00272376 & 0.066208879 & 0.07555 & 1.1 \\
\hline 65 & & & 0.002745016 & 0.270456615 & 0.05683 & 0.2 \\
\hline 66 & & & 0.002938317 & 0.26949011 & 0.05683 & 0.2 \\
\hline 67 & & & 0.003085801 & 3.077472158 & 0.61858 & 0.2 \\
\hline 68 & & & 0.003257952 & 3.076611404 & 0.61858 & 0.2 \\
\hline 69 & & & 0.003288297 & 0.267740209 & 0.05683 & 0.2 \\
\hline 70 & & & 0.003456155 & 3.612027601 & 0.72586 & 0.2 \\
\hline 71 & & & 0.003492353 & 2.653332572 & 1.0648 & 0.4 \\
\hline 72 & & & 0.003873667 & 0.045312653 & 0.09449 & 2 \\
\hline 73 & & & 0.004030469 & 0.045234252 & 0.09449 & 2 \\
\hline 74 & & & 0.004075412 & 0.263804633 & 0.05683 & 0.2 \\
\hline 75 & $\mathrm{x}$ & Detection Level & 0.004851177 & 5.111557855 & 1.0272 & 0.2 \\
\hline 76 & $\mathrm{x}$ & Detection Level & 0.004870597 & 5.111460756 & 1.0272 & 0.2 \\
\hline 77 & & & 0.005268574 & 3.420358799 & 0.68934 & 0.2 \\
\hline 78 & & & 0.005304662 & 2.503312378 & 1.0066 & 0.4 \\
\hline 79 & & & 0.006294791 & 3.415227711 & 0.68934 & 0.2 \\
\hline 80 & & & 0.006750559 & 2.827152038 & 1.1376 & 0.4 \\
\hline 81 & & & 0.00727424 & 2.573544159 & 1.0367 & 0.4 \\
\hline 82 & & & 0.007499421 & 2.571723291 & 1.0362 & 0.4 \\
\hline 83 & & & 0.008070472 & 2.823852257 & 1.1376 & 0.4 \\
\hline 84 & & & 0.01330216 & 5.982336496 & 1.2098 & 0.2 \\
\hline 85 & & & 0.014025605 & 8.584840817 & 3.448 & 0.4 \\
\hline 86 & & & 0.014772494 & 5.974984826 & 1.2098 & 0.2 \\
\hline 87 & & & 0.014823621 & 0.398376761 & 0.09449 & 0.2 \\
\hline 88 & & & 0.01578704 & 0.393559662 & 0.09449 & 0.2 \\
\hline 89 & & & 0.015964378 & 0.392672974 & 0.09449 & 0.2 \\
\hline 90 & & & 0.016375423 & 5.065349548 & 1.0294 & 0.2 \\
\hline
\end{tabular}


WSRC-TR-2003-00180

Page 40 of 66

Table B2. The strontium experimental data set.

\begin{tabular}{|c|c|c|c|c|c|c|}
\hline Data Number & $\begin{array}{l}\text { Data not } \\
\text { Selected }\end{array}$ & Reason & [Sr] (umole/L) & $\begin{array}{l}\text { Loaded Sr } \\
\text { (umole/g of } \\
\text { MST) }\end{array}$ & $\begin{array}{c}\text { Initial[Sr] } \\
\text { (umol/L) }\end{array}$ & MST g/L \\
\hline 91 & & & 0.016408441 & 0.390452657 & 0.09449 & 0.2 \\
\hline 92 & & & 0.017075723 & 1.796738261 & 0.73577 & 0.4 \\
\hline 93 & & & 0.017871227 & 5.057870524 & 1.0294 & 0.2 \\
\hline 94 & $x$ & Detection Level & 0.021154544 & 4.994005883 & 1.02 & 0.2 \\
\hline 95 & $x$ & Detection Level & 0.021167932 & 5.118677388 & 1.0449 & 0.2 \\
\hline 96 & & & 0.024342116 & 5.596162051 & 1.1436 & 0.2 \\
\hline 97 & & & 0.026123578 & 5.587254743 & 1.1436 & 0.2 \\
\hline 98 & & & 0.029914906 & 2.769241173 & 1.1376 & 0.4 \\
\hline 99 & & & 0.032012677 & 0.312431478 & 0.09449 & 0.2 \\
\hline 100 & & & 0.032521254 & 15.35292157 & 6.1737 & 0.4 \\
\hline 101 & & & 0.03477421 & 0.298623812 & 0.09449 & 0.2 \\
\hline 102 & & & 0.035788856 & 16.1275457 & 6.4868 & 0.4 \\
\hline 103 & & & 0.043941696 & 15.22218962 & 6.1328 & 0.4 \\
\hline 104 & & & 0.045726185 & 17.59592527 & 7.0841 & 0.4 \\
\hline 105 & $x$ & $\begin{array}{c}\text { Exceeds total } \\
\text { mass } \\
\text { equivalents } \\
\text { for available } \\
\text { sites }\end{array}$ & 0.050927845 & 2.716708825 & 1.1376 & 0.4 \\
\hline 106 & & & 0.056004145 & 17.46554615 & 7.0422 & 0.4 \\
\hline 107 & $x$ & $\begin{array}{c}\text { Exceeds total } \\
\text { mass } \\
\text { equivalents } \\
\text { for available } \\
\text { sites }\end{array}$ & 0.065106723 & 2.68126163 & 1.1376 & 0.4 \\
\hline 108 & & & 0.066589985 & 21.00238487 & 8.4675 & 0.4 \\
\hline 109 & $x$ & $\begin{array}{l}\text { Exceeds total } \\
\text { mass } \\
\text { equivalents } \\
\text { for available } \\
\text { sites }\end{array}$ & 0.066649828 & 18.56293621 & 7.4918 & 0.4 \\
\hline 110 & & & 0.068988778 & 23.43843079 & 9.4444 & 0.4 \\
\hline
\end{tabular}


WSRC-TR-2003-00180

Page 41 of 66

Table B3. The neptunium experimental data set.

\begin{tabular}{|c|c|c|c|c|c|c|}
\hline Data Number & $\begin{array}{c}\text { Data Not } \\
\text { Used }\end{array}$ & Reason & [Np] (umole/L) & $\begin{array}{l}\text { Np (umole/g } \\
\text { of MST) }\end{array}$ & $\begin{array}{c}\text { [Np] initial } \\
(\mu \mathrm{Mol} / \mathrm{L})\end{array}$ & MST g/L \\
\hline 1 & $\mathbf{x}$ & $\begin{array}{l}\text { Detection } \\
\text { Limit }\end{array}$ & 0.008438819 & 4.127349444 & 4.548523 & 1.1 \\
\hline 2 & $x$ & $\begin{array}{l}\text { Detection } \\
\text { Limit }\end{array}$ & 0.008438819 & 4.127349444 & 4.548523 & 1.1 \\
\hline 3 & $\mathbf{x}$ & $\begin{array}{l}\text { Detection } \\
\text { Limit }\end{array}$ & 0.008438819 & 4.127349444 & 4.548523 & 1.1 \\
\hline 4 & $x$ & $\begin{array}{l}\text { Detection } \\
\text { Limit }\end{array}$ & 0.008438819 & 4.127349444 & 4.548523 & 1.1 \\
\hline 5 & $x$ & $\begin{array}{l}\text { Detection } \\
\text { Limit }\end{array}$ & 0.008438819 & 0.713080169 & 1.434599 & 2 \\
\hline 6 & $\mathbf{x}$ & $\begin{array}{l}\text { Detection } \\
\text { Limit }\end{array}$ & 0.008438819 & 0.713080169 & 1.434599 & 2 \\
\hline 7 & $\mathbf{x}$ & $\begin{array}{l}\text { Detection } \\
\text { Limit }\end{array}$ & 0.015021097 & 1.796854622 & 1.991561 & 1.1 \\
\hline 8 & $\mathbf{x}$ & $\begin{array}{l}\text { Detection } \\
\text { Limit }\end{array}$ & 0.015021097 & 1.796854622 & 1.991561 & 1.1 \\
\hline 9 & $x$ & $\begin{array}{l}\text { Detection } \\
\text { Limit }\end{array}$ & 0.015021097 & 1.796854622 & 1.991561 & 1.1 \\
\hline 10 & $x$ & $\begin{array}{l}\text { Detection } \\
\text { Limit }\end{array}$ & 0.015021097 & 1.796854622 & 1.991561 & 1.1 \\
\hline 11 & $\mathbf{x}$ & $\begin{array}{l}\text { Detection } \\
\text { Limit }\end{array}$ & 0.015021097 & 1.796854622 & 1.991561 & 1.1 \\
\hline 12 & $\mathbf{x}$ & $\begin{array}{l}\text { Detection } \\
\text { Limit }\end{array}$ & 0.015021097 & 1.796854622 & 1.991561 & 1.1 \\
\hline 13 & $\mathbf{x}$ & $\begin{array}{l}\text { Detection } \\
\text { Limit }\end{array}$ & 0.015021097 & 7.393248945 & 1.493671 & 0.2 \\
\hline 14 & $\mathbf{x}$ & $\begin{array}{l}\text { Detection } \\
\text { Limit }\end{array}$ & 0.015021097 & 7.393248945 & 1.493671 & 0.2 \\
\hline 15 & $x$ & $\begin{array}{l}\text { Detection } \\
\text { Limit }\end{array}$ & 0.015021097 & 0.739324895 & 1.493671 & 2 \\
\hline 16 & $\mathbf{x}$ & $\begin{array}{l}\text { Detection } \\
\text { Limit }\end{array}$ & 0.015021097 & 0.739324895 & 1.493671 & 2 \\
\hline 17 & $x$ & $\begin{array}{l}\text { Detection } \\
\text { Limit }\end{array}$ & 0.015021097 & 1.23721519 & 2.489451 & 2 \\
\hline 18 & $\mathbf{x}$ & $\begin{array}{l}\text { Detection } \\
\text { Limit }\end{array}$ & 0.015021097 & 1.23721519 & 2.489451 & 2 \\
\hline 19 & $\mathbf{x}$ & $\begin{array}{l}\text { Detection } \\
\text { Limit }\end{array}$ & 0.017890295 & 2.983352512 & 3.299578 & 1.1 \\
\hline 20 & $\mathbf{x}$ & $\begin{array}{l}\text { Detection } \\
\text { Limit }\end{array}$ & 0.017890295 & 2.983352512 & 3.299578 & 1.1 \\
\hline 21 & $x$ & $\begin{array}{l}\text { Detection } \\
\text { Limit }\end{array}$ & 0.017890295 & 2.983352512 & 3.299578 & 1.1 \\
\hline 22 & $\mathbf{x}$ & $\begin{array}{l}\text { Detection } \\
\text { Limit }\end{array}$ & 0.017890295 & 2.983352512 & 3.299578 & 1.1 \\
\hline 23 & $\mathbf{x}$ & $\begin{array}{l}\text { Detection } \\
\text { Limit }\end{array}$ & 0.017890295 & 2.983352512 & 3.299578 & 1.1 \\
\hline 24 & $\mathbf{x}$ & $\begin{array}{l}\text { Detection } \\
\text { Limit }\end{array}$ & 0.017890295 & 2.983352512 & 3.299578 & 1.1 \\
\hline 25 & & & 0.017890295 & 12.31561181 & 2.481013 & 0.2 \\
\hline 26 & $\mathbf{x}$ & $\begin{array}{l}\text { Detection } \\
\text { Limit }\end{array}$ & 0.017890295 & 1.231561181 & 2.481013 & 2 \\
\hline 27 & $x$ & $\begin{array}{l}\text { Detection } \\
\text { Limit }\end{array}$ & 0.017890295 & 1.231561181 & 2.481013 & 2 \\
\hline 28 & & & 0.103957215 & 2.291081937 & 1.02039 & 0.4 \\
\hline 29 & & & 0.104472574 & 6.650632911 & 1.434599 & 0.2 \\
\hline 30 & & & 0.108607595 & 4.03628692 & 4.548523 & 1.1 \\
\hline 31 & & & 0.108860759 & 6.628691983 & 1.434599 & 0.2 \\
\hline 32 & & & 0.109496181 & 1.990257431 & 0.905599 & 0.4 \\
\hline 33 & & & 0.110740928 & 11.85135865 & 2.481013 & 0.2 \\
\hline 34 & & & 0.128185654 & 4.018488684 & 4.548523 & 1.1 \\
\hline 35 & & & 0.141007374 & 3.935148079 & 1.715067 & 0.4 \\
\hline 36 & & & 0.147031994 & 3.92008653 & 1.715067 & 0.4 \\
\hline
\end{tabular}


WSRC-TR-2003-00180

Page 42 of 66

Table B3. The neptunium experimental data set.

\begin{tabular}{|c|c|c|c|c|c|}
\hline Data Number & $\begin{array}{l}\text { Data Not } \\
\text { Used }\end{array}$ & [Np] (umole/L) & $\begin{array}{l}\mathrm{Np} \text { (umole/g } \\
\text { of MST) }\end{array}$ & $\begin{array}{c}{[\mathrm{Np}] \text { initial }} \\
(\mu \mathrm{Mol} / \mathrm{L})\end{array}$ & MST g/L \\
\hline 37 & & 0.165127426 & 1.980727426 & 4.126582 & 2 \\
\hline 38 & & 0.202700422 & 6.296413502 & 2.721266 & 0.4 \\
\hline 39 & & 0.204664979 & 1.96095865 & 4.126582 & 2 \\
\hline 40 & & 0.216421293 & 3.88359624 & 1.76986 & 0.4 \\
\hline 41 & & 0.225000581 & 1.441689422 & 0.801676 & 0.4 \\
\hline 42 & & 0.240590717 & 4.257805907 & 1.943713 & 0.4 \\
\hline 43 & & 0.244882905 & 2.009609976 & 1.048727 & 0.4 \\
\hline 44 & & 0.254626743 & 3.693276711 & 1.731937 & 0.4 \\
\hline 45 & & 0.279845062 & 7.176107718 & 1.715067 & 0.2 \\
\hline 46 & & 0.296503541 & 1.888175628 & 1.051774 & 0.4 \\
\hline 47 & & 0.31907173 & 4.321729958 & 2.047764 & 0.4 \\
\hline 48 & & 0.346944344 & 6.84061131 & 1.715067 & 0.2 \\
\hline 49 & & 0.351123699 & 1.443499031 & 0.928523 & 0.4 \\
\hline 50 & & 0.378575485 & 1.631083091 & 1.031009 & 0.4 \\
\hline 51 & & 0.425170725 & 1.239069574 & 0.920799 & 0.4 \\
\hline 52 & & 0.479436458 & 6.111413781 & 1.701719 & 0.2 \\
\hline 53 & & 0.48556962 & 3.905485232 & 2.047764 & 0.4 \\
\hline 54 & & 0.503106377 & 1.282707115 & 1.016189 & 0.4 \\
\hline 55 & & 0.503610366 & 6.07880536 & 1.719371 & 0.2 \\
\hline 56 & & 0.504050633 & 3.326033755 & 7.156118 & 2 \\
\hline 57 & & 0.553670886 & 3.301223629 & 7.156118 & 2 \\
\hline 58 & & 0.628523207 & 3.548101266 & 2.047764 & 0.4 \\
\hline 59 & & 0.629873418 & 3.544725738 & 2.047764 & 0.4 \\
\hline 60 & & 0.667237131 & 9.11107173 & 2.489451 & 0.2 \\
\hline 61 & & 0.728438819 & 3.298312236 & 2.047764 & 0.4 \\
\hline 62 & & 0.771633755 & 8.589088608 & 2.489451 & 0.2 \\
\hline 63 & & 0.824921519 & 16.5083038 & 4.126582 & 0.2 \\
\hline 64 & & 0.872132547 & 3.211493527 & 2.15673 & 0.4 \\
\hline 65 & & 0.908606386 & 0.968275351 & 1.295917 & 0.4 \\
\hline 66 & & 0.986160338 & 45.07654008 & 91.13924 & 2 \\
\hline 67 & & 1.167520675 & 14.79530802 & 4.126582 & 0.2 \\
\hline 68 & & 1.220253165 & 44.95949367 & 91.13924 & 2 \\
\hline 69 & & 2.429451477 & 23.71772152 & 7.172996 & 0.2 \\
\hline 70 & & 2.496202532 & 23.38396624 & 7.172996 & 0.2 \\
\hline 71 & & 7.953080169 & 102.4745685 & 120.6751 & 1.1 \\
\hline 72 & & 8.107257384 & 71.47379747 & 151.0549 & 2 \\
\hline 73 & & 8.57628692 & 71.2392827 & 151.0549 & 2 \\
\hline 74 & & 8.606919831 & 101.8801688 & 120.6751 & 1.1 \\
\hline 75 & & 8.832151899 & 101.6754124 & 120.6751 & 1.1 \\
\hline 76 & & 8.987088608 & 101.5345608 & 120.6751 & 1.1 \\
\hline 77 & & 9.061265823 & 101.467127 & 120.6751 & 1.1 \\
\hline 78 & & 16.55974684 & 36.02392405 & 88.60759 & 2 \\
\hline 79 & & 18.43265823 & 35.08746835 & 88.60759 & 2 \\
\hline 80 & & 19.05400844 & 92.3828155 & 120.6751 & 1.1 \\
\hline 81 & & 29.91873418 & 306.1025316 & 91.13924 & 0.2 \\
\hline 82 & & 30.26312236 & 304.3805907 & 91.13924 & 0.2 \\
\hline
\end{tabular}


WSRC-TR-2003-00180

Page 43 of 66

Table B3. The neptunium experimental data set.

\begin{tabular}{|c|c|c|c|c|c|c|}
\hline Data Number & $\begin{array}{c}\text { Data Not } \\
\text { Used }\end{array}$ & Reason & [Np] (umole/L) & $\begin{array}{l}\text { Np (umole/g } \\
\text { of MST) }\end{array}$ & $\begin{array}{c}\text { [Np] initial } \\
(\mu \mathrm{Mol} / \mathrm{L})\end{array}$ & MST g/L \\
\hline 83 & & & 39.04278481 & 53.89632911 & 146.8354 & 2 \\
\hline 84 & & & 40.05383966 & 53.39080169 & 146.8354 & 2 \\
\hline 85 & & & 40.38295359 & 69.92420407 & 117.2996 & 1.1 \\
\hline 86 & & & 40.95679325 & 69.40253165 & 117.2996 & 1.1 \\
\hline 87 & & & 42.63848101 & 229.8455696 & 88.60759 & 0.2 \\
\hline 88 & & & 43.5657384 & 22.52092827 & 88.60759 & 2 \\
\hline 89 & & & 43.83392405 & 22.38683544 & 88.60759 & 2 \\
\hline 90 & & & 45.0307173 & 217.8843882 & 88.60759 & 0.2 \\
\hline 91 & & & 46.70751055 & 64.17460683 & 117.2996 & 1.1 \\
\hline 92 & & & 47.39206751 & 518.3139241 & 151.0549 & 0.2 \\
\hline 93 & $x$ & $\begin{array}{l}\text { Detection } \\
\text { Limit }\end{array}$ & 47.57637131 & 63.38473341 & 117.2996 & 1.1 \\
\hline 94 & $x$ & $\begin{array}{l}\text { Detection } \\
\text { Limit }\end{array}$ & 47.57637131 & 63.38473341 & 117.2996 & 1.1 \\
\hline 95 & & & 49.52185654 & 61.61611047 & 117.2996 & 1.1 \\
\hline 96 & & & 53.87459916 & 485.9012658 & 151.0549 & 0.2 \\
\hline 97 & & & 61.48345992 & 51.66252397 & 118.3122 & 1.1 \\
\hline 98 & & & 64.00514768 & 123.0122363 & 88.60759 & 0.2 \\
\hline 99 & & & 64.98860759 & 409.2341772 & 146.8354 & 0.2 \\
\hline 100 & & & 66.03848101 & 112.8455696 & 88.60759 & 0.2 \\
\hline 101 & & & 69.28953586 & 387.7295359 & 146.8354 & 0.2 \\
\hline 102 & & & 73.54852321 & 40.69428462 & 118.3122 & 1.1 \\
\hline 103 & & & 76.56413502 & 37.95281933 & 118.3122 & 1.1 \\
\hline 104 & & & 77.15156118 & 37.41879555 & 118.3122 & 1.1 \\
\hline 105 & & & 78.03063291 & 36.61963943 & 118.3122 & 1.1 \\
\hline 106 & & & 78.40219409 & 36.28185654 & 118.3122 & 1.1 \\
\hline 107 & & & 88.99265823 & 29.34333333 & 147.6793 & 2 \\
\hline 108 & & & 92.31535865 & 27.68198312 & 147.6793 & 2 \\
\hline 109 & & & 95.91409283 & 258.8261603 & 147.6793 & 0.2 \\
\hline 110 & & & 97.12008439 & 252.7962025 & 147.6793 & 0.2 \\
\hline
\end{tabular}


WSRC-TR-2003-00180

Page 44 of 66

Table B4. The uranium experimental data.

\begin{tabular}{|c|c|c|c|c|c|c|}
\hline Data Number & Data not used & Reason & [U] (umole/L) & $\begin{array}{l}\text { Loaded U } \\
\text { (umole/g of } \\
\text { MST) }\end{array}$ & $\begin{array}{l}{[\mathrm{U}] \text { initial }} \\
(\mu \mathrm{Mol} / \mathrm{L})\end{array}$ & MST g/L \\
\hline 1 & $\mathbf{x}$ & $\begin{array}{l}\text { Detection } \\
\text { Limit }\end{array}$ & 0.008403361 & 3.180672269 & 6.3697 & 2 \\
\hline 2 & $\mathbf{x}$ & $\begin{array}{l}\text { Detection } \\
\text { Limit }\end{array}$ & 0.008403361 & 3.180672269 & 6.3697 & 2 \\
\hline 3 & $x$ & $\begin{array}{l}\text { Detection } \\
\text { Limit }\end{array}$ & 0.008403361 & 3.281512605 & 6.5714 & 2 \\
\hline 4 & $x$ & $\begin{array}{l}\text { Detection } \\
\text { Limit }\end{array}$ & 0.008403361 & 2.903361345 & 5.8151 & 2 \\
\hline 5 & $\mathbf{x}$ & $\begin{array}{l}\text { Detection } \\
\text { Limit }\end{array}$ & 0.008403361 & 2.903361345 & 5.8151 & 2 \\
\hline 6 & & & 0.047394958 & 3.262016807 & 6.5714 & 2 \\
\hline 7 & & & 0.314369748 & 6.742475172 & 7.7311 & 1.1 \\
\hline 8 & & & 0.345882353 & 7.47776929 & 8.5714 & 1.1 \\
\hline 9 & & & 0.351176471 & 7.625744843 & 8.7395 & 1.1 \\
\hline 10 & & & 0.377394958 & 6.685179526 & 7.7311 & 1.1 \\
\hline 11 & & & 0.383445378 & 5.270462185 & 10.924 & 2 \\
\hline 12 & & & 0.407815126 & 4.62802521 & 9.6639 & 2 \\
\hline 13 & & & 0.411512605 & 7.570893812 & 8.7395 & 1.1 \\
\hline 14 & & & 0.413445378 & 5.255462185 & 10.924 & 2 \\
\hline 15 & & & 0.41697479 & 7.413139801 & 8.5714 & 1.1 \\
\hline 16 & & & 0.424453782 & 7.559129106 & 8.7395 & 1.1 \\
\hline 17 & & & 0.429579832 & 6.637738732 & 7.7311 & 1.1 \\
\hline 18 & & & 0.432184874 & 7.55210084 & 8.7395 & 1.1 \\
\hline 19 & & & 0.438487395 & 7.393582888 & 8.5714 & 1.1 \\
\hline 20 & & & 0.448991597 & 7.536822002 & 8.7395 & 1.1 \\
\hline 21 & & & 0.449831933 & 7.383269672 & 8.5714 & 1.1 \\
\hline 22 & & & 0.455966387 & 7.377692895 & 8.5714 & 1.1 \\
\hline 23 & & & 0.485630252 & 6.586783804 & 7.7311 & 1.1 \\
\hline 24 & & & 0.508739496 & 4.577563025 & 9.6639 & 2 \\
\hline 25 & & & 0.511848739 & 6.562948816 & 7.7311 & 1.1 \\
\hline 26 & & & 0.54487395 & 6.532925898 & 7.7311 & 1.1 \\
\hline 27 & & & 0.617310924 & 7.231016043 & 8.5714 & 1.1 \\
\hline 28 & & & 0.673697479 & 4.650546218 & 9.9748 & 2 \\
\hline 29 & & & 0.713865546 & 4.630462185 & 9.9748 & 2 \\
\hline 30 & & & 1.305294118 & 6.758365164 & 8.7395 & 1.1 \\
\hline 31 & & & 2.199915966 & 18.07605042 & 5.8151 & 0.2 \\
\hline 32 & & & 2.334285714 & 17.40420168 & 5.8151 & 0.2 \\
\hline 33 & & & 2.508487395 & 20.31470588 & 6.5714 & 0.2 \\
\hline 34 & & & 2.550840336 & 20.10294118 & 6.5714 & 0.2 \\
\hline 35 & & & 2.815546218 & 17.7710084 & 6.3697 & 0.2 \\
\hline 36 & & & 2.900756303 & 17.4289916 & 6.3866 & 0.2 \\
\hline 37 & & & 4.675714286 & 29.1747479 & 63.025 & 2 \\
\hline 38 & & & 4.994705882 & 29.0152521 & 63.025 & 2 \\
\hline 39 & & & 5.334789916 & 21.64537815 & 9.6639 & 0.2 \\
\hline 40 & & & 5.72907563 & 19.67394958 & 9.6639 & 0.2 \\
\hline 41 & & & 5.92512605 & 29.89457983 & 65.714 & 2 \\
\hline 42 & & & 6.344201681 & 22.90084034 & 10.924 & 0.2 \\
\hline 43 & & & 6.681512605 & 21.21428571 & 10.924 & 0.2 \\
\hline
\end{tabular}


WSRC-TR-2003-00180

Page 45 of 66

Table B4. The uranium experimental data.

\begin{tabular}{|c|c|c|c|c|c|c|}
\hline Data Number & Data not used & Reason & [U] (umole/L) & $\begin{array}{l}\text { Loaded U } \\
\text { (umole/g of } \\
\text { MST) }\end{array}$ & $\begin{array}{l}{[\mathrm{U}] \text { initial }} \\
(\mu \mathrm{Mol} / \mathrm{L})\end{array}$ & MST g/L \\
\hline 44 & & & 7.273445378 & 29.22042017 & 65.714 & 2 \\
\hline 45 & & & 7.973265412 & 25.39963534 & 18.133 & 0.4 \\
\hline 46 & & & 8.011008403 & 13.72647059 & 10.756 & 0.2 \\
\hline 47 & & & 8.029134864 & 27.08234349 & 18.862 & 0.4 \\
\hline 48 & & & 8.681596639 & 10.37352941 & 10.756 & 0.2 \\
\hline 49 & & & 9.606470588 & 26.24718487 & 62.101 & 2 \\
\hline 50 & & & 10.27344538 & 25.91369748 & 62.101 & 2 \\
\hline 51 & & & 10.87142555 & 35.44980916 & 25.051 & 0.4 \\
\hline 52 & & & 13.22752749 & 24.57049501 & 23.056 & 0.4 \\
\hline 53 & & & 14.38852611 & 38.7760839 & 29.899 & 0.4 \\
\hline 54 & & & 15.82579832 & 44.60810924 & 105.04 & 2 \\
\hline 55 & & & 16.28697479 & 44.37752101 & 105.04 & 2 \\
\hline 56 & & & 16.72306411 & 27.74539406 & 27.821 & 0.4 \\
\hline 57 & & & 16.82296227 & 31.26855767 & 29.33 & 0.4 \\
\hline 58 & & & 18.33731948 & 28.25576597 & 29.64 & 0.4 \\
\hline 59 & & & 21.47247615 & 31.24467433 & 33.97 & 0.4 \\
\hline 60 & & & 22.46702699 & 38.55148238 & 37.888 & 0.4 \\
\hline 61 & & & 22.5677754 & 38.29961138 & 37.888 & 0.4 \\
\hline 62 & & & 24.27344538 & 42.48512605 & 109.24 & 2 \\
\hline 63 & & & 24.43386555 & 42.40491597 & 109.24 & 2 \\
\hline 64 & & & 25.43830881 & 33.28239753 & 38.751 & 0.4 \\
\hline 65 & & & 25.95134454 & 38.705 & 103.36 & 2 \\
\hline 66 & & & 26.02613445 & 38.66760504 & 103.36 & 2 \\
\hline 67 & & & 26.74391033 & 31.75087484 & 39.444 & 0.4 \\
\hline 68 & & & 27.1905042 & 51.52276547 & 83.866 & 1.1 \\
\hline 69 & & & 28.06013552 & 39.12693543 & 43.711 & 0.4 \\
\hline 70 & & & 28.59697951 & 46.45320218 & 37.888 & 0.2 \\
\hline 71 & & & 28.65672269 & 53.12647059 & 49.907 & 0.4 \\
\hline 72 & & & 29.39823615 & 42.44691897 & 37.888 & 0.2 \\
\hline 73 & & & 29.88537815 & 49.07288006 & 83.866 & 1.1 \\
\hline 74 & & & 30.02394958 & 48.94690604 & 83.866 & 1.1 \\
\hline 75 & & & 30.16663866 & 52.02574484 & 87.395 & 1.1 \\
\hline 76 & & & 30.20983193 & 48.77792208 & 83.866 & 1.1 \\
\hline 77 & & & 30.36252101 & 48.63911383 & 83.866 & 1.1 \\
\hline 78 & & & 30.73394958 & 51.51000764 & 87.395 & 1.1 \\
\hline 79 & & & 30.90243697 & 27.44306723 & 41.88 & 0.4 \\
\hline 80 & & & 30.9305042 & 51.33132162 & 87.395 & 1.1 \\
\hline 81 & & & 31.72218487 & 50.61161192 & 87.395 & 1.1 \\
\hline 82 & & & 32.25941176 & 50.12322383 & 87.395 & 1.1 \\
\hline 83 & & & 33.93890756 & 30.68676471 & 46.214 & 0.4 \\
\hline 84 & & & 34.12991597 & 39.44348739 & 49.907 & 0.4 \\
\hline 85 & & & 34.54705882 & 44.83498854 & 83.866 & 1.1 \\
\hline 86 & & & 34.90352941 & 43.51779985 & 82.773 & 1.1 \\
\hline 87 & & & 35.19527487 & 12.62721136 & 37.721 & 0.2 \\
\hline 88 & & & 35.33529412 & 43.12528648 & 82.773 & 1.1 \\
\hline
\end{tabular}


WSRC-TR-2003-00180

Page 46 of 66

Table B4. The uranium experimental data.

\begin{tabular}{|c|c|c|c|c|c|c|}
\hline Data Number & Data not used & Reason & [U] (umole/L) & $\begin{array}{l}\text { Loaded U } \\
\text { (umole/g of } \\
\text { MST) }\end{array}$ & $\begin{array}{l}{[\mathrm{U}] \text { initial }} \\
(\mu \mathrm{Mol} / \mathrm{L})\end{array}$ & MST g/L \\
\hline 89 & & & 36.0689916 & 42.45828877 & 82.773 & 1.1 \\
\hline 90 & & & 36.42220466 & 7.764736875 & 37.975 & 0.2 \\
\hline 91 & & & 37.33285714 & 45.51100076 & 87.395 & 1.1 \\
\hline 92 & & & 37.83714286 & 40.85087853 & 82.773 & 1.1 \\
\hline 93 & & & 38.63890756 & 40.12200153 & 82.773 & 1.1 \\
\hline 94 & & & 40.36243697 & 23.86218487 & 49.907 & 0.4 \\
\hline 95 & & & 40.93403361 & 22.43319328 & 49.907 & 0.4 \\
\hline 96 & & & 40.95008403 & 38.02093201 & 82.773 & 1.1 \\
\hline 97 & & & 43.55537815 & 15.87983193 & 49.907 & 0.4 \\
\hline 98 & & & 45.23457244 & 25.37969285 & 55.386 & 0.4 \\
\hline 99 & & & 47.55016807 & 90.82058824 & 65.714 & 0.2 \\
\hline 100 & & & 48.78739496 & 84.63445378 & 65.714 & 0.2 \\
\hline 101 & & & 49.82260504 & 66.01302521 & 63.025 & 0.2 \\
\hline 102 & & & 50.64806723 & 61.88571429 & 63.025 & 0.2 \\
\hline 103 & & & 53.60420168 & 42.48319328 & 62.101 & 0.2 \\
\hline 104 & & & 53.86327731 & 41.18781513 & 62.101 & 0.2 \\
\hline 105 & & & 64.06831933 & 196.4651261 & 103.36 & 0.2 \\
\hline 106 & & & 65.68571429 & 217.789916 & 109.24 & 0.2 \\
\hline 107 & & & 65.97521008 & 195.3340336 & 105.04 & 0.2 \\
\hline 108 & & & 66.27495798 & 185.4319328 & 103.36 & 0.2 \\
\hline 109 & & & 71.04436975 & 169.9882353 & 105.04 & 0.2 \\
\hline 110 & & & 72.23487395 & 185.0441176 & 109.24 & 0.2 \\
\hline
\end{tabular}


WSRC-TR-2003-00180

Page 47 of 66

Table B5. The total equivalence (maximum number of atoms) adsorbed on MST for that testing. We used a maximum of $3 \mathrm{wt} \%$ as a criteria for eliminate some plutonium and strontium data.

Sample \#

1

2

3

4

5

6

7

8

9

10

11

12

13

14

15

16

17

18

19

20

21

22

23

24

25

26

27

28

29

30

31

32

33

34

35

36

37

38

39

40

41

42

43

44
Total/MST In Percent of total Maximum

0.052574

0.052573

0.052708

0.052708

0.054632

0.054632

0.052574

0.052574

0.052708

0.052708

0.054632

0.054632

0.052574

0.052574

0.052708

0.052708

0.054632

0.054632

0.003986

0.003986

0.003803

0.003803

0.003199

0.003199

0.003986

0.003986

0.003803

0.003803

0.003199

0.003199

0.003986

0.003986

0.003803

0.003803

0.003199

0.003199

0.014287

0.014321

0.015746

0.015746

0.013229

0.013229

0.216786

0.216786 
WSRC-TR-2003-00180

Page 48 of 66

Table B5. The total equivalence (maximum number of atoms) adsorbed on MST for that testing. We used a maximum of $3 \mathrm{wt} \%$ as a criteria for eliminate some plutonium and strontium data.

Sample \#

45

46

47

48

49

50

51

52

53

54

55

56

57

58

59

60

61

62

63

64

65

66

67

68

69

70

71

72

73

74

75

76

77

78

79

80

81

82

83

84

85

86

87

88
Total/MST In Percent of total Maximum

0.218314

0.218314

0.226339

0.226339

0.001429

0.001429

0.001575

0.001575

0.001323

0.001323

0.021679

0.021679

0.021831

0.021831

0.022634

0.022634

0.029002

0.029002

0.026178

0.026178

0.021985

0.021985

0.361031

0.361031

0.36301

0.36301

0.375807

0.41676

0.002742

0.002742

0.002618

0.002618

0.002198

0.002198

0.036103

0.036103

0.036301

0.036301

0.037581

0.037581

0.040241

0.040241

0.080481

0.080481 
WSRC-TR-2003-00180

Page 49 of 66

Table B5. The total equivalence (maximum number of atoms) adsorbed on MST for that testing. We used a maximum of $3 \mathrm{wt} \%$ as a criteria for eliminate some plutonium and strontium data.

Sample \#

89

90

91

92

93

94

95

96

97

98

99

100

101

102

103

104

105

106

107

108

109

110
Total/MST In Percent of total Maximum

0.082329

0.082741

0.04288

0.04219

0.050011

0.045886

0.057936

0.052855

0.052855

0.052855

0.052855

0.052855

0.039015

0.042672

0.029282

0.037639

0.02641

0.033722

0.054667

0.025498

0.036918

0.038747 
WSRC-TR-2003-00180

Page 50 of 66

\section{Appendix C. Results of the Fowler-Guggenheim Models.}

This section shows the results for the Fowler-Guggenheim-Jovanovich-Freundlich and Fowler-Guggenheim-Langmuir-Freundlich models. These two models successfully captured the non-classical sorption behavior for uranium onto MST at higher mass loadings. Only these two models and the Dubinin-Astashov model adequately replicated this behavior.

7) $[P u]=\frac{[-\operatorname{Ln}(1-\text { Loaded Pu/ } / 3.7)]^{1 / 3.3}}{1.3 \times e^{35 \times^{\text {Loaded } P u} / 3.7}}$ $F G / J F$

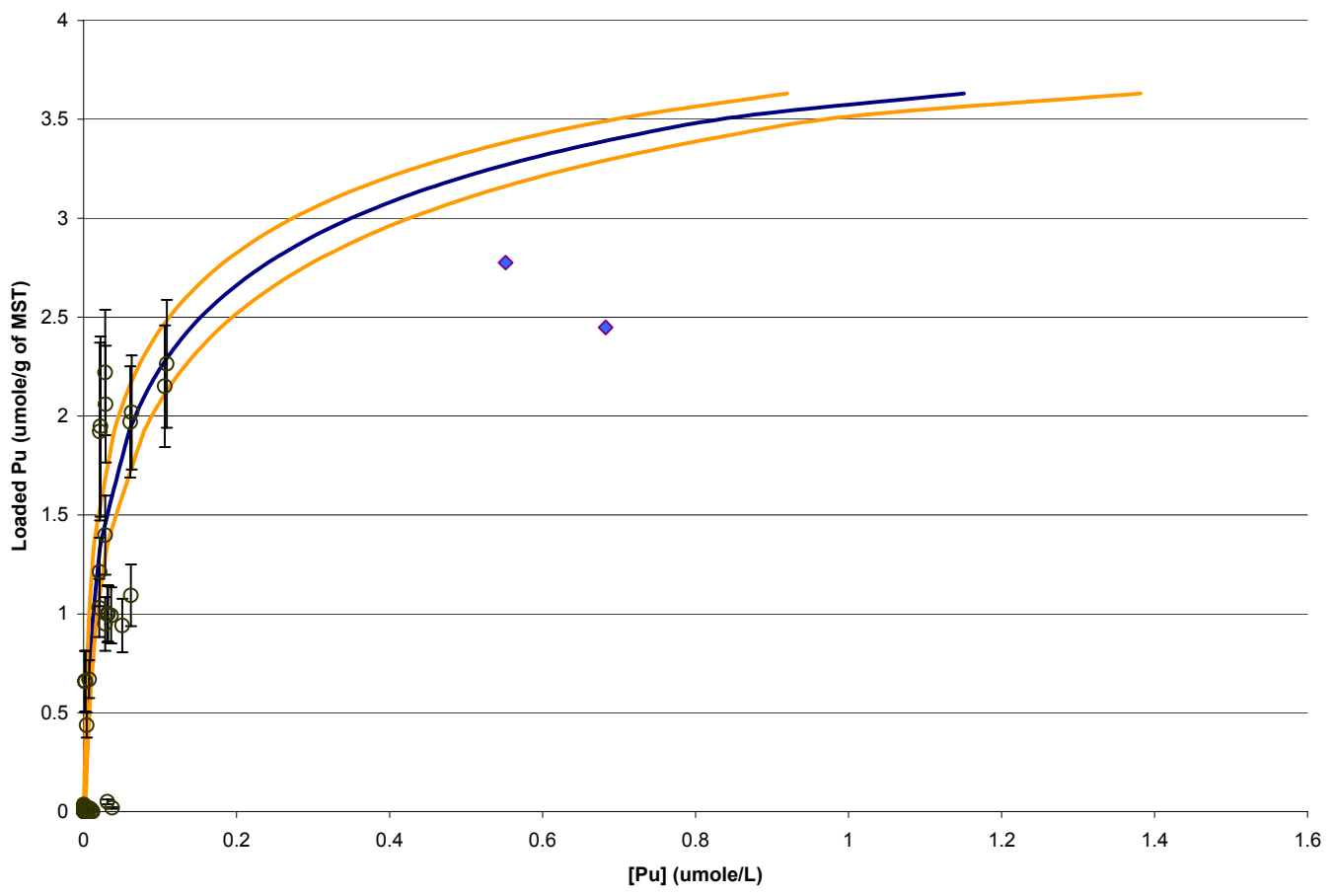

Figure C1. Performance prediction of the FG-JF model for the 168-hour Pu data. The filled points are from radioactive waste testing. The two data points located after $[\mathrm{Pu}]>0.6 \mathrm{umol} / \mathrm{L}$ are actual waste data and we excluded these from the FG-JF model during optimization. 
WSRC-TR-2003-00180

Page 51 of 66

\section{Strontium}

The FG-JF models explained $97 \%$ of the Sr data. The functional form of the model follows.

8) $[S r]=\frac{\left[-\operatorname{Ln}\left(1-{ }^{\text {Loaded } S r} / 83\right)\right]^{1 / 1.31}}{1 \times e^{0.1 \times^{\text {Loaded } S r} / 83}}$

$F G / J F$

The chosen model indicates the adsorption process takes place on a heterogeneous sorbent. The equation also assumes significant lateral interactions between the adsorbed sorbates. In addition, the successful fitting with the Jovanovic model gives an indication a single monolayer adsorption.

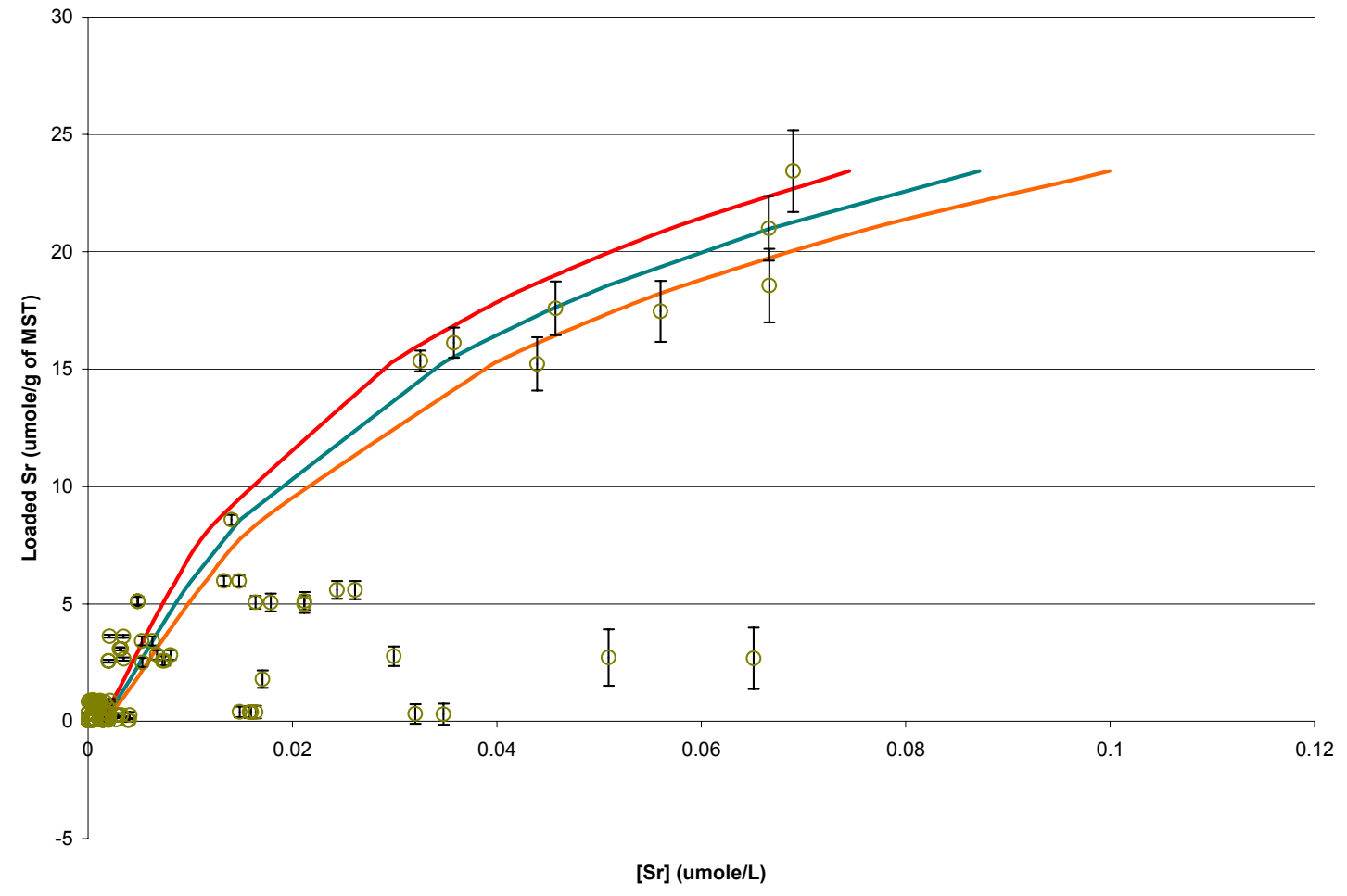

Figure C2. The prediction performance of the FG-JF model on the Sr adsorption data. 
WSRC-TR-2003-00180

Page 52 of 66

\section{Uranium}

The uranium concentration range is one order of magnitude larger than the concentration ranges of plutonium and strontium. Evaluation of the uranium data revealed the same functional model found in the previous sorbates. The FG-JF and FG-LF models fitted $97 \%$ of the uranium data (see Figure C4). Table C3 shows the fitting performance of these models.

\section{Neptunium}

The neptunium concentration range studied here is as large as the uranium data. We tested the fitting performance of each isotherm with the neptunium data. Table C4 shows the fitting results. We omit the figures for neptunium since we still need to assess the complex interaction of uranium and neptunium at high mass loadings. We found significant sensitivity of the neptunium loading isotherm for changes in temperature. We modeled the coefficients of the FG-JF model as a function of temperature. We investigated an exponential function (i.e., Arrhenius function) for fitting each coefficient. The coefficient representing the Fowler-Guggenheim interaction had the highest temperature dependency. We omit the equations at this time due to the uncertainty about the high mass loading data and the most appropriate modeling approach.

Inspection of data in Table C4, the FG-JF model shows low variance and Akaike number and high correlation coefficient. The FG-JF and FG-LF models fitted about $82 \%$ of the $\mathrm{Np}$ data. Again, the $\mathrm{Np}$ data can only be fitted with isotherms that include lateral interactions, heterogeneous sorbents and single layer formation. We did not need to include competitive adsorption by other sorbates.

Tables $\mathrm{C} 1$ through $\mathrm{C} 4$ summarize the performance of each thermodynamically consistent isotherm in replicating the experimental data.

Table C1. The isotherm performance of the Plutonium data.

\begin{tabular}{|c|c|c|c|c|c|c|c|}
\hline $\mathrm{Pu}$ & $r^{2}$ & Akaike \# & Score & Ranking & \# Parameters & \# Operations & Variance \\
\hline Dubinin-Astashov & 0.72 & 66.24111 & 5 & 1 & 3 & 10 & 9.09 \\
\hline Langmuir Uniform Distribution & 0.69 & 69.06384 & 8 & 2 & 3 & 6 & 10.13 \\
\hline Khan & 0.69 & 69.08955 & 9 & 3 & 3 & 12 & 10.14 \\
\hline Langmuir & 0.69 & 69.1409 & 10 & 4 & 3 & 6 & 10.16 \\
\hline Competive Quadratic with U & 0.69 & 69.19214 & 12 & 5 & 3 & 6 & 10.18 \\
\hline FG-JF & 0.752 & 70.56626 & 15 & 6 & 6 & 13 & 8.07 \\
\hline FG-LF & 0.687 & 69.16653 & 15 & 6 & 3 & 6 & 10.17 \\
\hline SRS & 0.687 & 69.21772 & 17 & 8 & 3 & 6 & 10.19 \\
\hline Jaroniec-Marczweski & 0.687 & 69.21772 & 17 & 8 & 3 & 10 & 10.19 \\
\hline Langmuir-Freunlich & 0.678 & 67.62537 & 18 & 10 & 2 & 2 & 10.47 \\
\hline BET & 0.679 & 69.92407 & 23 & 11 & 3 & 8 & 10.47 \\
\hline Bubinin-Radushevik & 0.679 & 69.92407 & 23 & 11 & 3 & 6 & 10.47 \\
\hline
\end{tabular}


WSRC-TR-2003-00180

Page 53 of 66

$\begin{array}{cccccccc}\text { Myers } & 0.679 & 72.30791 & 27 & 13 & 4 & 10 & 10.47 \\ \text { Redlich-Peterson } & 0.685 & -103.932 & 30 & 14 & 5 & 13 & 0.011 \\ \text { Radke-Prausnitz } & 0.616 & 72.24317 & 32 & 15 & 2 & 3 & 12.5 \\ \text { Toth } & 0.617 & -103.646 & 35 & 16 & 3 & 5 & 0.0134 \\ \text { General-Y } & 0.67 & -105.021 & 36 & 17 & 4 & 14 & 0.0116 \\ \text { Volmer } & 0.585 & -99.3871 & 38 & 18 & 4 & 11 & 0.0144 \\ \text { Temkin } & 0.46 & 81.23325 & 38 & 18 & 2 & 5 & 17.65 \\ \text { IAST } & 0.616 & -105.945 & 39 & 20 & 2 & 10 & 0.0134 \\ \text { Jovanovic } & 0.616 & -105.945 & 39 & 20 & 2 & 2 & 0.0134\end{array}$

Table C2. The performance of the various models of the $\mathrm{Np}$ data.

Isotherm
Multicomponent Freundlich
Dubinin-Radushekiv
Radke-Prausdnik
Relich-Peterson
Toth
Myers
Temkim
IAST
Volmer
General-Y
Jovanovic
Jaroniec

$\begin{array}{ccccc}\text { Parameter } & \text { \# operation } & \text { Variance } & \text { Akaike } & \mathrm{r}^{2} \\ 4 & 7 & 488065 & 636.3095 & 0.42 \\ 4 & 7 & 450808 & 632.516 & 0.39 \\ 3 & 6 & 452480 & 630.4969 & 0.39 \\ 5 & 9 & 108413 & 566.6745 & 0.97 \\ 3 & 6 & 421 & 297.052 & 0.18 \\ 3 & 5 & 40191 & 514.8351 & 0.55 \\ 2 & 4 & 393188 & 621.6324 & 0.34 \\ 4 & 11 & 27619 & 499.1098 & 0.38 \\ 2 & 11 & 41058 & 513.7002 & 0.56 \\ 5 & 13 & 29703 & 504.8236 & 0.4 \\ 2 & 4 & 400532 & 622.5165 & 0.4 \\ 3 & 7 & 462956 & 631.5903 & 0.35\end{array}$

Table C3. The isotherm performance of the strontium data.

\begin{tabular}{|c|c|c|c|c|c|c|c|}
\hline $\mathrm{Sr}$ & $\mathbf{r}^{2}$ & Akaike \# & Score & Ranking & \# Parameters & \# Operations & Variance \\
\hline Dubinin-Astashov & 0.975 & 141 & 8 & 2 & 3 & 10 & 45.9 \\
\hline Langmuir Uniform Distribution & 0.965 & 154 & 20 & 8 & 3 & 12 & 65.5 \\
\hline Khan & 0.9655 & 153 & 15 & 5 & 3 & 6 & 64.67 \\
\hline Langmuir & 0.9655 & 154 & 17 & 6 & 3 & 6 & 65.23 \\
\hline Competive Quadratic with U & 0.979 & 144 & 7 & 1 & 6 & 13 & 39.99 \\
\hline FG-JF & 0.96 & -246 & 33 & 19 & 4 & 11 & 0.00062 \\
\hline
\end{tabular}


WSRC-TR-2003-00180

Page 54 of 66

Table C3. The isotherm performance of the strontium data.

\begin{tabular}{|c|c|c|c|c|c|c|c|}
\hline $\mathrm{Sr}$ & $\mathbf{r}^{2}$ & Akaike \# & Score & Ranking & \# Parameters & \# Operations & Variance \\
\hline FG-LF & 0.965 & -251 & 30 & 16 & 4 & 14 & 0.00054 \\
\hline SRS & 0.96 & 157 & 30 & 16 & 2 & 2 & 76 \\
\hline Jaroniec-Marczweski & 0.962 & 159 & 29 & 15 & 4 & 10 & 70.5 \\
\hline Langmuir-Freunlich & 0.967 & 152 & 11 & 3 & 3 & 6 & 61.96 \\
\hline BET & 0.965 & 154 & 18 & 7 & 3 & 10 & 65.2 \\
\hline Bubinin-Radushevik & 0.962 & 156 & 26 & 13 & 3 & 8 & 70.5 \\
\hline Myers & 0.977 & -267 & 25 & 11 & 3 & 5 & 0.00036 \\
\hline Redlich-Peterson & 0.967 & 152 & 11 & 3 & 3 & 6 & 61.96 \\
\hline Radke-Prausnitz & 0.962 & 156 & 25 & 11 & 3 & 6 & 70.48 \\
\hline Toth & 0.96 & 158 & 31 & 18 & 3 & 6 & 74.25 \\
\hline General-Y & 0.98 & -268 & 23 & 9 & 5 & 13 & 0.00031 \\
\hline Volmer & 0.96 & -250 & 35 & 20 & 2 & 10 & 0.00062 \\
\hline Temkin & 0.431 & 249 & 39 & 21 & 2 & 5 & 1068 \\
\hline IAST & 0.98 & -270 & 24 & 10 & 2 & 2 & 0.00035 \\
\hline Jovanovic & 0.96 & 156 & 27 & 14 & 2 & 4 & 74.24 \\
\hline
\end{tabular}

Table C4. The isotherm performance of the uranium data.

$\begin{array}{cccccccc}\text { Uranium } & \mathbf{r}^{2} & \text { Akaike } & \text { Score } & \text { Ranking } & \text { \# Parameters } & \text { \# Operations } & \text { Variance } \\ \text { Dubinin-Astashov } & 0.77 & 489 & 21 & 9 & 3 & 10 & 25894 \\ \text { Langmuir Uniform Distribution } & 0.31 & 566 & 41 & 20 & 3 & 12 & 131598 \\ \text { Khan } & 0.776 & 513 & 24 & 14 & 3 & 6 & 42652 \\ \text { Langmuir } & 0.23 & 574 & 44 & 21 & 3 & 6 & 155345\end{array}$


WSRC-TR-2003-00180

Page 55 of 66

Table C4. The isotherm performance of the uranium data.

\begin{tabular}{|c|c|c|c|c|c|c|c|}
\hline Uranium & $\mathbf{r}^{2}$ & Akaike & Score & Ranking & \# Parameters & \# Operations & Variance \\
\hline Competive Quadratic with $\mathrm{Np}$ & 0.86 & 497 & 11 & 1 & 6 & 13 & 26242 \\
\hline FG-JF & 0.72 & 454 & 23 & 12 & 4 & 11 & 11622 \\
\hline FG-LF & 0.7 & 458 & 26 & 16 & 4 & 14 & 12676 \\
\hline SRS & 0.776 & 511 & 23 & 12 & 2 & 2 & 42742 \\
\hline Jaroniec-Marczweski & 0.814 & 507 & 18 & 6 & 4 & 10 & 35475 \\
\hline Langmuir-Freunlich & 0.827 & 501 & 13 & 2 & 3 & 6 & 33018 \\
\hline BET & 0.82 & 503 & 15 & 3 & 3 & 10 & 34327 \\
\hline Bubinin-Radushevik & 0.776 & 513 & 26 & 16 & 3 & 8 & 42742 \\
\hline Myers & 0.745 & 448 & 17 & 4 & 3 & 5 & 10755 \\
\hline Redlich-Peterson & 0.776 & 513 & 25 & 15 & 3 & 6 & 42740 \\
\hline Radke-Prausnitz & 0.776 & 513 & 26 & 16 & 3 & 6 & 42742 \\
\hline Toth & 0.8 & 508 & 21 & 9 & 3 & 6 & 38485 \\
\hline General-Y & 0.74 & 453 & 20 & 8 & 5 & 13 & 10988 \\
\hline Volmer & 0.74 & 447 & 17 & 4 & 2 & 10 & 10981 \\
\hline Temkin & 0.31 & 564 & 40 & 19 & 2 & 5 & 131846 \\
\hline IAST & 0.71 & 452 & 22 & 11 & 2 & 2 & 12246 \\
\hline Jovanovic & 0.81 & 504 & 18 & 6 & 2 & 4 & 36626 \\
\hline
\end{tabular}




\section{Appendix D}

The sensitivity plots of the DA model predictions for the Pu sorption data is shown in Figure D1.
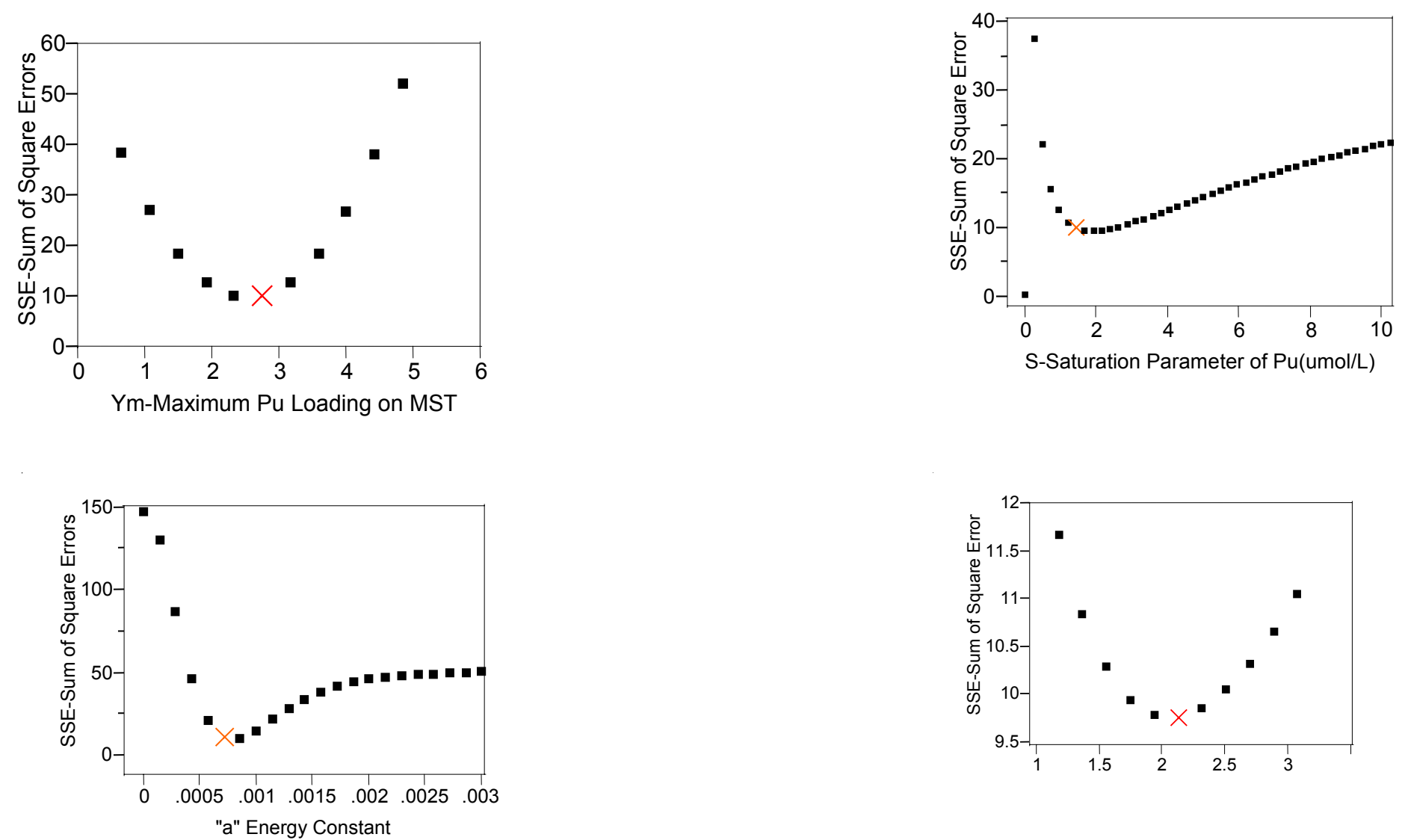

Figure D1. Sensitivity plots of the Dubinin-Astashov parameters determined from the Pu data at $25^{\circ} \mathrm{C}$. 
WSRC-TR-2003-00180

Page 57 of 66

In Figure D1, the ordinate variable is the Sum of Squares of the Error (SSE). Recall that SSE is the deviation or distance between the model at current parameter values and the data. In the four graphs shown in Figure D1, we changed only one variable at a time (shown in the coordinate scale) while keeping the other variables at the optimized values. Inspection of Figure D1 reveals the most sensitivity parameters - see Appendix A - are "Y $\mathrm{Y}_{\mathrm{m}}$ " (maximum loading, the pre-exponential term in the equation above) and the value "a", associated with the specific adsorption energy of the sites on MST. The parameter " $a$ " is equivalent to the parameter " $E$ " mentioned earlier. A significant increase in the SSE values with small changes in the "Y $\mathrm{m}$ " and "a" occurs. In Figure D1, the optimal parameter is at the minimum value of SSE. For example, looking at the SSE versus "n" sub-figure the data point marked with a red " $X$ " symbol is the value of " $n$ " used in the $\mathrm{Pu}$ isotherm equation. 

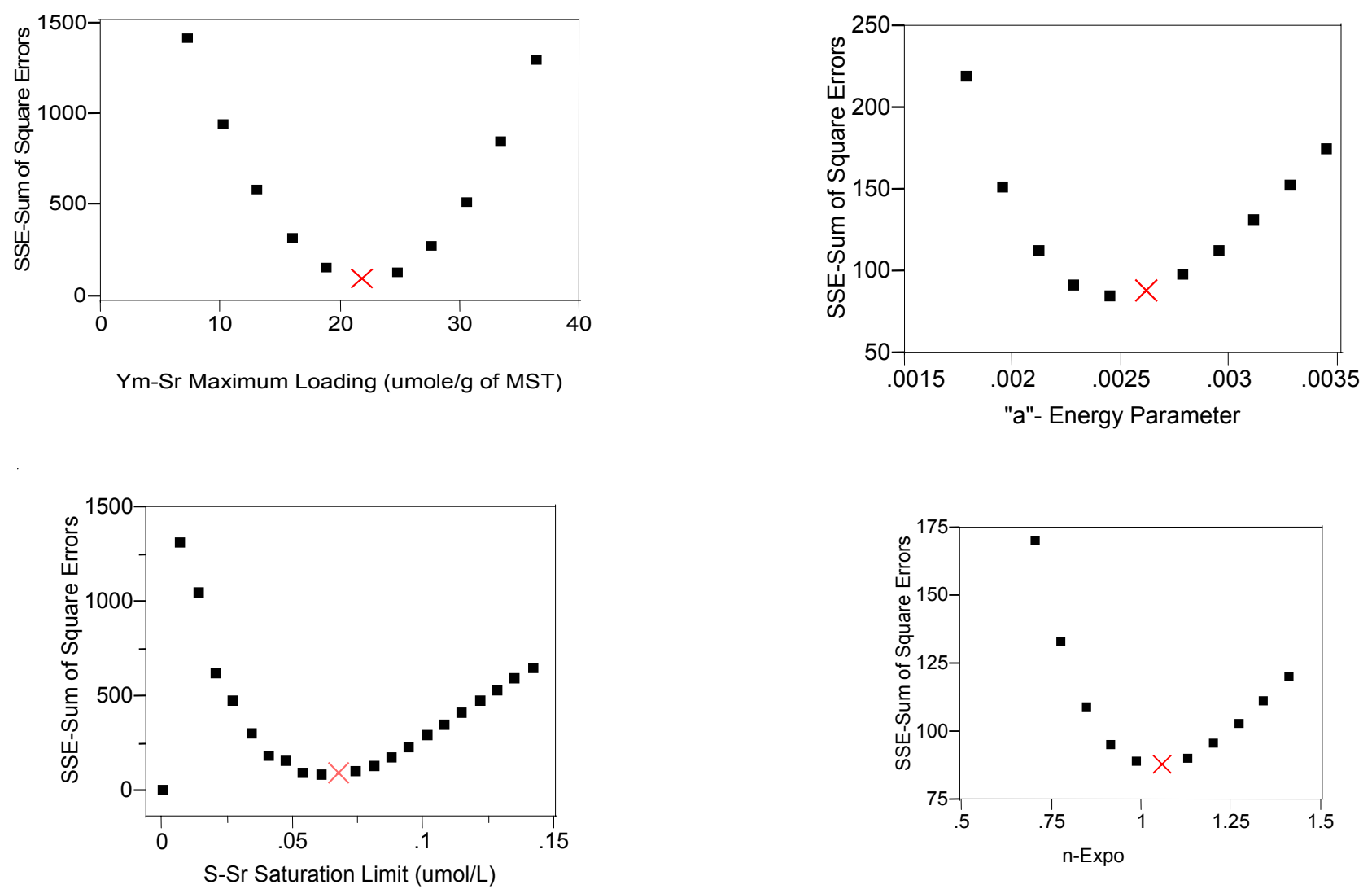

Figure D2. The sensitivity graphs of the Dubinin-Astashov model for the Sr loading data (at $25^{\circ} \mathrm{C}$ ). 

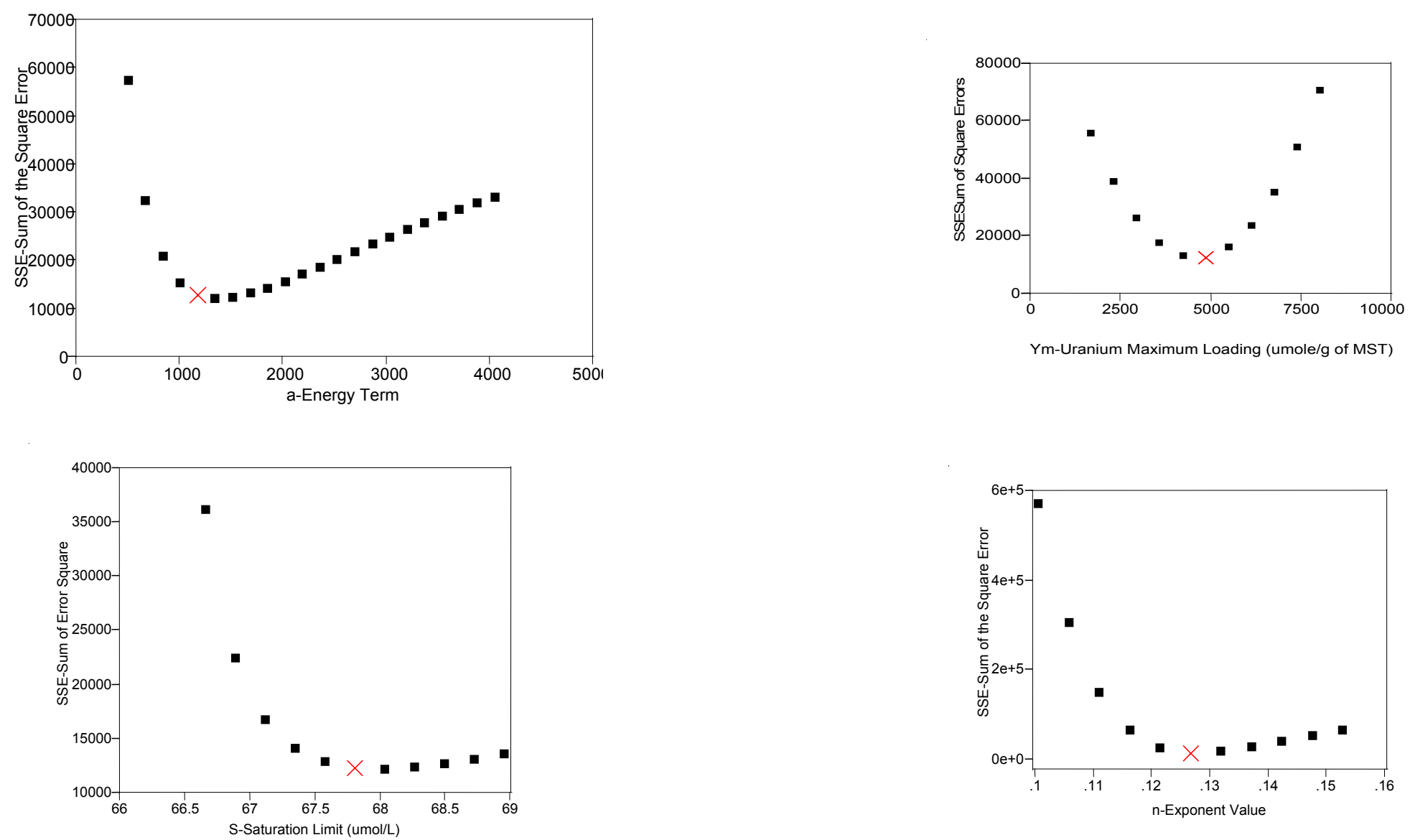

Figure D3. Sensitivity plots of the Dubinin-Astashov isotherm for uranium. 
WSRC-TR-2003-00180

Page 60 of 66

\section{Appendix E}

The $\mathrm{Pu}, \mathrm{Sr}, \mathrm{U}$ and $\mathrm{Np}$ sorption after 24 hours are shown in Figures E1, E2, E3 and E4. Except for Figure E4, the figures include the model prediction as well as the $95 \%$ prediction confidence curve.

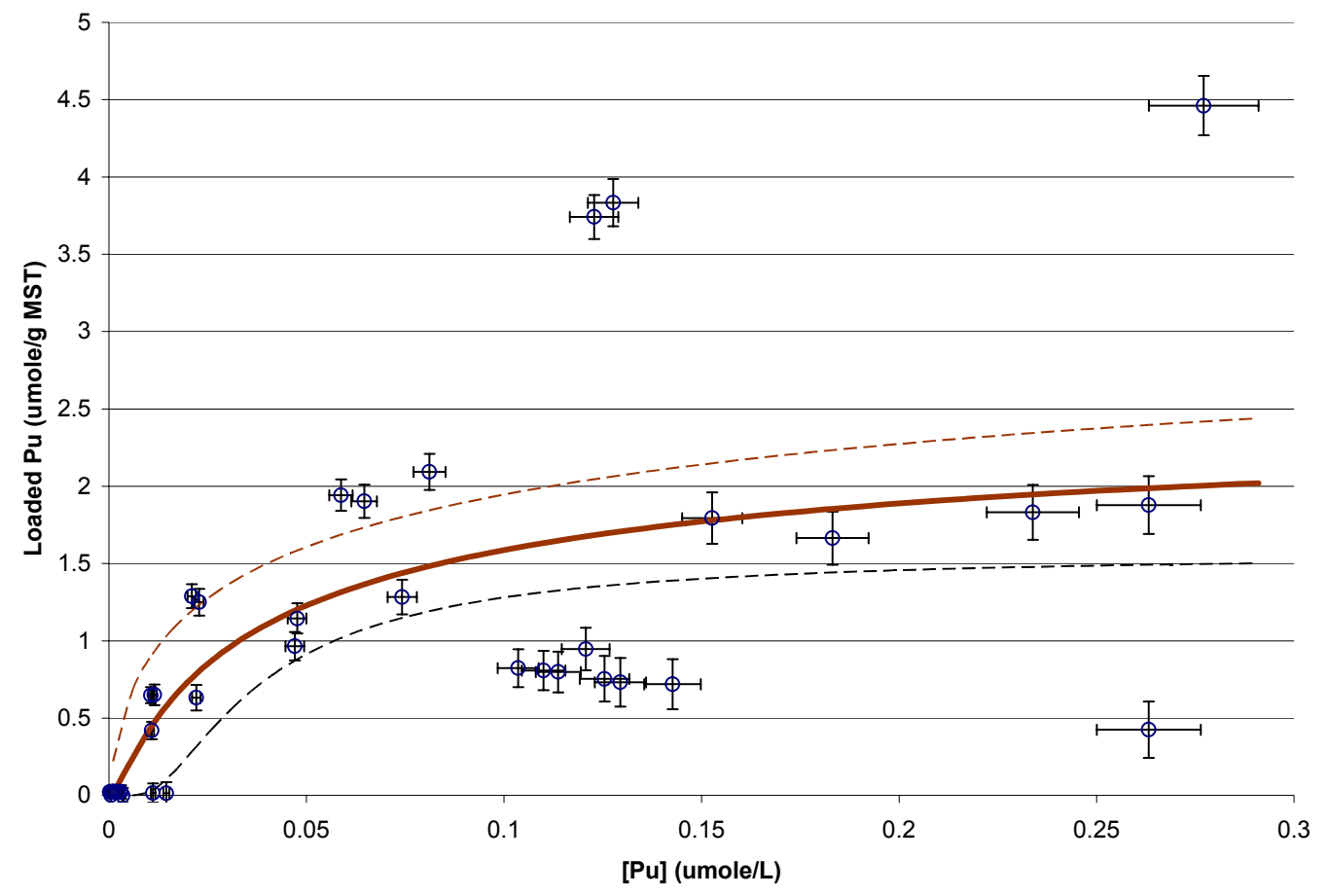

Figure E1. The Pu sorption data after 24 hours of testing. 
WSRC-TR-2003-00180

Page 61 of 66

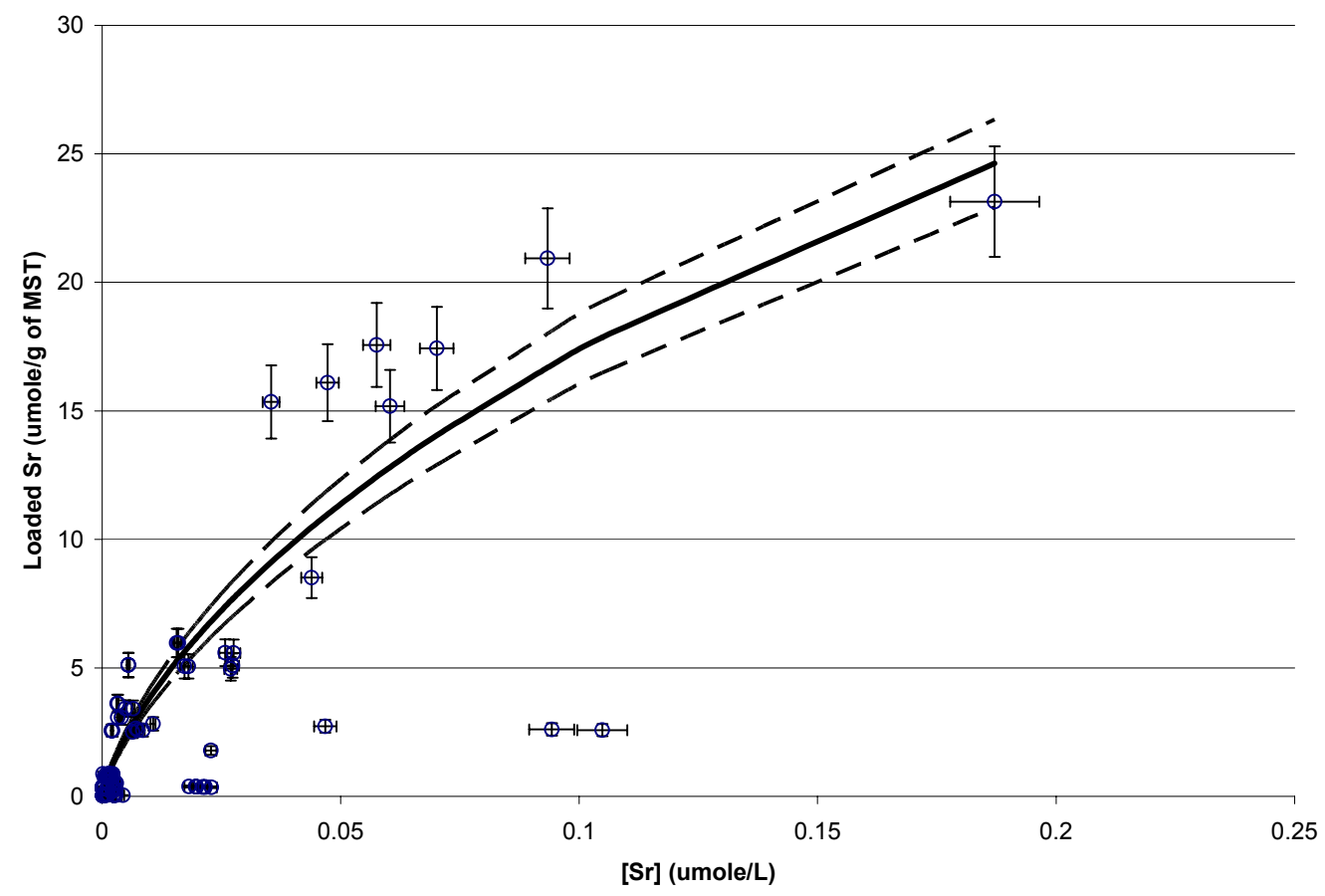

Figure E2. The Sr sorption data after 24 hours of testing.

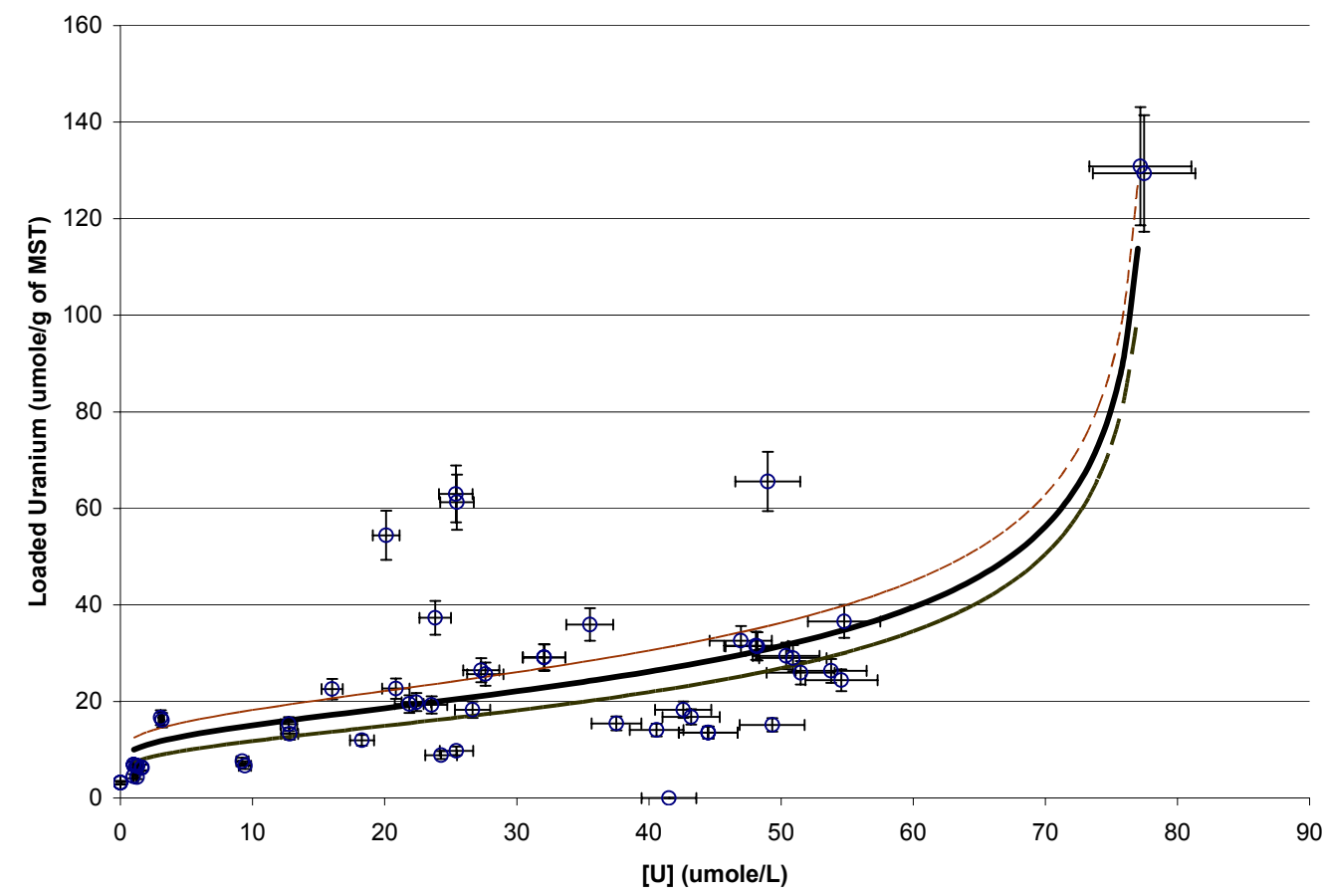

Figure E3. The Uranium Sorption data after 24 hours of testing. 
WSRC-TR-2003-00180

Page 62 of 66

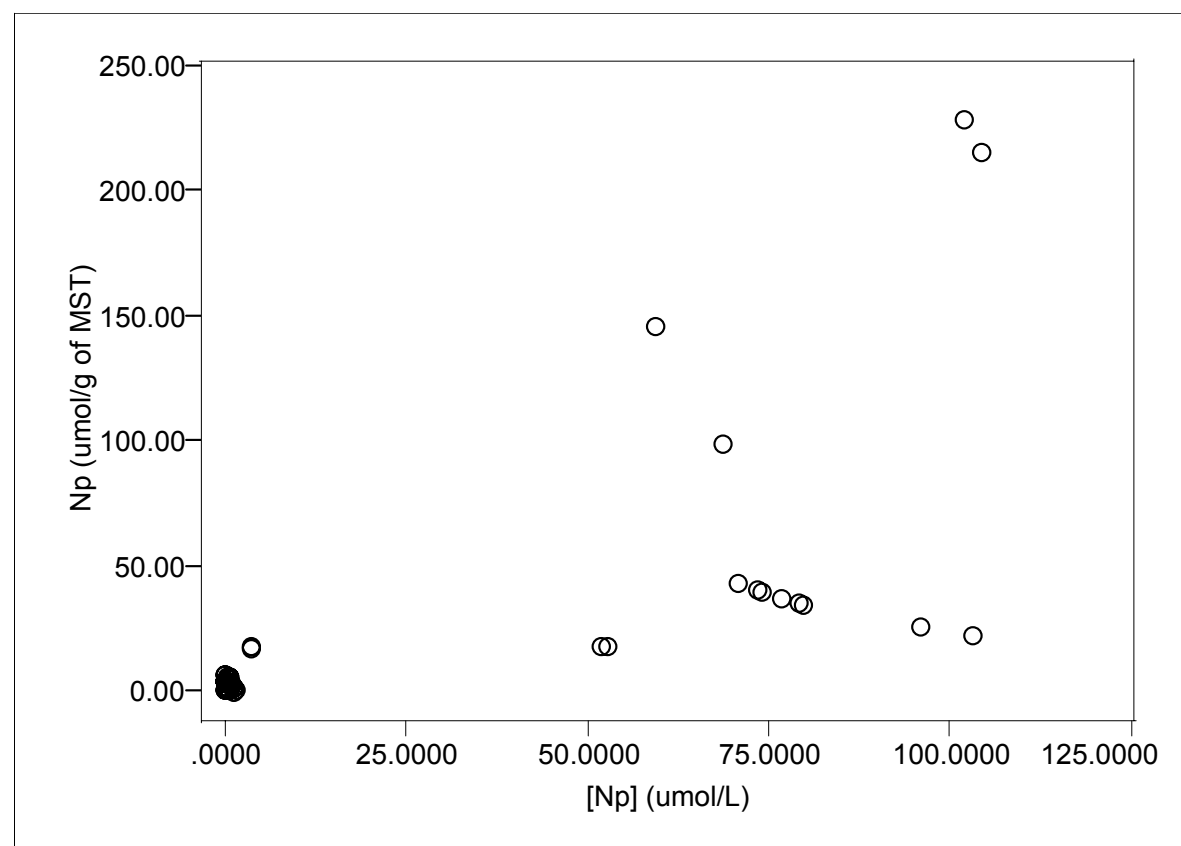

Figure E4. The Np sorption data at $25^{\circ} \mathrm{C}$.

\section{Appendix F}


WSRC-TR-2003-00180

Page 63 of 66

A summary of the Dubinin-Astashov equations for the four radionuclides are shown in Table F1.

Table F1. A summary of the Dubinin-Astashov parameters found for the radionuclides. Note the fitting with the $\mathrm{Np}$ data at $25^{\circ} \mathrm{C}$ was poor. No successful fitting was possible with the $\mathrm{Np}$ data at three different temperatures.

\begin{tabular}{|c|c|c|c|c|c|}
\hline Component & $\begin{array}{l}\text { Maximum } \\
\text { Loading } \\
\text { (umole/g of } \\
\text { MST) }\end{array}$ & $\begin{array}{c}\text { Pre- } \\
\text { temperature } \\
\text { coefficient " } a \text { " }\end{array}$ & $\begin{array}{l}\text { Saturation } \\
\text { Limit } \\
\text { (umol/L) }\end{array}$ & $\begin{array}{l}\text { Exponent } \\
\text { Value }\end{array}$ & $\begin{array}{c}\text { Calculated } \\
\text { Adsorption } \\
\text { Energy } \\
(\mathrm{J} / \mathrm{mole}) \\
\end{array}$ \\
\hline $\mathrm{Pu}-25^{\circ} \mathrm{C}$ & $2.6 \pm 0.5$ & $8.7 \pm 6.3 \mathrm{E}-4$ & $0.83 \pm 1.2$ & $2.1 \pm 1.5$ & 238 \\
\hline $\begin{array}{c}\mathrm{Pu}-25,45 \& \\
65^{\circ} \mathrm{C}\end{array}$ & $471 \pm 173$ & $0.27 \pm 0.14$ & $3.6 \pm 9.2$ & $0.41 \pm 0.02$ & 202 \\
\hline $\mathrm{Sr}-25^{\circ} \mathrm{C}$ & $23 \pm 25$ & $2.5 \pm 0.9 \mathrm{E}-3$ & $0.07 \pm 0.12$ & $1.1 \pm 0.28$ & 1929 \\
\hline $\begin{array}{l}\mathrm{Sr}-25,45 \\
\& 65^{\circ} \mathrm{C}\end{array}$ & $410 \pm 138$ & $0.09 \pm 0.02$ & $0.42 \pm 0.11$ & $0.55 \pm 0.01$ & 662 \\
\hline $\mathrm{U}-25^{\circ} \mathrm{C}$ & $4845 \pm 1266$ & $1248 \pm 1118^{*}$ & $67.8 \pm 0.46$ & $0.126 \pm 0.01$ & $2 \mathrm{E}-10$ \\
\hline $\begin{array}{c}\mathrm{U}-25,45 \& \\
65^{\circ} \mathrm{C}\end{array}$ & $1866 \pm 472$ & $20 \pm 15^{*}$ & $68 \pm 0.3$ & $0.16 \pm 0.008$ & $6 \mathrm{E}-8$ \\
\hline $\mathrm{Np}-25^{\circ} \mathrm{C}$ & $65 \pm 9$ & $0.001 \pm 0.0006$ & $75.3 \pm 0.01$ & $1.1 \pm 0.5$ & 4437 \\
\hline
\end{tabular}

\section{References:}


${ }^{1}$ M. C. Duff, D. B. Hunter, D. T. Hobbs, and S. D. Fink, "Characterization of Sorbed Strontium on Monosodium Titanate," WSRC-TR-2001-00245, June 21, 2001.

${ }^{2}$ M. C. Duff, D. B. Hunter. D. T. Hobbs, M. J. Barnes, and S. D. Fink, "Characterization of Sorbed Actinides on Monosodium Titanate," WSRC-TR-2001-00467, September 27, 2001.

${ }^{3}$ N. L. Dietz, J. A. Fortner, Z. Dai, J. P. Bradley, M. C. Duff, D. T. Hobbs, and S. D. Fink, "Transmission Electron Microscopy Analysis of Strontium and Actinide-Bearing Monosodium Titanate and Permanganate Treatment Solid," WSRC-TR-2002-00363, August 26, 2002.

${ }^{4}$ I. Langmuir, "The Adsorption of Gases on Plane Surfaces of Glass, Mica and Platinum," J. Am. Chem. Soc. Vol. 40 (1918), p. 1361.

5 J. A. V. Butler and C. Ockrent, "Studies in Electrocapillarity. Part III. The Surface Tensions of Solutions Containing Two Surface Containing Two Surface Containing Two Surface-Active Solutes," J. Phys. Chem. Vol. 34(1930), pp. 2841-2845.

${ }^{6}$ H. M. Freundlich, J. Phys. Chem. Vol. 57(1906), pp. 385-470.

${ }^{7}$ M. M. Dubinin and L. V. Radushkevich, "Equation of the Characteristic Curve of Activated Charcoal," Chem. Zentr Vol. 1(1947), p. 875.

${ }^{8}$ M. M. Dubinin and L. V. Radushkevich, "Evaluation of Microporous materials with a New Isotherm,” Dokl. Akad. Nauk SSSR, Vol. 55(1966), p. 331.

${ }^{9}$ M. M. Dubinin and V. A. Astakhov, " $2{ }^{\text {nd }}$ Int. Conf. On Molecular-Sieving Zeolites," (1970).

${ }^{10}$ M. J. Tempkin and V. Pyzhev, "Recent modifications to Langmuir Isotherms," Acta Physiochim USSR, Vol. 12(1940), p. 217.

${ }^{11}$ D. M. Ruthven, "Principles of Adsorption and Adsorption Processes," J. Wiley, New York, 1984.

${ }^{12}$ R. R. Rounsley, "Benzene Adsorption on Activated Carbon," AIChE J. Vol. 7(1961), p. 308.

${ }^{13}$ R. H. Fowler and E. A. Guggenheim, "Statistical Thermodynamics," MacMillan, New York, 1939, p. 430.

${ }^{14}$ K. Kaczmarski and D. Antos, "Calculation of Chromatographic Band Profiles with an Implicit Isotherm," J. of Chromatography A, Vol. 862(1999), pp. 1-16.

${ }^{15}$ A. N. Frumkin, "A multicomponent Isotherm for Gas Adsorption," Z. Phys. Chem. Vol. 116(1925), p. 466.

${ }^{16}$ O. Relich and D. L. Peterson, "A useful Adsorption Isotherm," J. Phys. Chem. Vol. 63(1959), p. 1024.

17 J. Toth, "A Multicomponent Isotherm for Liquid Adsorption," Acta Chim. Acad. Sci. Hung., Vol. 69(1971), p. 311.

${ }^{18}$ M. D. LeVan and T. Vermeulen, "Binary Langmuir-like and Freundlich isotherms for ideal adsorbed solutions," J. Phys. Chem. Vol. 85(1981), pp. 3247-3250.

${ }^{19}$ S. Suwanayuen, and R. P. Danner, "A Gas Adsorption Isotherm Based on Vacancy Solution Theory," AIChE J. Vol. 26(1980), pp. 68-76.

${ }^{20}$ C. J. Radke and J. M. Prausnitz, "A New Adsorption Isotherm for Heterogeneous Surfaces," Ind. Eng. Chem. Fund., Vol. 4(1972), p. 445.

${ }^{21}$ A. Meghea, R. Mihalache, G. Bumbac and I. Constantinescu, "Recent developments in Isotherm Adsorption," Sci. Techn. Env. Protection, Vol. 3(1994), p. 10. 
WSRC-TR-2003-00180

Page 65 of 66

${ }^{22}$ N. G. Buckman, J. O. Hill, and R. J. Magee, "A New Adsorption Isotherm for Gases," Microchem. J., Vol. 28(1983), p. 470.

${ }^{23}$ G. Sposito, "Derivation of the Freundlich Equations for Ion Exchange Reactions in Soils," Soil Sci. Soc. Am. J. Vol. 44(1980), p. 652.

${ }^{24}$ M. Jaroniec and R. Madey, "Physical Adsorption on Heterogeneous Solids," Elsevier, Amsterdam, (1998).

${ }^{25}$ I. Quinones and G. Guiochon, "Isotherms for Liquid Adsorption Systems," J. Chromatogr. A, Vol. 15(1998), p. 796.

${ }^{26}$ M. Jaroniec and J. Toth, "Modifications to the Langmuir Isotherm: Extension to Multicomponent Adsorption Systems," J. Colloid Polym. Sci., Vol. 254(1976), p. 643.

${ }^{27}$ J. F. Porter, G. McKay, and K. H. Choy, "The Prediction of Sorption from a Binary Mixture of Acidic Dyes Using Single- and Mixed-isotherm Variants of the Ideal Adsorbed Solute Theory," Chemical Engineering Science, Vol. 54(1999), pp. 5863-5885.

${ }^{28}$ A. L. Myers and J. M. Prausnitz, "Thermodynamics of Mixed-gas Adsorption," AIChE J. Vol. 11(1965), pp. 121-127.

${ }^{29}$ C. J. Radke and J. M. Prausnitz, "Thermodynamics of Multi-solute Adsorption from Dilute Liquid Solution,"AIChE J. Vol. 18(1972), pp-761-768.

${ }^{30}$ C. Sheindorf, M. Rebhum and M. Sheintuch, "A Freundlich-type multicomponent isotherm,” J. Colloid Interface Sci. Vol. 79(1981), pp. 136-142.

${ }^{31}$ D. T. Hobbs, M. G. Bronikowski, T. B. Edwards, and R. L. Pulmano, "Final Report of Phase III Testing of Mono-Na Titanate Adsorption Kinetics," WSRC-TR-99-00134, Rev. 0, May 28, 1999.

${ }^{32}$ D. T. Hobbs, and R. L. Pulmano, "Phase IV Simulant Testing of Mono-Na Titanate Adsorption Kinetics”, WSRC-TR-99-00219, Rev. 0, June 29, 1999.

${ }^{33}$ D. T. Hobbs, "Phase V Simulant Testing of Monosodium Titanate Adsorption", WSRC-TR-2000-00142, Rev. 0, May 22, 2000.

${ }^{34}$ D. T. Hobbs, "Solution Composition and Alternate Materials," WSRC-TR-200100436, August, 2001.

${ }^{35}$ D. T. Hobbs and S. D. Fleichman, "Fissile Solubility and MST Loading Test," WSRCRP-92-1273, March 29, 1992.

${ }^{36}$ A. McQuarrie, R. Shumway, and C. L. Tsai, "The Model Selection Criterion AICu," Statistics \& Probability Letters 34(1997) PP 285-292.

${ }^{37}$ G. Atun and Z. Kaplan, "Influences of Salt Concentration, Loading and pH on Strontium Adsorption," Journal of Radioanalytical and Nuclear Chemistry, Articles, Vol. 211, No 2 (1996), pp. 425-434.

${ }^{38}$ P. Jandera, Z. Posvec and P. Vraspir, "Mobile Phase Effects on Single-Component and Competitive Adsorption Isotherms in Reversed-Phase Systems," J. of Chromatography A, 734 (1996), PP 125-136.

${ }^{39}$ A. Meghea, H. H. Rehner, I. Peleanu, and R. Mihalache, “Test-fitting on Adsorption Isotherms of Organic Pollutants from Waste Waters on Activated Carbon," J. of RadioAnalytical and Nuclear Chemistry, 229 (1998), PP 105-110.

${ }^{40} \mathrm{~S}$. Al-Asheh, F. Banat, R. Al-Omari, and Z. Duvnjak, "Predictions of Binary Sorption Isotherms for the Sorption of Heavy Metals by Pine Bark Using Single Isotherm Data," Chemosphere 41(2000), PP 659-665.

${ }^{41}$ M. M. Dubinin, and V. A. Asthasov, “A New Modified DA Isotherm Equation,” Izvest. Akad. Nauk. SSSR (ser. Khim.), 11(1971), p 4. 
WSRC-TR-2003-00180

Page 66 of 66

${ }^{42}$ C. Wittrock, H. H. Kohler, and J. Seidel, “A Multilayer Adsorption Isotherm for Solutions,” Langmuir, 12(1996) p. 5550.

${ }^{43}$ I. Quinones, and G. Guiochon, "Application of Different Isotherm Models to the Description, of Single-Component and Competitive Adsorption Data," J. of Chromatography A, 734(1996), PP 83-96.

${ }^{44}$ D. P. Valenzuela and A. L. Myers, “Adsorption Equilibrium Data Handbook,” Prentice Hall, New Jersey, 1989.

${ }^{45}$ A. R. Khan, I. R. Al-Waheab and A. Al-Haddad, "A Generalized Equation for Adsorption Isotherms for Multi-Component Organic Pollutants in Dilute Aqueous Solutions," Environ. Tech. 17 (1996), PP. 13-23.

${ }^{46}$ A. R. Khan, M. R. Riazi and Y. A. Al-Roomi, " A Thermodynamic Model for Liquid Adsorption Isotherms," Separation and Purification, Techn. 18(2000), PP 237-250.

${ }^{47}$ M. Jaroniec and A. W. Marcewski, " A generalized Isotherm Model for Liquid Adsorption," Monatsh. Chem., 115(1984), p. 541.

${ }^{48}$ R. H. Fowler and E. A. Gugenheim, "Statistical Thermodynamics," MacMillan, NY 1939, p 430. 